\title{
SUR LA QUESTION DE L’ÉLITE DES CELTES ORIENTAUX À L’ÂGE DU FER
}

\author{
M. SZABÓ \\ Institut Archéologique, l’Université Lorand Eötvös, \\ Faculté des Lettres, Muzeum krt. 4/B, H-1088 Budapest, Hongrie \\ szabo.miklos@btk.elte.hu
}

\begin{abstract}
In relation to socio-historical research of the last quarter of a century this study deals with the problem of Iron Age eastern Celtic elite. Although cemetery analysis can only provide evidence of restricted value, the excavations of almost fully explored north Hungarian necropolises (Ludas, Sajópetri) seem to indicate that in the period of the Balkan expansion (3rd century B.C.) members of the Celtic elite considered themselves mainly as warriors. The analysis has also shown regional differences between archeological sites.
\end{abstract}

Keywords: Celtic elite, North Hungarian Celtic cemeteries, Balkan expansion

Au cours du dernier quart de siècle, la recherche sur l'aristocratie, étymologiquement «le règne des meilleurs », dépassant les cadres des civilisations anciennes dites «classiques», a gagné progressivement du terrain au sein de l'étude des cultures périphériques. ${ }^{1}$ Cette nouvelle tendance a attiré l'attention sur les Celtes chez qui, grâce à notamment une situation «protohistorique» particulière, la problématique de l'aristocratie ou de la nobilitas peut être analysée en confrontant les sources écrites gréco-romaines avec les données qui se déduisent de la tradition culturelle «locale». Ajoutons le fait bien documenté dans l'historique de la recherche que cette nouvelle approche à la question, qui dépasse largement les cadres diachroniques et géographiques traditionnels, a été inspirée par le programme archéologique visant la réévaluation des «tombes princières» de l'âge du Fer. Sans entrer ici dans les détails, ${ }^{2}$ le changement de perspective peut être illustré avant tout par les recherches consacrées aux élites conduites à Mayence, lesquelles - préconisant explicitement ou implicitement la primauté du matériel archéologique - proposent une réforme terminologique et méthodologique majeure.

Il s'en suit de l'approche archéologique que les notions «aristocrate» et «noble» héritées aux sources anciennes seraient remplacées par l'appellation «élite» (du verbe élire, issu du latin vulgaire exlegere) qui remonte à la terminologie française du XVIII ${ }^{e}$ siècle. Il s'agit donc de la fine fleur de la société, des «meilleurs» charismatiques sortant du lot, qui forment la couche dirigeante ou reignante. ${ }^{3}$ Ce terme technique s'oppose aux catégories «romantiques» largement utilisées depuis le XIX ${ }^{\mathrm{e}}$ siècle telles tombe ou siège «princiers» (Fürstengrab-Fürstensitz). La difficulté de faire la distinction dans tous les cas entre l'aristocratie et le peuple en se basant sur les sources archéologiques, est aussi un argument en faveur du terme élite. Par contre, les critères du statut d'élite ou d'aristocrate (origines, gloire au combat, etc.) sont très proches les uns des autres voire ils sont quasi identiques. ${ }^{4}$ En tout cas, en conséquence des raisons exposées ci-dessus, l'utilisation du terme élite est devenue, de nos jours, de plus en

${ }^{1}$ Cf. par ex., Fernoux - Stein 2007.

${ }^{2}$ Voir SCHÖNFELDER 2009, 59-61.
${ }^{3}$ EGG - QUAST 2009, VII.

${ }^{4}$ Cf. SCHÖNFELDER 2007a, 11-12, 23. 
plus fréquente ${ }^{5}$ en archéologie, sans être le terme exclusif. La persistance de l'expression aristocratie peut être illustrée notamment par le titre du colloque «L'aristocratie celte à la fin de l'âge du Fer» organisé à Glux-en-Glenne en 1999, ainsi que par les actes y relatifs. ${ }^{6}$ Naturellement, il ne s'agit pas ici uniquement du titre : au matériel de la table ronde s'ajoutait, en annexe, une collection de sources anciennes traitant de l'aristocratie celtique. ${ }^{7}$ En fonction des cadres chronologiques fixés par avance, cette dernière ne remontait pas dans le temps au-delà du dernier quart du III ${ }^{\mathrm{e}}$ siècle av. J.-Chr., tandis que les événements les plus récents y relatés datent des années $70-80$ ap. J.-Chr. ${ }^{8}$ C'est-à-dire que cette collection ne pouvait pas viser l'intégralité, pour la période plus ancienne il faut se tourner vers d'autres sources ou vers des études y consacrées. ${ }^{9}$

Dans tous les cas, il est important de souligner ici qu'en parlant, par habitude, d' «aristocratie celte», on n'emprunte évidemment pas à des sources celtiques de l'Antiquité. Cependant, cela ne veut pas dire que les documents écrits qui nous restent des Celtes anciens ne reflètent pas certaines particularités de l'élite de l'âge du Fer. Citons d'abord les données numismatiques : les noms figurant sur les monnaies celtiques - rien qu'en Gaule, plus de 300 ! - étaient sans aucun doute ceux de chefs, dans certains cas, même leur rang avait été indiqué. Les titres rex/ basileus renvoient à un type de gouvernement monarchique, alors que vercobreto (équivalent approximatif de consul) à un gouvernement oligarchique. Nous connaissons également le titre d'arcantodan, magistrat responsable du monnayage. ${ }^{10}$ Néanmoins, dans la plupart des cas, à défaut de titre, seules des données statistiques (nombre et diffusion des monnaies) permettent de conclure (avec prudence) au statut social du porteur du nom. C'est ainsi que Biatec, ayant donné son nom au type dominant du monnayage boïen du bassin des Carpates, devient «führender Häuptling », et le protagoniste le deuxième en fréquence, Nonnos, est appelé «zweiter grosser Fürst ». ${ }^{11}$ (Ajoutons entre parenthèses, que le document numismatique le plus «parlant» du point de vue de l'histoire des Celtes orientaux, celui avec la légende Gesatorix rex Ecritusiri regis filius, est un faux selon les numismates. ${ }^{12}$ La réalité contemporaine était sans doute beaucoup plus complexe que celle fondée sur des arguments statistiques : des inscriptions funéraires galates d'Asie mineure nous apprennent par exemple que Déiotaros était en même temps roi (basileus) et tétrarque (tetrachés). ${ }^{13}$ Ces sources relativement pauvres ont l'avantage de nous éclairer d'un point de vue celtique, c'est-à-dire authentique, sur certains des titres utilisés au sein de l'élite celte. Par contre, l'équivalence entre magalo et «prince» en langue celtique continentale, ou celle entre brigant et «noble», appartiennent au domaine des spéculations linguistiques ou sont, dans les meilleurs des cas, des hypothèses. ${ }^{14}$ Notons que l'élément rix (roi) souvent ajouté aux noms celtiques doit être interprété probablement comme un superlatif et non comme un titre réel. ${ }^{15}$ Dans la littérature grecque et romaine, qui donne les priorités aux individus au détriment des groupes et des classes reflétant la division de la société, il est beaucoup plus fréquemment question de l'aristocratie celte que dans les sources examinées ci-dessus. ${ }^{16}$ Mais il ne faut pas oublier que ces récits sont en général marqués par les préjugés et les stéréotypes formulés par les «civilisés» sur les «barbares $» .{ }^{17}$ Cette constatation n'exclut pas cependant l'existence de récits fiables du point de vue de l'histoire des sociétés celtiques. Citons à titre d'exemple la définition par César de la classe des equites, l'appartenance à laquelle dépendait des origines et de la fortune. ${ }^{18}$ Sans entrer dans la discussion stérile sur l'influence éventuelle du livre XXIII de l'ouvrage ethnographique perdu de Posidonios, ${ }^{19}$ notons que Dumnorix, représentant de l'ordre de chevalerie celte, faisait partie, selon les Commentaires sur la Guerre des Gaules, des relations personnelles de César. ${ }^{20}$ Outre les informations, généralement de première main, conservées par César, nous disposons également de données intéressantes de seconde, voire d' «énième» main. Nous pouvons trouver plusieurs exemples chez Strabon. La description de la communauté des Galates d'Asie mineure (koinon Galaton) présente une structure tétrarchique considérée comme un patrimoine celtique. ${ }^{21} \mathrm{Il}$ n'est pas moins intéressant de souligner que selon Strabon, l'état gaulois était généralement de type

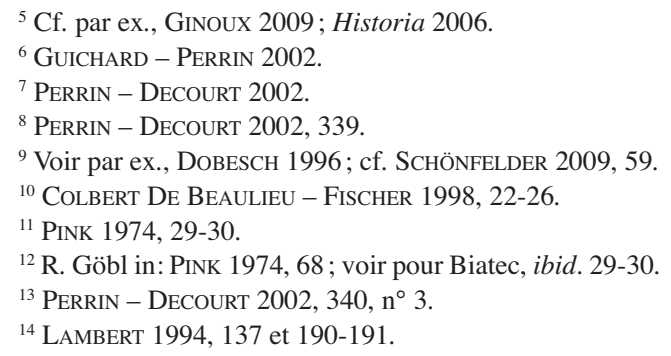

${ }^{15}$ Perrin - Decourt 2002, 342; cf. Delamarre 2001, 220-221

${ }^{16}$ Perrin - Decourt 2002, 343.

${ }^{17}$ Cf. Thollard 2006.

${ }^{18}$ César, BG VI, 15, 1-2 = Perrin - DeCourt 2002, 350,

$n^{\circ} 37$.

${ }^{19}$ Cf. Malitz 1983, 170.

${ }^{20}$ Cf. Perrin - Decourt 2002, 350-351.

${ }^{21}$ Strabon XII, 5, 1 = PERRIN - DECOURT 2002, 353, $n^{\circ} 55$; cf. SZABÓ 2005a, 79. 
aristocratique, et les Gaulois avaient la vieille coutume d'élire un chef (hégémón) chaque année, ou un chef de guerre (stratégos) en cas de conflit armé. ${ }^{22}$

Ces données font poser la question de savoir quels titres grecs et latins étaient réservés par les sources anciennes aux personnalités celtes éminentes. Nous n'avons que l'embarras du choix. ${ }^{23}$ L'emploi des termes basileus ou rex témoigne sans doute d'un régime monarchique. L'utilisation des titres basiliskos et regulus est moins claire, et le fait que le Gaulois Cincibulus est mentionné chez Tite-Live soit comme rex, soit comme regulus, ne fait qu'ajouter à la confusion. ${ }^{24}$ Le même Tite-Live donne le titre de regulus à Lonorius (sic!) et Lutarius qui ont conduit les Celtes en Asie mineure (XXXVIII, 16), tandis que chez Memnon (=Photius 227b-228a), c'est le terme koryphaios qui renvoie à eux. D'après Strabon, Leonnorios était archégos (XII, 5, 1). ${ }^{25}$ Diodore oppose les titres de basileus et de dynastés (V, 21, 6), ainsi, ce dernier, en tant que chef, aurait été en possession du pouvoir. Toute une série d'autres titres peut être interprétée comme l'équivalent de «chef» : par exemple, archégos, archón, hégémón, koryphaios, stratégos, ainsi que princeps, dux et imperator.

Il est plus difficile de savoir si les fonctions de chef et de chef de guerre, dont parle Strabon (IV,4,3), peuvent être distinguées sans ambiguitté d'un point de vue terminologique. Selon lui, le hégémón était un chef élu en temps de paix, cependant, les chefs de l'offensive balkanique comme Kambaulés (Pausanias 10, 19, 5-6) ou Bathanattos (Athénée 6, 24, 234a-c) portaient le même titre. ${ }^{26}$ Les termes stratégos, dux ou imperator renvoient à la fonction de chef de guerre d'une manière plus évidente. Les débats autour de la possibilité d'interpréter le nom de certains protagonistes des invasions celtiques (par ex., celui de Brennos ou de Bathanattos) comme titre, s'ajoutent aussi à la complexité du problème. ${ }^{27} \mathrm{Le}$ fait que la figure de proue des invasions balkaniques, Brennos, apparaît parfois comme chef de guerre (dux: Justin, 24, 5-6; 24,8; 25, 1-2; archón: Pausanias 10, 19, 5-6.), parfois comme basileus (Polyainos, Strat. 7, 35, 1; Diodore 22, 9, 1-3, etc.) dans les sources anciennes, est non moins problématique. Les exemples comme ceux qui viennent d'être cités, semblent indiquer que les auteurs anciens faisaient preuve d'un manque de cohérence dans leur choix de termes relatifs à la position sociale, au rang de l'élite celtique; des titres ayant originellement des contenus fort différents pouvaient ainsi devenir interchangeables. Autrement dit, ces auteurs étaient incapables d'appliquer d'une manière convaincante la terminologie gréco-romaine à la hiérarchie caractéristique des sociétés celtiques. C'est-à-dire que les titres dont affublaient les sources anciennes les éminents représentants de l'aristocratie celte ne correspondaient qu'approximativement voire pas du tout au rang social réel de l'intéressé. Ce problème fait naturellement poser des questions quant à l'authenticité des sources en question, d'où, par exemple, le débat sur l'interprétation du passage de Strabon relatif aux tétrarchies galates d'Asie mineure (XII, 5,1). Nous avons noté ci-dessus que de nombreux spécialistes considèrent cela comme la preuve de la subsistance d'une ancienne structure sociale celtique chez les Galates vivant en milieu hellénistique, ${ }^{28}$ alors que pour d'autres, ce régime leur aurait été imposé par les Attalides. ${ }^{29}$

D'un point de vue géographique, les sources anciennes relatives à l'aristocratie celtique sont très inégalement réparties. Nous sommes relativement bien informés au sujet des Gaulois, des Celtes d'Italie ou des Galates d'Asie mineure, tandis que leurs parents de la région du moyen Danube restent essentiellement dans l'obscurité. Ce fait ne doit pas surprendre étant donné que vu les connaissances des géographes grecs relatives à cette région, pour ces derniers, tout ce qui se trouvait au nord de la ligne Save - Bas-Danube était terra incognita, et cette situation ne changera, dans le fond, qu' avec l'occupation romaine. ${ }^{30}$

Par conséquent, nos connaissances des protagonistes de l'histoire des Celtes orientaux dans le bassin des Carpates sont extrêmement lacunaires. Les figures de proue des mouvements balkaniques - Brennos, Belgios, Bathanattos, etc. - étaient selon toute probabilité des chefs militaires, même si Diodore considère Brennos comme un roi (voir plus haut) et parle de l'attribution du titre de roi à Kichórios (ou Akichórios) pendant la retraite. (Diodore 22, 9, 2; cf. Pausanias 10, 19, 7-8: Brennos et Akichórios partagent la fonction d'archón.) N'oublions pas cependant que rien ne prouve la relation entre ces derniers et la région du moyen Danube ${ }^{31}$ exception faite de Bathanattos, l'unique protagoniste de l'ethnogenèse scordisque dont le nom soit explicité. ${ }^{32}$ Mais nous ne savons pratiquement

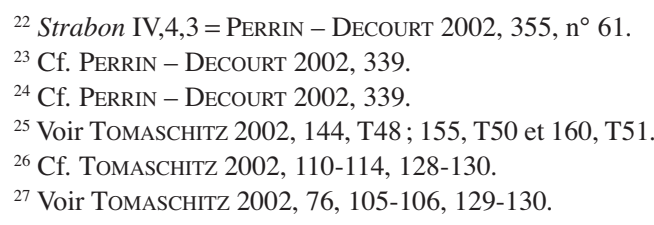

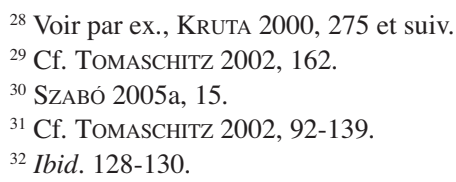


rien d'autre de lui, comme nous ne connaissons pas non plus l'organisation tribale des Scordisques, ainsi, nous ne sommes pas en mesure de supposer l'existence d'un royaume scordisque comparable à celui des Celtes de Tylis. ${ }^{33}$

En ce qui concerne les Celtes établis dans le bassin des Carpates, il y a un exemple qui est souvent cité pour appuyer l'hypothèse de la monarchie. Il s'agirait de Kritasiros, roi des Boïens ou des Taurisques, vaincu par le Dace Burebista. ${ }^{34}$ Cependant, si nous faisons abstraction de la fausse monnaie avec la mention du nom Gesatorix citée plus haut, d'après les deux passages de Strabon (VII, 3, 11 et VII, 5, 2.), Kritasiros était probablement le chef des deux armées tribales réunies, ${ }^{35}$ et non un rex, comme le document numismatique semble l'indiquer.

La qualité ou l'exactitude de la traduction grecque ou latine des titres des personnalités éminentes de l'aristocratie celtique peut sembler un problème secondaire. Dans le cas des régions ayant la préférence des sources écrites, les analyses critiques peuvent aboutir à des conclusions valables malgré les contradictions qui viennent d'être citées. Par contre, dans le cas des régions pauvres en documents écrits, il vaut mieux se contenter de questions posées avec beaucoup de prudence.

La comparaison de textes semble, cependant, offrir de précieux points de repère quant à la description générale de l'aristocratie celtique. Quels sont les critères de l'appartenance à l'aristocratie ? Premièrement, la naissance. Nous disposons de nombreuses données y relatives dans le domaine des Celtes occidentaux. Dans le cas d'Eduens distingués, César parle de famille très ancienne (BG VII, 32 : antiquissima familia natum), alors qu'il fait ailleurs référence à des origines royales. (BG IV, 12.) Les allusions à ces dernières subsisteront aussi parmi les élites provinciales (Tacite, Hist. IV, 13, 1 : regia stirpe). Selon plusieurs sources, Boudicca, femme du roi des Iceni de Bretagne, avait du sang royal dans les veines. (Tacite, Agricola XVI : generis regii femina duce.) Il est particulièrement intéressant de citer ici le cas de Crixus, un Bö̈en pouvant être considéré comme originaire d'Europe centrale, qui a déclaré descendre de Brennos (Silius Italicus, Punica IV, 147-156) qui avait occupé Rome. Cette généalogie correspond en effet à 6 ou 7 générations, c'est-à-dire environ 150 ans. $^{36}$

Le deuxième critère comprend les vertus guerrières et le pouvoir obtenu grâce à des prouesses au combat. Selon Posidonios, dans la société hiérarchisée des Gaulois, c'était le chef, sortant du lot par ses qualités de guerrier, sa naissance et richesse, qui occupait aux festins la place de choix. (Athénée IV, 152b.) Les Gaulois aimaient faire la guerre (par ex., Polybe XXII, 21) et estimaient avant tout les chefs conquérants (Stobée IV, 2, 25). Mais le chef ne se contentait pas de commander, il participait personnellement au combat (Tacite, Agricola XII), de plus, les guerres se sont souvent réduites à des duels entre chefs, cherchés voire provoqués par ces derniers (cf. par ex., Polybe III, 62, 5). Le torque et la tête coupée du vaincu revenaient au chef victorieux. ${ }^{37}$

Le troisième critère de l'appartenance à l'aristocratie était la fortune. A ce sujet, nous pourrions citer de nombreuses données fournies par des auteurs anciens, des trésors fabuleux de l'Arverne Luernios (Athénée IV, 2 , 2; Strabon IV, 2, 3) jusqu'aux richesses d'Orgetorix, l'Helvète (César, BG I, 2). ${ }^{38}$

En fin de compte, c'est avant tout le militarisme de l'aristocratie celtique qui se dessine grâce aux descriptions des auteurs de l'antiquité. Ce sont les écrits de Tite-Live qui nous donnent des idées sur les proportions de l'élite au sein de la population totale. En 192/1 av. J.-Chr., à l'époque de la dernière guerre menée par les Boïens cisalpins contre les Romains, compte tenu du bilan de leur défaite (morts, prisonniers de guerre, butin), les aristocrates ne devaient pas dépasser quelques milliers au sein d'une population de 150-250 000. (Tite-Live XXXV, 22 ; XXXVI, 38 et 40.) Cependant, l'élément dynamique de la tribu était constitué par l'aristocratie guerrière laquelle - selon l'information fournie par Polybe (II, 17) - était capable d'entrer dans la composition de groupes intertribaux (hétaireia), corps armés jouant probablement un rôle majeur dans les conquêtes. ${ }^{39}$

Dans ce qui suit, nous allons essayer d'étudier l'aristocratie celtique à partir du matériel archéologique. Nous allons concentrer notre attention surtout aux nécropoles celtiques de la région du Danube, et plus particulièrement à celles mises au jour à Ludas et à Sajópetri. (Fig. 1) Vu la conclusion tirée des sources écrites, c'est-à-dire le caractère «militariste» de l'élite celte, notre analyse sera fondée essentiellement sur l'étude des tombes de guerriers.

Les IV-III' siècles av. J.-Chr., c'est-à-dire l'époque de l'expansion celtique, se situent entre deux périodes lesquelles, par leurs sépultures spectaculaires, permettent de conclure à une division profonde au sein de la société

\footnotetext{
33 TOMASCHITZ 2002, 139-141.

${ }^{34}$ Voir par ex., Mócsy 1974, 19; KRUTA 2000, 700.

${ }^{35}$ Cf. Dobesch 1983, 19.

${ }^{36}$ Voir PERrin - DeCOURT 2002, 345-350.
}

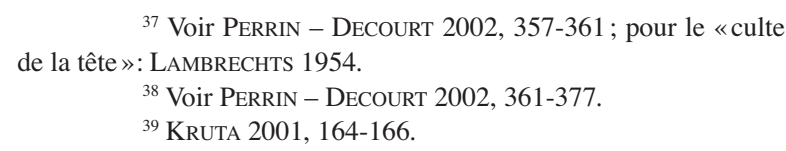

${ }^{37}$ Voir Perrin - DeCOURT 2002, 357-361 ; pour le « culte

${ }^{39}$ KRUTA 2001, 164-166. 


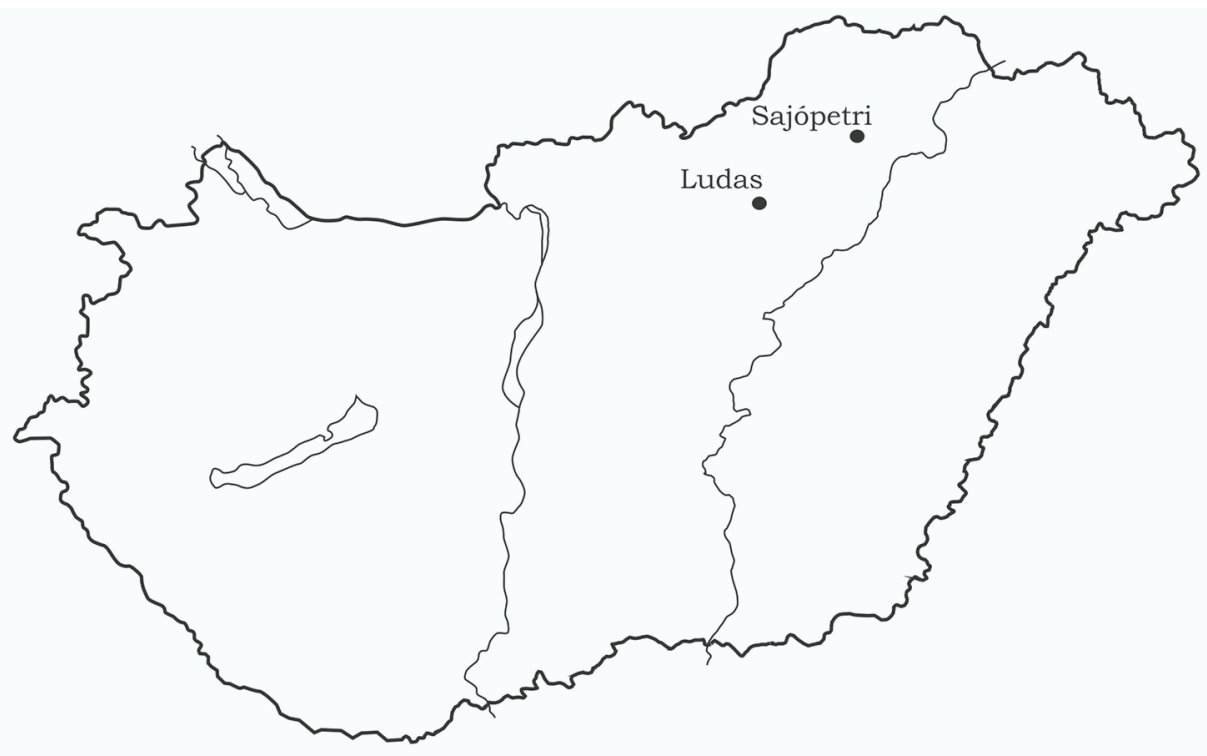

Fig. 1. La Hongrie avec les deux sites (Ludas, Sajópetri)

du second âge du Fer. Pendant la période des «princes» celtiques (LT A/LT B1a; 450-350 av. J.-Chr.), dans la région de la Sarre, sur le territoire de Rheinpfalz et de la culture Hunsrück-Eifel, les tumulus témoignent non seulement de la puissance de l'élite locale, mais aussi des limites géographiques de leur zone d'influence. Par contre, la concentration de tombes à char en Champagne, avec leur mobilier de casques métalliques, d'épées et de lances en fer, reflète avant tout le militarisme de l'élite locale, plutôt que l'existence d'une couche «princière» fondée sur la naissance. ${ }^{40}$

A l'époque de La Tène finale, au temps des oppida (LT D; 150/120-30 av. J.-Chr.), nous pouvons constater que la conception des «tombes princières» a subi des modifications. Le rite de l'incinération ne nécessite plus le dépôt des restes sous un tertre, ainsi, les tumulus commencent à se faire plus rares. Il manque les vases en or ou en argent et les bijoux du mobilier, le luxe «funéraire» étant représenté surtout par des vases romains en bronze et des amphores italiques. Plutôt que de refléter la structure sociale, ces faits témoignent du conservatisme des élites. ${ }^{41}$

Les nécropoles de la période de l'expansion sont fondamentalement différentes des précédentes. A partir du milieu du IV ${ }^{\text {e }}$ siècle av. J.-Chr., la culture de La Tène montre une image uniformisée. Les objets de prestige disparaissent progressivement, le port des parures se démocratise, et seules les différences dans la façon de porter des objets de types quasi identiques témoignent des spécificités régionales. ${ }^{42}$ Ces constatations semblent indiquer des changements sociaux profonds par rapport à l'époque des «tombes princières». Il n'est pas surprenant que la recherche de la deuxième moitié du XX $\mathrm{X}^{\mathrm{e}}$ siècle, inspirée par l' "apparence archéologique », a supposé l'écroulement et la transformation radicale du monde des princes de La Tène ancienne qui aurait été remplacé par une société égalitaire sans élite. Selon la formulation plus nuancée de F. Fischer, la société de la période des «princes », caractérisée par des divisions profondes, a été remplacée par une structure peu différenciée. Contrairement à U. Kahrstedt, il ne voulait pas expliquer ces changements dramatiques par une révolte paysanne, mais il envisageait la phase qui avait directement précédé les migrations historiques des Celtes comme une «coupure». ${ }^{43}$ Pourtant, ce sont justement les sources anciennes relatives aux migrations des $\mathrm{IV}^{\mathrm{e}}$ et III ${ }^{\mathrm{e}}$ siècles, qui prouvent que ces migrants n'étaient pas des hordes désorganisées, liées au meilleur des cas par des liens de parenté, mais des communautés pouvant, selon toute probabilité, être considérées comme les débuts des civitates de l'avenir. ${ }^{44} \mathrm{C}^{\prime}$ est-à-dire qu'à la période de l'expansion celtique, au contraire du $\mathrm{V}^{\mathrm{e}}$ siècle av. J.-Chr., l'appartenance à l'élite ne se manifestait pas par le rite funéraire. D'après les mobiliers funéraires, on peut observer, aux IV-III siècles av. J.-Chr., une division nette entre

${ }^{40}$ SCHÖNFELDER 2007a, 15-18.

${ }^{41}$ SCHÖNFELDER 2007a, 20-22.

${ }^{42}$ Cf. Kruta 2000, 214-215.

\author{
${ }^{43}$ FISCHER 1981, 68-69. \\ 44 Jud 1998, 123; cf. DoBesch 1996.
}


la «classe» des guerriers et les «autres», donc l'élite se définissait essentiellement comme guerrière. ${ }^{45}$ Cette constatation est naturellement corroborée par ce qui, d'après les sources anciennes, a été dit plus haut sur le caractère «militariste» de l'aristocratie celtique, qui se manifestait notamment par la création de corps armés intertribaux. Ces «hétairies» ont probablement joué un rôle majeur dans les conquêtes des Celtes.

En retournant aux sources archéologiques, faisons brièvement état des aspects méthodologiques de l'étude des nécropoles. Dans la deuxième moitié du $\mathrm{XX}^{\mathrm{e}}$ siècle, la méthode dominante était l'analyse statistique fondée sur la classification des mobiliers funéraires. La reconstitution de la structure sociale reposait en grande partie sur le pourcentage des tombes de guerriers. Ajoutons que les limites de ce type d'évaluation sont constituées par la très grande variabilité qualitative et quantitative de la documentation archéologique. C'est-à-dire que, en Europe occidentale et centrale, peu de nécropoles du second âge du Fer ont été fouillées dans leur intégralité et en faisant preuve d'un professionnalisme digne de ce nom. En ce qui concerne le bassin des Carpates, les possibilités et les limites des recherches y relatives sont bien représentées par le travail de Bujna ${ }^{46}$ qui a visé l'analyse quantitative et qualitative des sépultures. Il est important de noter ici que l'auteur a dû se contenter de l'hypothèse selon laquelle la population d'un habitat donné avait utilisé une seule nécropole commune. ${ }^{47}$ La révision de cette thèse remonte aux années 90.

L'étude des nécropoles du IIIe siècle av. J.-Chr. en Île-de-France a permis de distinguer au minimum deux grandes catégories de sites : les cimetières de l'élite avec des tombes à char et des mobiliers exceptionnels, et les cimetières du «peuple».48

Il n'est peut-être pas inutile de faire ici un petit détour. Dans le titre de son article cité plus haut, S. Marion se propose d'analyser les sépultures du III e siècle des environs de Paris. L'avantage de l'utilisation de la chronologie absolue est de résoudre dans une certaine mesure la contradiction entre les chronologies laténiennes de l'Europe occidentale et de l'Europe centrale. Néanmoins, quant à la définition archéologique, Marion fait sienne la terminologie de la chronologie relative de l'Europe centrale (La Tène B2, C1). ${ }^{49}$ Cela, vu de l'Occident, peut paraître un compromis, pourtant, les déplacements de populations ${ }^{50}$ qui ont lieu sur le vaste territoire entre le littoral atlantique et l'Anatolie centrale à l'époque des migrations balkaniques des Celtes justifient en eux-mêmes la volonté d'harmoniser les systèmes chronologiques. Nous pouvons retrouver les traces de cette tendance depuis les années 1990: dans la pratique, il s'agit de l'application de plus en plus répandue du système chronologique centre-européen dans la partie occidentale de l'ancienne Celtique. ${ }^{51}$ Il faut citer ici les travaux majeurs de R. Gebhard qui, en étudiant les trouvailles en verre de Manching, a focalisé son attention sur la chronologie de La Tène moyenne en Europe centrale sur la base des observations relatives aux nécropoles et aux habitats. Les horizons ainsi définis (horizon $4=\mathrm{LT}$ B2a; horizon $5=\mathrm{LT} \mathrm{B} 2 \mathrm{~b}$; horizon $6=$ LT C1a) facilitent considérablement le rapprochement des différents systèmes chronologiques. ${ }^{52}$ Il est à noter que les communications du colloque de l'AFEAF, organisé à Clermont-Ferrand en 2003, témoignent de l'utilisation largement répandue du système centre-européen ${ }^{53} \mathrm{Il}$ ne s'agissait pas pour autant d'un renversement total de la situation: par exemple, en 2009, N. Ginoux, lors de la publication de la nécropole celtique de Plessis-Gassot (Vald'Oise), donne sa préférence à la chronologie absolue, et en appliquant la chronologie relative de l'Europe centrale, n'oublie pas de préciser que c'est une spécificité des auteurs de langue allemande. ${ }^{54}$ Cette remarque risque de produire un effet quelque peu comique de nos jours étant donné que la plupart des intervenants du colloque de Clermont-Ferrand (M. Saurel, J. Gomez de Soto, L. Angier, L. Baray, etc.), et G. Kaenel non plus, ${ }^{55}$ n'appartiennent pas à cette catégorie.

Nous avons fait allusion ci-dessus à un certain avantage de la chronologie absolue. Il est cependant important de préciser que contrairement à la culture grecque historique, une fois sortis de leur contexte chronologique relatif, c'est-à-dire, d'un horizon donné de découvertes, les objets de production locale appartenant à un milieu protohistorique sont extrêmement difficiles à dater. En plus, en datant un type, par exemple, de la phase ancienne ou récente du $\mathrm{III}^{\mathrm{e}}$ siècle (début ou fin du $\mathrm{III}^{\mathrm{e}}$ siècle av. J.-Chr.), nous nous basons explicitement ou implicitement sur un système chronologique donné. ${ }^{56}$ Ainsi, pour terminer l'analyse de cette problématique, il nous semble logique d'exiger de la part des spécialistes confrontés au problème de la datation de trouvailles laténiennes, l'indication, d'une part, de la chronologie relative, et, d'autre part, de la chronologie absolue aussi.

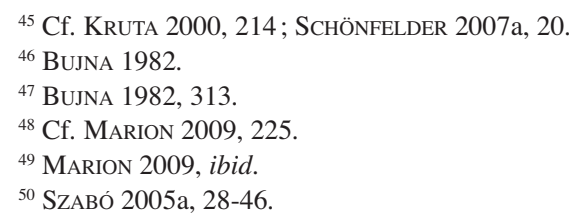


En retournant aux cimetières d'élite des environs de Paris du III ${ }^{\mathrm{e}}$ siècle av. J.-Chr. (Nanterre, Roissy-enFrance, Plessis-Gassot, Bouqueval), il est à noter que les sépultures sont relativement peu nombreuses (min. 5 max. 30) et la présence d'un ou plusieurs guerrier(s) est systématique dans ces nécropoles ${ }^{57}$ qui ont fait leur apparition quasiment d'un seul coup à la fin du $\mathrm{IV}^{\mathrm{e}}$ siècle ou au début du III ${ }^{\mathrm{e}}$ siècle av. J.-Chr. L'interprétation historique peut, en principe, aboutir à plusieurs conclusions. Certains expliquent le phénomène par le morcellement du territoire en conséquence de la formation de la tribu des Parisii. Il semblerait néanmoins plus logique de l'analyser dans le cadre des migrations ouest-est qui culmineront par les offensives balkaniques, et qui permettent sans doute de peupler des zones auparavant peu habitées. Ce processus est particulièrement bien illustré par les tombes à char qui font leur apparition au nord de la Seine dans le courant du deuxième quart du III ${ }^{e}$ siècle av. J.-Chr. Ces dernières, tout en symbolisant l'attachement de l'élite celte aux traditions, reflètent la mobilité de ces guerriers qui se sont retrouvés au sommet de la structure sociale. Tout cela témoigne sans doute de l'apparition de nouvelles conditions sociales qui s'expliquaient par le besoin de fédérer la population migrante d'origines tribales hétérogènes.$^{58} \mathrm{Ce}$ type de cimetière s'oppose radicalement aux nécropoles comme Bobigny, dans le nord-est de la banlieue parisienne, où sur un total de plus de 500 tombes seulement 10 étaient celles de guerriers. ${ }^{59}$

Ces recherches conduites en Île-de-France ont ouvert un nouveau chapitre dans l'historique de l'étude des élites de l'expansion celtique. Nous établirons une comparaison entre leurs résultats et la situation dans la région du moyen Danube plus bas dans ce texte.

Le résultat le plus surprenant des études de nécropoles appliquées à la recherche sur les élites est dû à l'analyse de la structure du cimetière de Münsingen-Rain par P. Jud. Nous devons à J. Wiedmer-Stern l'observation étant devenue une des doctrines de base de la chronologie laténienne, selon laquelle la nécropole de Münsingen avait évolué de manière organique du nord vers le sud, donc les emplacements des tombes plus récentes avaient été désignés à côté des sépultures existantes. Autrement dit, l'ordre topographique des sépultures correspondait dans les grandes lignes à leur chronologie relative. L'analyse de F. R. Hodson, laquelle distingue 22 horizons, s'est jointe en fin de compte à la conception précédente, tout en modifiant et en nuançant la chronologie de Wiedmer-Stern. ${ }^{60}$ Par contre, selon P. Jud, la structure se caractérise avant tout par l'existence de 5 enclos funéraires qui reflètent certes une continuité chronologique du nord vers le sud, mais dont les plus anciens ne cessaient pas d'être utilisés au moment de la création d'un nouvel enclos funéraire. Quatre enclos se sont organisés autour des tombes d'hommes et de femmes riches. La composition démographique des défunts semblait indiquer aussi que Münsingen-Rain n'avait pas été la nécropole d'une seule communauté (clan ou village). Des différences vestimentaires se présentaient uniquement dans le cas des femmes. Cinq d'entre elles, d'après leurs anneaux en or, se trouvaient en haut de la hiérarchie sociale. Quatre parmi les tombes de guerriers répondent aux critères de «sépulture de chef» élaborés par Jud. En fin de compte, d'après l'analyse, la structure de la nécropole de Münsingen présente de façon évidente les traits caractéristiques d'une société hiérarchisée. Ce constat permet de conclure à une importante communauté dont certaines composantes vivaient éventuellement à une distance considérable par rapport au site. ${ }^{61}$

Avant de passer en revue les trouvailles celtiques du bassin des Carpates, il faut préciser que la recherche a longtemps attaché aux élites certains types d'objets exceptionnels découverts au sein du mobilier funéraire. Nous pouvons citer ici par exemple les épées ou poignards à la poignée anthropomorphe ou pseudo-anthropomorphe, ${ }^{62}$ les lances à décor ajouré ${ }^{63}$ qu'on considère comme des insignes de guerre. On peut y ajouter également les torques en or, ${ }^{64}$ les casques qui sont rares dans le bassin des Carpates, ${ }^{65}$ ainsi que les cottes de mailles de fer ${ }^{66}$ Mais n'oublions pas les armes richement ornées (fourreaux, lances) non plus parmi lesquelles les épées dites à la paire de dragons qui, selon l'expression de De Navarro, représentent une tendance interceltique, ${ }^{67}$ contrairement aux représentantes du «style des épées hongroises» qui appartiennent, quant à elles, à une tendance régionale. ${ }^{68} \mathrm{La}$ mise en doute de cette dernière consatation ${ }^{69}$ est, à notre avis, la conséquence d'une erreur d'interprétation de la chronologie laténienne. ${ }^{70}$

${ }^{57}$ GinOuX 2009, 120-125 ; cf. MARION 2007, 102-108.

${ }^{58}$ GINOUX 2009, 120-125.

${ }^{59}$ GinOuX 2009, 12 ; cf. MARION 2009, 229.

${ }^{60}$ Hodson 1968, 9 et suiv. et 71.

${ }^{61}$ JUd 1998, 142-143.

${ }^{62}$ Dinnyés, Szendrő, etc., cf. Petres 1979.

${ }^{63}$ Halmajugra, Mannersdorf; GinOuX 2009, 91-92, fig. 80.

${ }^{64}$ Par ex., Hercegmárok/Gajić: SzaBó 2001, 104-109. 173, fig. $23-25$

${ }^{65}$ Mihovo, Batina, Apahida, etc., cf. SCHAAFF 1974, 17149 , note 50

${ }^{66}$ Horny Jatov-Trnovec nad Váhom, etc.: Rustolu 2006,

${ }^{67}$ Cf. SZABó 1989a.

${ }^{68}$ SZABÓ 1996; cf. Ginoux 2003.

${ }^{69}$ LEJARS 2003, 37-38.

${ }^{70}$ SZABó 2009c.

Acta Archaeologica Academiae Scientiarum Hungaricae 65, 2014 
Pour mieux comprendre le problème il faut se rappeler que la plupart des œuvres - en général des chefsd'œuvre - ne proviennent pas de fouilles archéologiques bien documentées. Ainsi, pour ne citer qu'un exemple parmi d'autres, l'hypothèse selon laquelle le torque de Hercegmárok aurait été porté par un guerrier n'est que spéculation. ${ }^{71}$ Il faut citer dans ce contexte le torque en argent de la sépulture de guerrier de Reisenberg (Basse-Autriche) qui faisait partie d'un ensemble funéraire relativement médiocre. ${ }^{72}$ Quant aux casques, leurs porteurs ne pouvaient pas être tous des chefs vu leur fréquence dans le milieu italo-celtique. ${ }^{73}$

Il est important de citer ici que les tombes à char, témoins de la hiérarchisation de la société celte de l'époque de l'offensive contre le monde hellénistique et présentes de Normandie jusqu'à Mezek en Bulgarie, ne sont pas absentes dans le bassin des Carpates non plus. ${ }^{74}$ Outre ces dernières, les sépultures de «chefs » sont représentées essentiellement par les trouvailles de Ciumeşti lesquelles, malgré les incertitudes concernant les conditions de la découverte,$^{75}$ constituent - grâce au casque en fer orné d'un rapace en bronze aux ailes articulées, à la cotte de mailles en fer et aux jambières grecques, un ensemble unique dans le monde celtique. ${ }^{76}$ Selon l'interprétation la plus récente (et qui ne sera sans doute pas la dernière), le défunt aurait été un chef ayant recruté des mercenaires pour participer aux opérations militaires visant la Méditerranée. ${ }^{77} \mathrm{Il}$ n'est pas sûr que la paire de jambières grecques autorisent des conclusions tellement poussées. Il est néanmoins certain que la nécropole avec les 32 sépultures réparties autour de la tombe du $\operatorname{chef}^{78}$ mérite d'être comparée aux cimetières d'élite des environs de Paris, cités ci-dessus.

Des documents exceptionnels relatifs à l'élite militaire des Celtes orientaux ont été mis au jour dans l'oppidum scordisque situé sur le sommet Veliki Vetren des monts Juhor. Le «dépôt» composé, entre autres, d'un mors circulaire et de treize mors à levier, ainsi que d'un umbo, d'une grande lance, d'une paire d'éperons et de 3 torques, a été interprété par Stojić comme l'équipement d'une unité de cavalerie de 14 personnes, sous la direction d'un chef et de 2 sous-chefs. Cette «triade» fait penser à l'expression trimarkisia employée par Pausanias et qui signifie une unité tactique constituée de 3 cavaliers. ${ }^{79}$ Le passage des Celtes au mode de combat à cheval a commencé probablement à l'époque des invasions balkaniques de $280 \mathrm{av}$. J.-Chr. L'apparition puis la généralisation du type d'épée de LT moyenne témoignent du fait que ce processus venait d'atteindre son apogée ${ }^{80}$ Les trouvailles de Veliki Vetren, datées de manière convaincante du tournant de LT C2 et LT D1, reflètent sans doute le point culminant de cette transformation dans le nord des Balkans ${ }^{81}$ Les données archéologiques que nous venons de passer brièvement en revue semblent suggérer qu'à l'instar des Gaulois, il existait aussi chez les Scordisques la classe dite des equites, des «chevaliers» qui constituaient la principale composante de l'élite tribale. ${ }^{82}$

Dans les mobiliers funéraires de Pécs-Hőerőmü, récemment publiés, on retrouve le type de mors à levier découvert à Veliki Vetren. ${ }^{83}$ Ce dernier est appelé mors «thrace» d'après Venedikov vu que son aire de répartition correspond dans les grandes lignes au nord-ouest de la Bulgarie actuelle et à l'Olténie voisine, c'est-à-dire au territoire du groupe de Padea-Panagjurski Kolonii dont la formation et la floraison à l'époque de La Tène moyenne et à l'époque de LT finale sont attribuées aux Scordisques par la recherche. La diffusion du mors à levier s'explique par la même situation historique. ${ }^{84}$

Par la suite, nous analyserons deux nécropoles mises au jour dans le nord-est de la Hongrie. Dans les deux cas, nous disposons des résultats de fouilles modernes qui, dans la mesure du possible, ont exploré la totalité des sites en question.

Ludas se situe au pied des monts Mátra, à la frontière de la Grande plaine hongroise et du Massif du Nord. Le site, le lieu-dit de Varjú-dűlö, se trouve au nord du village, sur le versant de la colline longeant la vallée du ruisseau Bene. Sa mise au jour a été effectuée, dans le cadre de fouilles de prévention, en conséquence des besoins en lignite de la centrale thermique de Mátra, entre 1998 et 2002. Le site avait été touché auparavant par une culture intensive de vignes qui a endommagé une partie des tombes. Heureusement, 11 sépultures perturbées voire détruites

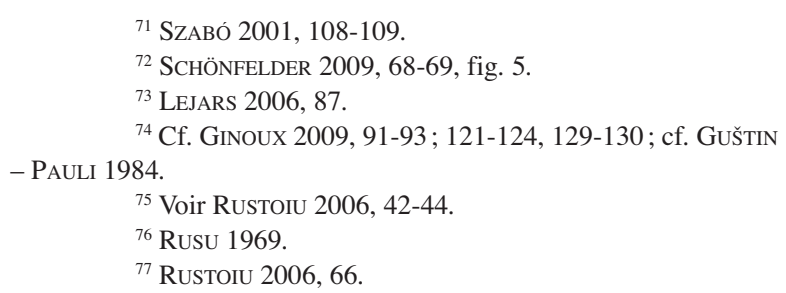

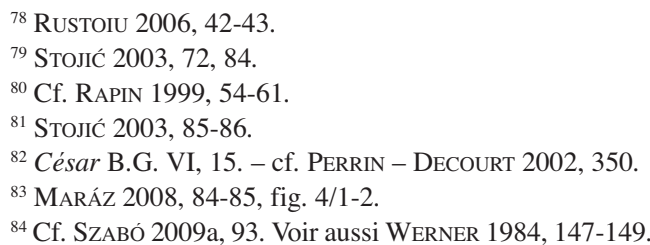

${ }^{78}$ Rustoiu 2006, 42-43.

${ }^{81}$ SтолÍ́ 2003, 85-86.

${ }^{83}$ MARÁz 2008, 84-85, fig. 4/1-2.

${ }^{84}$ Cf. SZABÓ 2009a, 93. Voir aussi Werner 1984, 147-149. 
ont pu être localisées. En fin de compte, les 82 tombes de la nécropole, datées de LT B2 et de la phase ancienne de LT C1, corroborent une utilisation qui s'étend de la fin du IV ${ }^{\mathrm{e}}$ siècle au début du II ${ }^{e}$ siècle av. J.-Chr. ${ }^{85}$ (Fig. 2)

Lors de l'analyse de la structure de la nécropole, il est avantageux d'utiliser le positionnement des sépultures faciles à dater comme point de départ. Le bien-fondé des horizons selon Gebhard a été justifié par l'analyse par sériation présentée dans la monographie consacrée à la nécropole de Ludas. ${ }^{86}$ Ainsi, les horizons 4 et 5 , généralement difficiles à séparer (LT B2a et LT B2b), peuvent être définis sans ambiguïté. L'horizon 6 (LT C1a) se distingue nettement des précédents grâce à la modification du port des bijoux. ${ }^{87}$

Ayant ajouté les tombes classées dans les horizons corrigés par sériation (fig. 3) au plan de la nécropole, il parait évident que les sépultures les plus anciennes (horizon 4) se trouvent dans la zone nord-est de la nécropole, réparties en deux groupes. Les tombes de l'horizon 5 se situent plus à l'ouest sur un territoire plus vaste; l'alignement des sépultures qu'on observe ici est également caractéristique de l'horizon 6. Les défunts de ce dernier ont été enterrés dans la zone sud de Ludas-Varjú-dülő. Durant la dernière phase de la nécropole, les secteurs nord et nordest ne sont plus utilisés. ${ }^{88}$

Nous pouvons conclure l'analyse de la nécropole en constatant qu'à l'instar de Münsingen, Ludas semble aussi avoir été constitué de groupes de sépultures: au total, de six enclos funéraires. (Fig. 4)

Dans la zone nord-est de la nécropole, l'enclos A comprend essentiellement des tombes d'hommes armés. (Cette zone a été détruite, sur le côté nord-ouest, par l'exploitation minière.) Les sépultures y mises au jour abritaient les restes de guerriers armés d'une épée (1288), d'une épée et d'un bouclier (1005), d'une lance et d'un bouclier (1290), uniquement d'une lance (1003) ou d'un bouclier (998). Le groupe B, situé dans les secteurs nord et est du cimetière, était majoritairement constitué de sépultures de femmes et d'enfants et, dans certains cas, de celles d'hommes non armés. La zone centrale dite enclos $C$ était occupée par des tombes de guerriers, ensevelis à peu de distance les uns par rapport aux autres, entrecoupées de sépultures féminines. C'est ici qu'avait été enterré, compte tenu du mobilier funéraire, le membre le plus important de la communauté de Ludas : on a découvert, dans le mobilier, une épée, un bouclier, un anneau en or, un bracelet richement orné à décor ajouré, ainsi que les restes d'un nouveau-né inhumé avec le défunt (tombe 686). Les tombes des autres hommes armés d'épées, de boucliers ou de lances $(703,904,1055,1056,1057$, et 1140$)$ constituent un demi-cercle autour de la précédente, et parmi elles il y a quelques sépultures de femmes $(685,740,699,711)$ et d'enfants $(1039,1010)$. Plus à l'ouest, dans le groupe $\mathrm{D}$, des tombes de femmes et d'hommes armés de lances $(708,692,725,729)$ ont été mises au jour. ${ }^{89}$

Il est important d'insister ici sur les différences entre l'armement des guerriers des groupes $\mathrm{C}$ et $\mathrm{D}:$ les derniers n'avaient pas d'épées, ils étaient armés exclusivement de lances. L'enclos E, constitué de sépultures féminines à peu de distance les unes par rapport aux autres, se situe près de la limite ouest de la nécropole. Le guerrier de la tombe 879 repose à la périphérie nord-ouest du cimetière, dans l'enclos F, non loin de deux femmes $(951,953)$ et d'un enfant (882). ${ }^{90}$

En fin de compte, nous pouvons distinguer, au sein de la nécropole de Ludas, des groupes de sépultures (A-F) entre lesquels il y a des chevauchements chronologiques. Cette constatation ne contredit pas l'évolution générale nord-est - sud-ouest de la nécropole, mais un ordre linéaire proprement dit n'a jamais existé. C'est-à-dire qu'à Ludas, comme à Münsingen, le cimetière a évolué à partir de plusieurs enclos funéraires qui, au moins en partie, ont été utilisés parallèlement. La division sociale de la communauté (ou des communautés) enterrée ici se reflète avant tout par le positionnement des tombes d'hommes armés qui détermine l'organisation spatiale de la nécropole y compris l'emplacement des sépultures féminines. Les tombes à armes les plus anciennes se trouvent à la périphérie nord-est du cimetière dans l'enclos A. Le guerrier le plus «prestigieux» avec les hommes armés enterrés autour de lui reposait dans la zone centrale (enclos funéraire C). Les hommes armés de lances font partie du groupe D. L'unique guerrier, à armement complet, de l'enclos F est séparé des autres. Par contre, la question de savoir pourquoi le groupe E, côté sud-ouest, ne comprend que des sépultures féminines et pourquoi, le groupe B est constitué uniquement d'hommes sans armes en dehors des femmes et des enfants, reste ouverte. ${ }^{91}$

\footnotetext{
${ }^{85}$ SZABÓ - TANKÓ 2006, 325-326; SZABÓ 2012, 150.

${ }^{86}$ SZABÓ - TANKó 2006, 331-334, fig. 4-6; SzABÓ 2012

${ }^{87}$ SZABÓ 2012, 141-146, fig. 184-187.

${ }^{88}$ SZABÓ 2012, 147, fig. 188.
}

\footnotetext{
${ }^{89}$ SZABÓ 2012, 147-148.

${ }^{90}$ SZABÓ 2012, 148

${ }^{91}$ SZABÓ 2012, 148-149.
}

Acta Archaeologica Academiae Scientiarum Hungaricae 65, 2014 


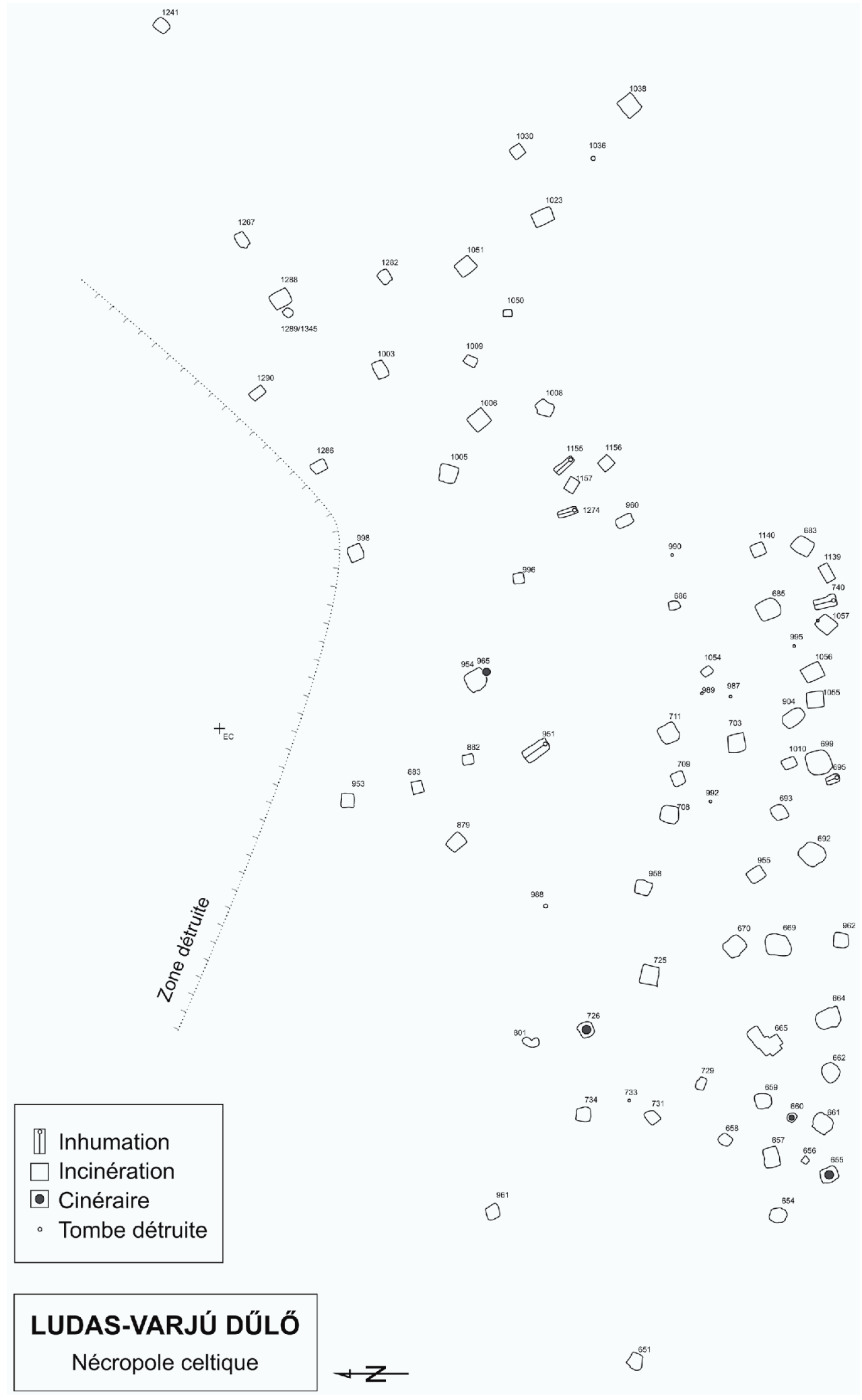

Fig. 2. Le plan de la nécropole de Ludas avec l'indication des rites funéraires 


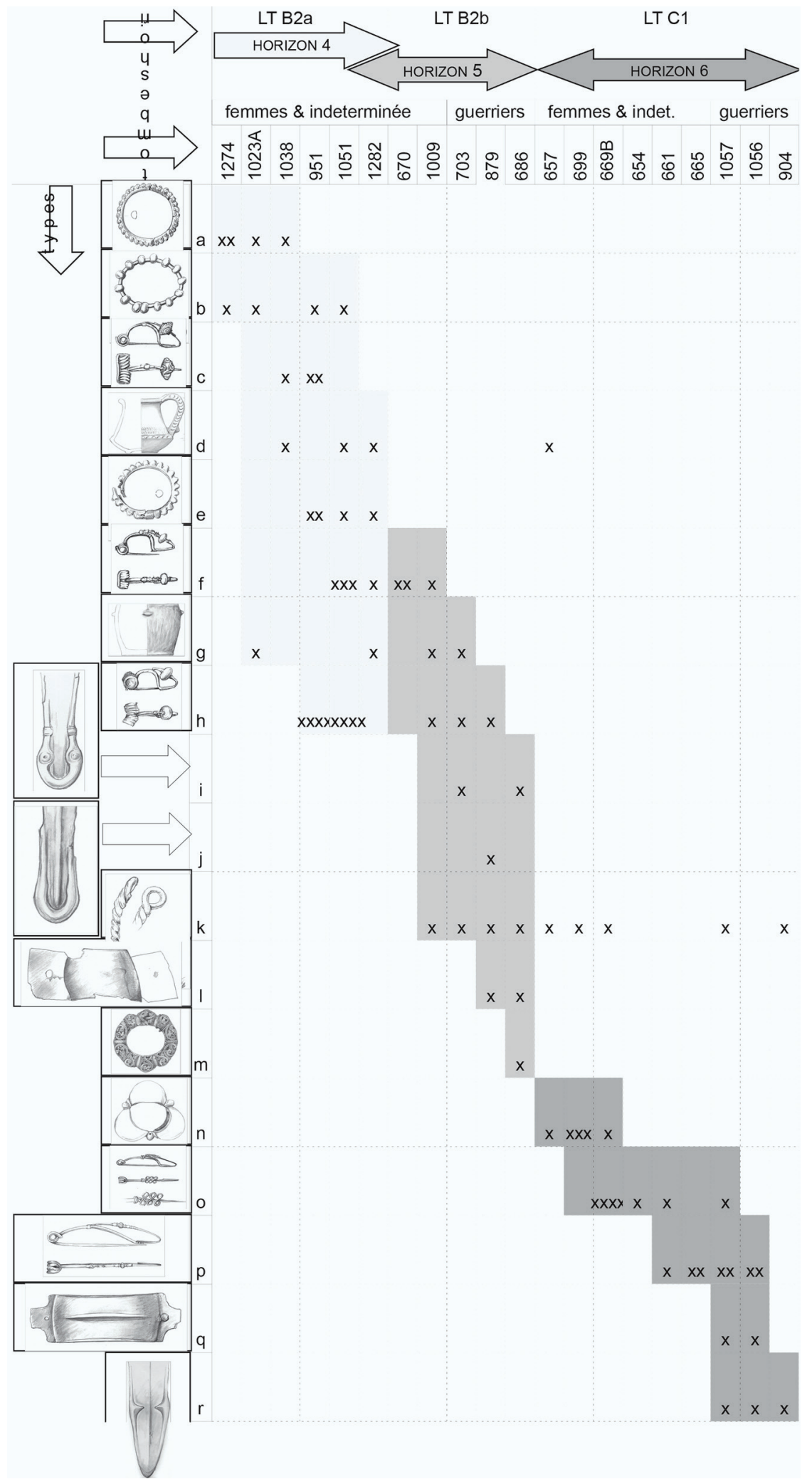

Fig. 3. Ludas: tableau de sériation des sépultures 


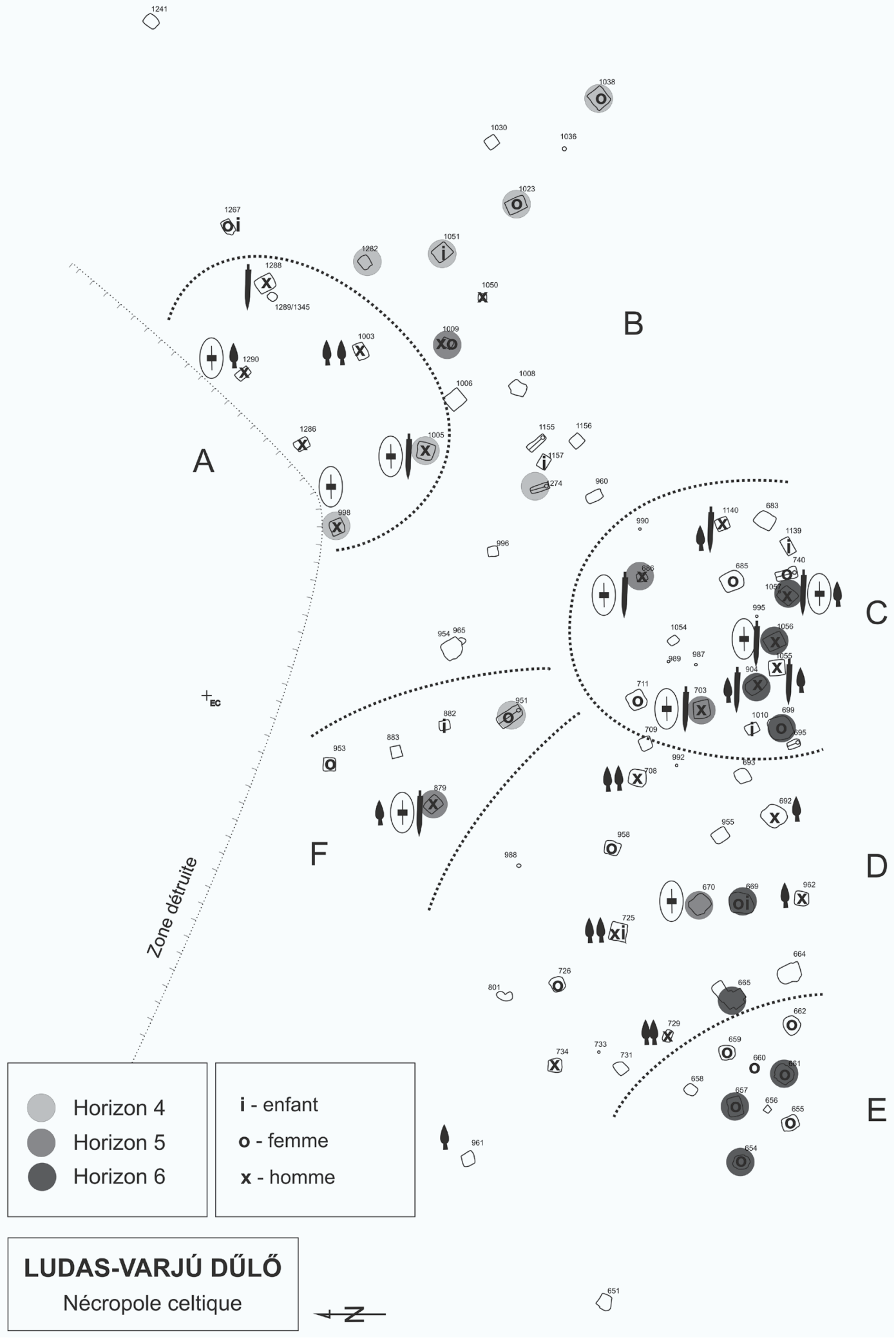

Fig. 4. Ludas: enclos funéraires (A-F) 
Pour retourner aux guerriers, les sépultures les plus anciennes de l'enclos A datent de LT B2a. ${ }^{92}$ Du point de vue de la chronologie absolue, ces dernières sont certainement antérieures à l'offensive balkanique de 280-279 av. J.-Chr., et ainsi corroborent l'hypothèse selon laquelle l'occupation massive du nord-est de la Hongrie par les Celtes s'est produite à la veille de l'invasion, à la fin du IV ${ }^{\mathrm{e}}$ siècle av. J.-Chr. D'après le mobilier, la tombe du guerrier le plus «prestigieux » du groupe C (686) a été datée de LT B2b, donc elle n'est pas antérieure à la dernière phase de LT ancienne, c'est-à-dire aux 2-3 décennies entre 280-260/50 av. J.-Chr. ${ }^{93}$ Quant aux hommes armés enterrés autour de sa tombe, il faut attirer l'attention sur deux d'entre eux, ensevelis dans la phase ancienne de la période de LT moyenne (LT C1a), donc dans la deuxième moitié du III' siècle av. J.-Chr. : vu leurs outils particuliers, le défunt de la sépulture 904 devait être chirurgien, alors que celui de la sépulture 1057, artisan. ${ }^{94}$

D'après l'analyse des sources anciennes, les immigrants celtes étaient d'une composition ethnique hétérogène et les nouvelles formations (voir par ex. le cas des Scordisques) ne se sont créées qu'après l'échec de l'invasion contre le monde hellénistique. Ainsi, la consolidation qui succédait à l'établissement marquait également le début d'une ethnogenèse. ${ }^{95}$

L'analyse des tombes de guerrier permet justement d'identifier un des symptômes de ce processus. Les sources anciennes citées ci-dessus confirment l'existence d'une aristocratie celtique fondée sur la filiation, sans éclaircir les cadres chronologiques de la formation d'une telle élite. L'exemple cité du chef boïen Crixus évoque une généalogie remontant 6-7 générations, jusqu'à Brennos, connu pour la prise de Rome. D’un point de vue archéologique, l'autre critère essentiel de l'appartenance aux «meilleurs», la gloire au combat, peut sembler plus facile à appréhender. Cependant, cela ne signifie pas que l'analyse des mobiliers funéraires permette de déterminer sans ambiguïté la situation sociale du défunt. Cette remarque est particulièrement valable pour la période de l'expansion celtique dont la documentation archéologique doit se passer de tombes dites princières, ce qui indique, qu'au moins d'un point de vue archéologique, les frontières entre l'aristocratie et le peuple se sont estompées. Cette constatation explique la préférence accordée au terme élite dans la littérature archéologique de la dernière dizaine d'années.

Sur les territoires nouvellement conquis, comme dans le nord-est de la Hongrie, la formation des nouvelles organisations tribales s'accompagne, sans doute, de l'apparition de la couche dirigeante, de l'élite. En revenant à l'étude de la nécropole, il paraît justifié de considérer les tombes de guerriers comme un témoignage de ce processus dans la phase qui se succède à l'échec de l'offensive balkanique (LT B2b-LT C1a). Nous avons déjà fait allusion à l'importance de la tombe de guerrier 686. (Fig. 5) En ce qui concerne le mobilier, il est important de citer ici l'anneau en fil d'or en forme de «selle» dit «Schaukelfingerring», ainsi que la paire de bracelets. ${ }^{96}$ Le premier est la seule trouvaille en métal précieux de la nécropole de Ludas, et elle est datée, comme nous l'avons vu plus haut, de la période de LT B2. Les représentants de ce type se retrouvent dans le bassin des Carpates dans des sépultures de La Tène ancienne et moyenne. Selon le système de Waldhauser, il s'agit du type 510, utilisé entre les périodes de LT A2 et B2. ${ }^{97}$ Les anneaux en général, et les pièces en or en particulier sont considérés, en principe, comme des accessoires du costume féminin. ${ }^{98} \mathrm{Il}$ n'empêche pas que la parure de Ludas, comme celle de Dubnik, ${ }^{99}$ a été découverte dans une tombe de guerrier. La recherche est unanime : le port d'un anneau en or, qu'il s'agisse de sépultures féminines ou masculines, devait indiquer un statut éminent, sans doute celui d'un dirigeant, au sein de la communauté. ${ }^{100}$ Ajoutons que les anneaux font leur apparition dans des tombes de guerriers surtout à l'est de Dürrnberg. ${ }^{101}$

La sépulture 686 abritait deux bracelets. L'un était un bracelet fermé en tôle, creux à l'intérieur et à surface uniformément lisse, ${ }^{102}$ dont on connaît une proche analogie provenant du site slovaque de Palárikovo. ${ }^{103} \mathrm{D}$ 'après l'analyse effectuée pendant la restauration, l'autre bracelet ${ }^{104}$ avait été effectué par le procédé de la cire perdue. Ce bijou fait partie des parures annulaires relativement larges à section semi-circulaire (profil de « $\mathrm{C} »)$, dont le fermoir est un élément amovible. Du point de vu du décor, ce groupe est loin d'être homogène : outre le faux filigrane, ${ }^{105}$ on y retrouve aussi les représentants du Style plastique, produits probablement par les ateliers laténiens de Bo-

92 Cf. Szabó - TAnKó 2006, 331-333, fig. 4; SzABó 2012 142, fig. 184, tombes 951, 1051.

${ }^{93}$ Cf. SzABÓ 1995, 51-53.

${ }^{94}$ SZABÓ - TANKÓ 2006, 337 ; SZABÓ 2012, 150-152.

${ }^{95}$ Cf. SzABÓ 1995, 49-50.

${ }^{96}$ SZABÓ 2012, Pl. XIII.1,2,6.

${ }^{97}$ Bujna 2005, 71-75; Waldhauser 1998, 100, fig. 5.

${ }^{98}$ Bujna 2005, 71-76.

${ }^{99}$ BujNa 1991, 231.
100 JUD 1998, 142; WALDHAUSER 1998, 109.

101 WaLdHAUSER 1998, 98-100, tableau 7; cf. SCHÖNFELDER 2009, 68-69, fig. 4

${ }^{102}$ SzABÓ 2012, pl. XIII.1.

103 Bujna 2005, 89.

${ }^{104}$ SZABÓ 2005a, 156; SZABÓ 2009b, 68-71; SZABÓ 2012 , pl. XIII.2, 103 et suiv., fig. 160.

${ }^{105}$ KrUTA 1975, 69-70; cf. FILIP 1956, pl. XXXVI.9, pl. LIII.6: en ce qui concerne la série de Moravie.

Acta Archaeologica Academiae Scientiarum Hungaricae 65, 2014 
hême. ${ }^{106}$ Cette contradiction apparente au sein du groupe peut être résolue, d'après les dernières recherches, par l'hypothèse selon laquelle le centre de production bohémien supposé aurait été inspiré par des prototypes du moyen Danube qui seraient également responsables de l'introduction du faux filigrane dans la région. ${ }^{107}$

L'ornementation du bracelet de Ludas représente un des extrêmes du «style» du faux filigrane : elle est fondée sur une composition de rinceaux formant des peltes et des « $\mathrm{S}$ » inversés, alors que les extrémités des rinceaux sont ornées de «fleurs» à quatre pétales ou composées de deux à trois cercles. Ces dernières présentent des traces de pastillage. Ce décor de rinceaux ajouré de deux dimensions s'apparente en réalité non pas aux compositions baroques de trois dimensions du Style plastique mais à l'ornementation linéaire de la région du moyen Danube. En effet, les vraies analogies du décor du bracelet de Ludas sont à chercher avant tout parmi les œuvres du Style dit des épées hongroises, surtout en ce qui concerne l'esprit de ce type d'ornementation. Faisons ici allusion aux appliques ajourées sur certains des fourreaux «hongrois », surtout sur celui de la découverte de Pişcolt. ${ }^{108}$ Les analogies des peltes ${ }^{109}$ et des différentes variantes des $« \mathrm{~S} »{ }^{110}$ sont également présentes parmi les ornements gravés des fourreaux. Tous ces exemples semblent indiquer que l'atelier du bracelet de Ludas savait parfaitement utiliser le dialecte de l'art laténien du bassin des Carpates. Pour comprendre l'importance de cette constatation, il suffit de comparer ce chef-d'œuvre aux versions bohémiennes. ${ }^{111}$

L'autre extrême du «style» du faux filigrane est représenté par le bracelet de la tombe 14 de Chotin qui, à l'instar de la parure de Ludas, appartenait au mobilier funéraire d'un guerrier. ${ }^{112}$ Mais, contrairement à la trouvaille de Ludas, celui-ci illustre la monotonie de ce type d'ornementation : parmi les motifs, ce sont les « $\mathrm{S}$ » et les double spirales, ainsi que leurs variantes, qui dominent. Les motifs de «lyre» ou de tournant à quatre branches sont rares. Les lignes ondulées, les tresses et les hachures font également partie des motifs. ${ }^{113}$ (Fig. 6)

La sépulture 14 de Chotin, qui occupait une place de choix au sein de la nécropole, date, à l'instar de celle de Ludas, de la phase de LT B2b. ${ }^{114}$ C'est-à-dire que, compte tenu, entre autres, des bracelets exceptionnels qui viennent d'être présentés, les deux guerriers en question avaient un statut particulier dans leurs communautés respectives à l'époque de l'offensive balkanique ou, plutôt, quelque temps après cette dernière. Il serait néanmoins prématuré de considérer ce type de bijou comme une spécificité des Celtes de l'Est. Cette coutume a également été attestée beaucoup plus à l'ouest. ${ }^{115}$ Les bracelets à décor plastique ornant les statues de guerriers d'Entremont, ainsi que les «brassards» sans décor portés sur leurs bras comme les bijoux dont les originaux étaient sans doute en verre, en sont aussi des exemples convaincants. ${ }^{116}$

Selon les Celtes, il existait un lien particulier entre le guerrier et son épée. ${ }^{117}$ C'est-à-dire, le décor du fourreau doit être interprété dans ce contexte: le choix des motifs ne pouvait pas se faire au hasard, vu que ces derniers étaient porteurs d'une signification compréhensible par toute la communauté. ${ }^{118}$ Sur le fourreau du défunt de la tombe 686, une paire de dragons avait été identifiée au moment de la mise au jour, mais cette dernière n'a pas pu être conservée lors de la restauration. ${ }^{119}$ Le même décor ornait probablement l'arme du guerrier solitaire de l'enclos funéraire F (tombe 879), qui avait par ailleurs été enterré avec l'armement LT B2b complet. ${ }^{120}$ Si nous acceptons la supposition selon laquelle la paire de dragons était l'emblème de la couche guerrière jouant un rôle majeur dans l'expansion celtique et située en haut de la hiérarchie tribale, il peut sembler logique de considérer les défunts des tombes 686 et 879 comme des protagonistes de la conquête du nord-est de la Hongrie. Mais tout en envisageant cela comme une possibilité, les sépultures en question étant des incinérations, l'âge des défunts ne peut pas être déterminé. D'autre part, l'équipement de guerrier de type LT B2a $(998,1005)$ n'a été découvert à Ludas que dans un état mauvais ou lacunaire. ${ }^{121} \mathrm{Il}$ faut souligner cependant que les objets représentant le Style des épées hongroises, considéré comme un phénomène régional, font leur apparition à Ludas durant la phase LT C1a.

181, pl. 63, etc.
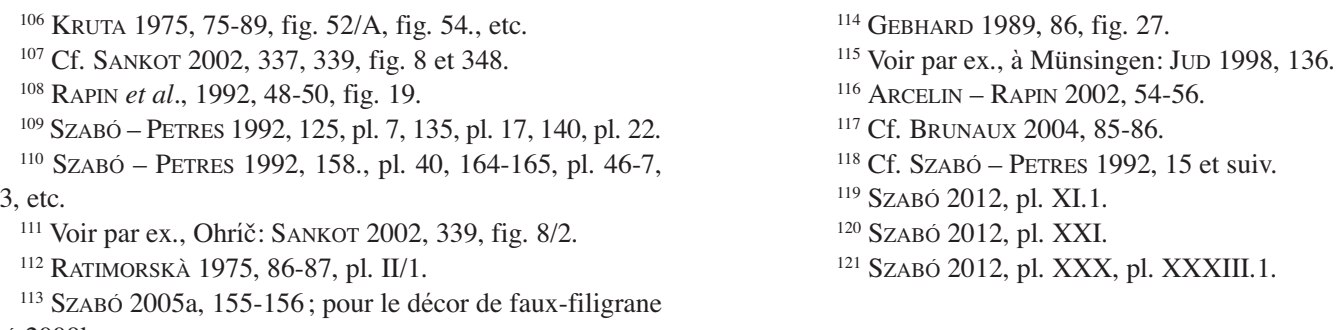
voir SZABÓ 2009b. 


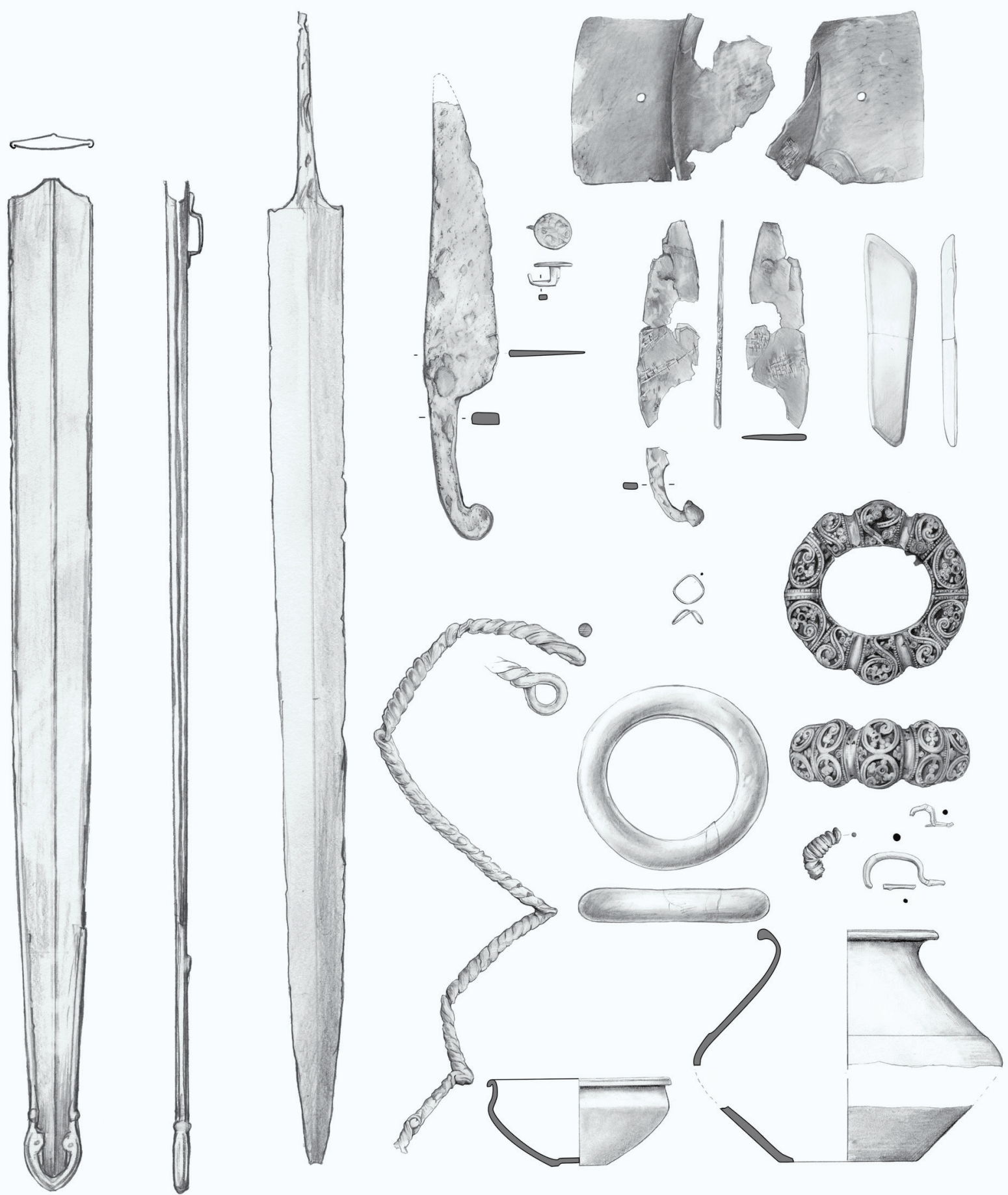

Fig. 5. Ludas: sépulture 686 


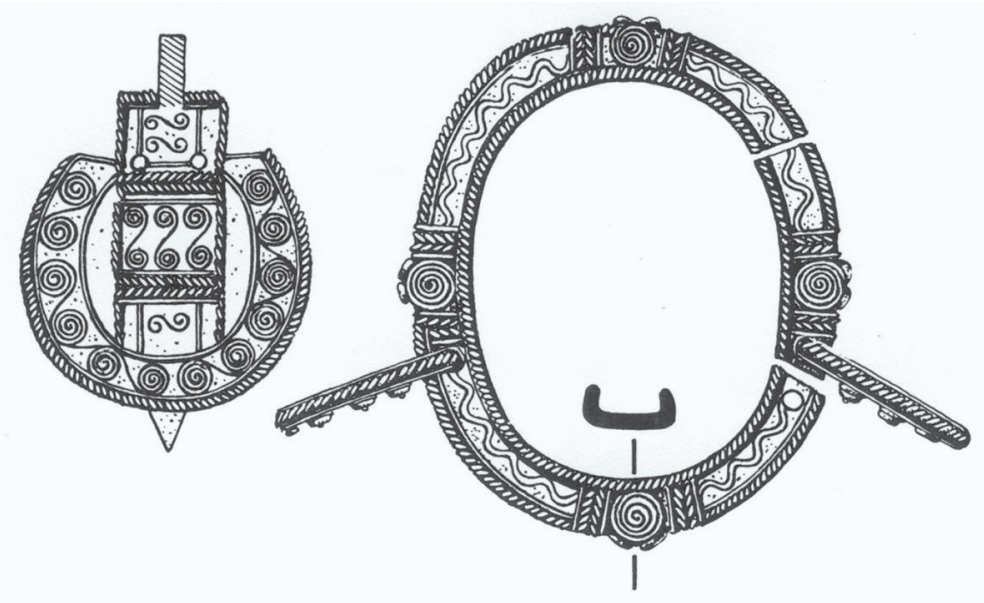

$\frac{a}{b}$

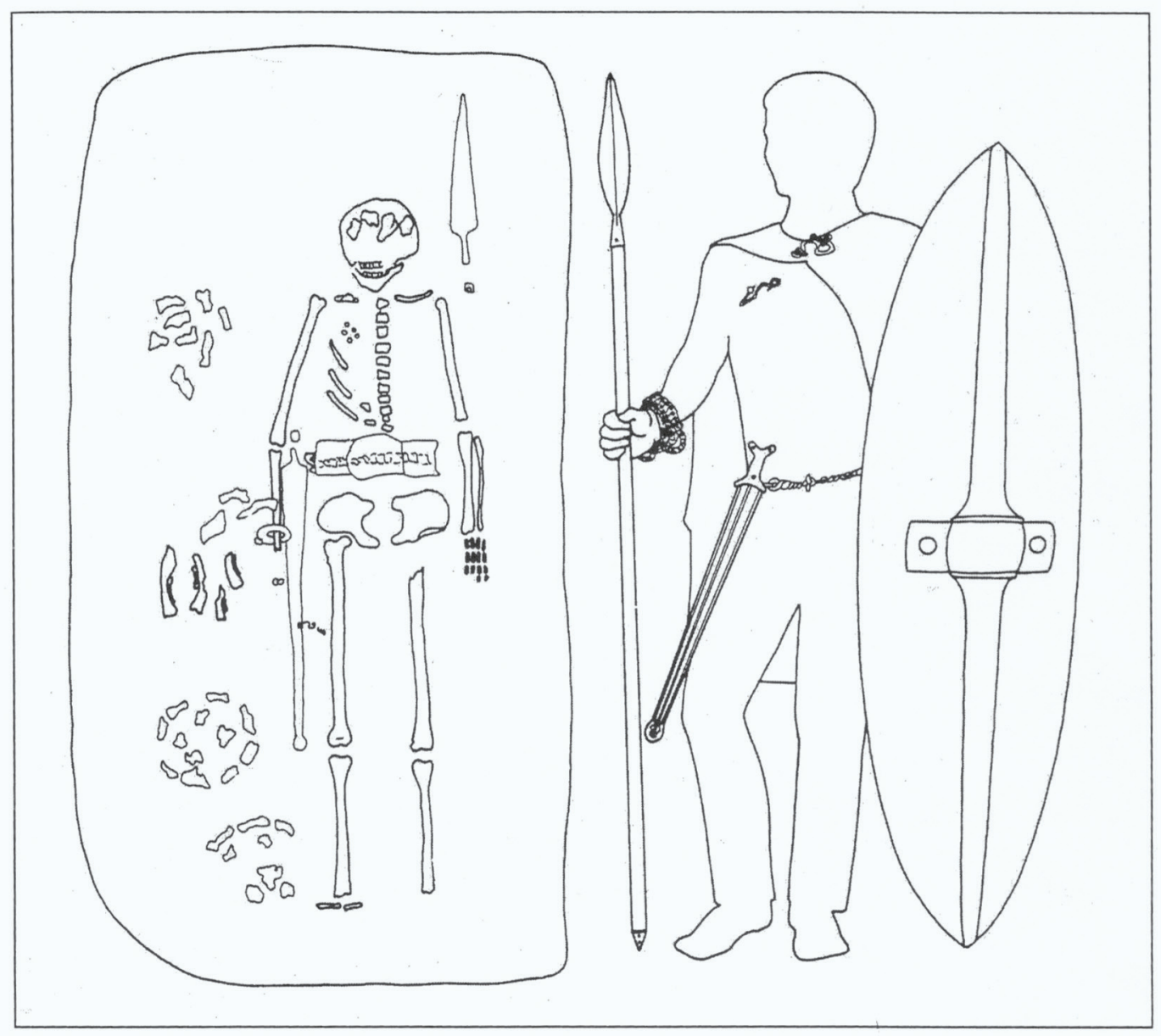

Fig. 6. Chotin sépulture 14. a: bracelet à décor de faux-filigrane (d'après RATIMORSKÁ 1975) b: reconstitution de l'armement et du costume du guerrier (d'après SZABÓ 1992) 
Cette constatation peut être interprétée comme un symptôme de l'homogénéisation d'une communauté d'origine tribale hétérogène. Mais le processus supposé peut être appuyé d'autres arguments aussi. D'après l'analyse par sériation, les pots modelés à la main et ornés de bosses, issus de la tradition scythe locale, et les tasses à anse unique, également ancrées dans les traditions locales mais présentant des influences morphologiques et décoratives laténiennes, remontent aux horizons 4 et 5 de la nécropole. ${ }^{122}$ Le début de l'horizon 6 n'est représenté que par une seule tasse à anse unique, mise au jour dans la tombe $657 .{ }^{123}$ La présence de types de vases d'origine locale dans les mobiliers funéraires est une preuve du mélange culturel entre les Celtes et les «Scythes» dont les origines remontaient au premier âge du Fer. L'absence de ce type de documentation archéologique dans le cas de la troisième génération de la communauté témoigne sans doute de l'assimilation de l'ethnie «scythe». ${ }^{124}$

Mais revenons aux guerriers et aux épées à décor gravé. Dans l'enclos $\mathrm{C}$, il y avait six défunts enterrés avec une épée parmi les sépultures disposées en demi-cercle autour de la tombe 686 . Une d'entre elles ${ }^{125}$ a été datée de LT B2b, les autres ${ }^{126}$ de LT C1a. La longueur des épées du début de La Tène moyenne varie entre 800 et $940 \mathrm{~mm}$, et compte tenu de leur exécution, ce n'étaient pas des armes d'estoc, mais des armes tranchantes. Entre autres, cela témoigne de la préférence accordée à la cavalerie par les Celtes laténiens dès cette époque. ${ }^{127} \mathrm{C}$ 'est-à-dire que la formation des equites - décrits par César - doit remonter à peu près à cette période.

Trois d'entre les épées du type de LT moyenne (tombes 904, 1056 et 1057) (fig. 7-8) comptent parmi les documents notables du Style des épées hongroises. L'épée de la sépulture 1055 était originellement sans décor, alors que les gravures visibles sur l'arme de la tombe 1140 ne permettent pas la reconstitution de la composition en raison du mauvais état de conservation de la pièce. Les décors identifiés sur les fourreaux des sépultures 904 et $1057^{128}$ appartiennent au groupe 2 du Style des épées hongroises, dont le «floruit» remonte à la phase de LT C1a et dont la diffusion caractérise avant tout l'est de la Transdanubie hongroise, l'ancienne Yougoslavie, le nord-est de la Hongrie et les territoires slovaques voisins. ${ }^{129}$

On peut retrouver les analogies des décors ${ }^{130}$ des fourreaux découverts dans les tombes 1057 et 904 (fig. 7) dans la zone entre Szob et Ižkovce. Les structures des deux compositions sont similaires : la partie supérieure est quasi symétrique, tandis que la partie inférieure évolue sous la forme d'un rinceau diagonal. Chacune se caractérise par la combinaison d'éléments végétaux (feuille de gui, fleur de trompette) et zoomorphes (becs crochus). La pièce de suspension du fourreau de l'épée 1057 est ornée d'une palmette ambivalente qui se prête à deux lectures différentes. Il s'agit d'un masque humain intégré à un motif végétal, ce qui, selon l'interprétation actuelle, est une représentation divine «doublée» de son attribut végétal. ${ }^{131}$ L'avers du fourreau de l'épée de la tombe 1056 est couvert d'un motif ressemblant à un filet continu (fig. 8), dont les analogies sont inconnues à l'état actuel de la recherche; il est constitué de tresses ovales et de feuilles stylisées en forme de cœur, les deux types de rinceaux s'entrelaçant à hauteur du deuxième tiers du fourreau. Bien que ce décor soit dépourvu d'analogies précises, l'esprit qu'il représente n'est pas inconnu dans l'art celtique : un filet de losanges ornant l'avers du fourreau est attesté notamment dans le cas d'épées du III siècle av. J.-Chr., et les origines de ce type d'ornementation peuvent être ramenées pratiquement aux débuts de l'art laténien. ${ }^{132}$

Etant donné que selon les Celtes, il y avait un lien particulier entre le guerrier et son épée, le décor de cette dernière était, par conséquent, l'expression symbolique de ce lien. C'est-à-dire, le choix et l'ordonnance des motifs ne se faisaient pas au hasard, car ils étaient porteurs de messages clairement identifiables par les Celtes, ce qui peut expliquer la diffusion géographique et chronologique, à travers de vastes territoires et de longs siècles, de motifs dont l'interprétation continue de nous poser problème. ${ }^{133}$ Nous pouvons supposer avec une forte probabilité que l'idéologie religieuse véhiculée par les décors des armes reflétait également la vision du monde de l'élite militariste.

122 SzABÓ 2012, 134.

${ }^{123}$ SZABÓ 2012, pl. III.6.

${ }^{124}$ Cf. Szabó - TANKó 2006, 339-341, fig. 10 /6.

125 703. = SZABÓ 2012, pl. XVI.1.

126 904. = SZABÓ 2012, pl. XXIV; 1055, 1056, $1057=$ SZABÓ 2012, pl. XL.1; pl. LI; pl. XLIII.2 et $1140=$ SZABÓ 2012, pl. XLVII. 2 .

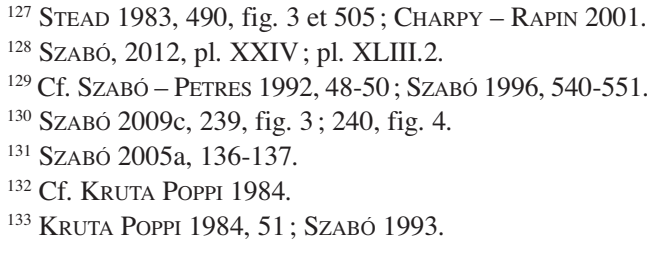

Acta Archaeologica Academiae Scientiarum Hungaricae 65, 2014 


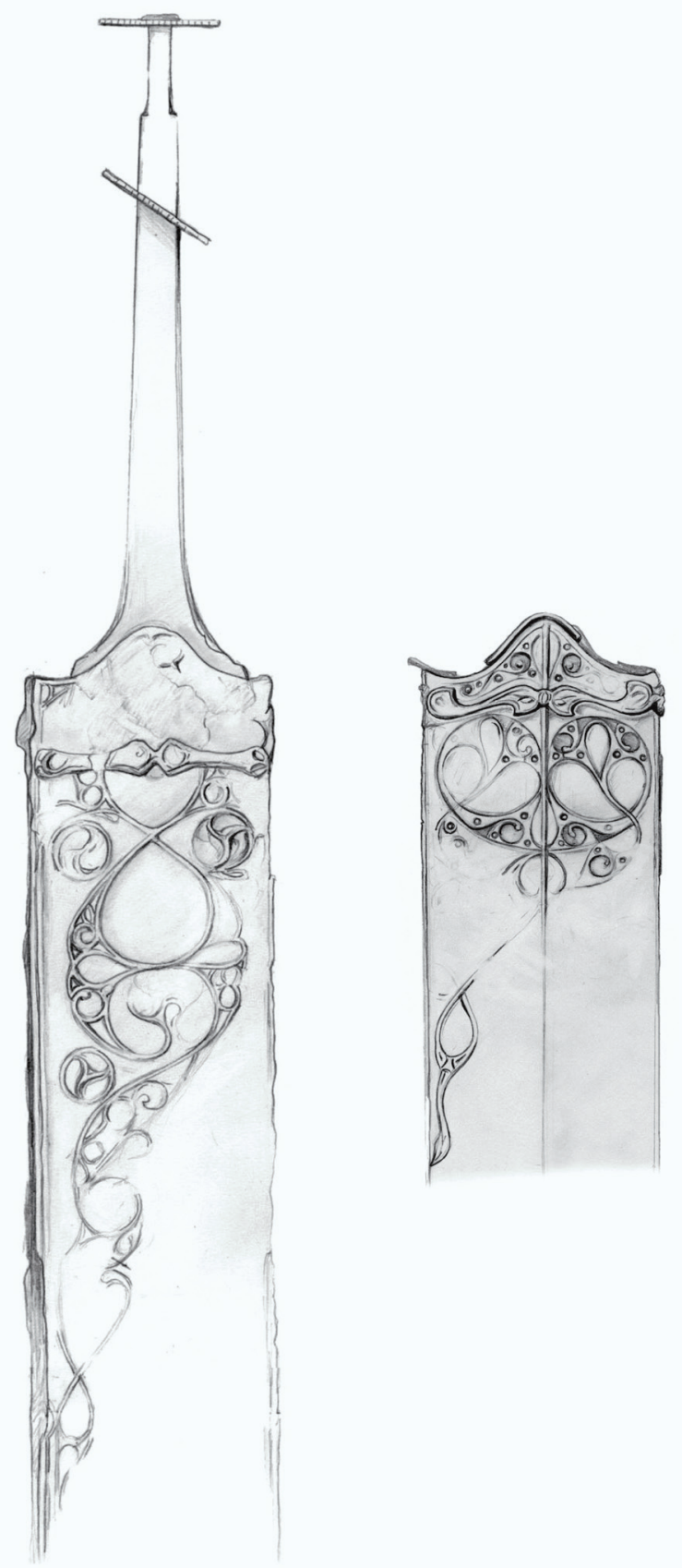

Fig. 7. Ludas: fourreaux à décor gravé (sépultures 904 et 1057)

Les outils de médecin (chirurgien) faisant partie du mobilier funéraire du guerrier 904 méritent une attention particulière. ${ }^{134}$ (Fig. 9) Néanmoins, nos connaissances actuelles ne justifieraient pas l'interprétation de cet ensemble important dans le contexte de l'identification archéologique des druides. ${ }^{135}$ 


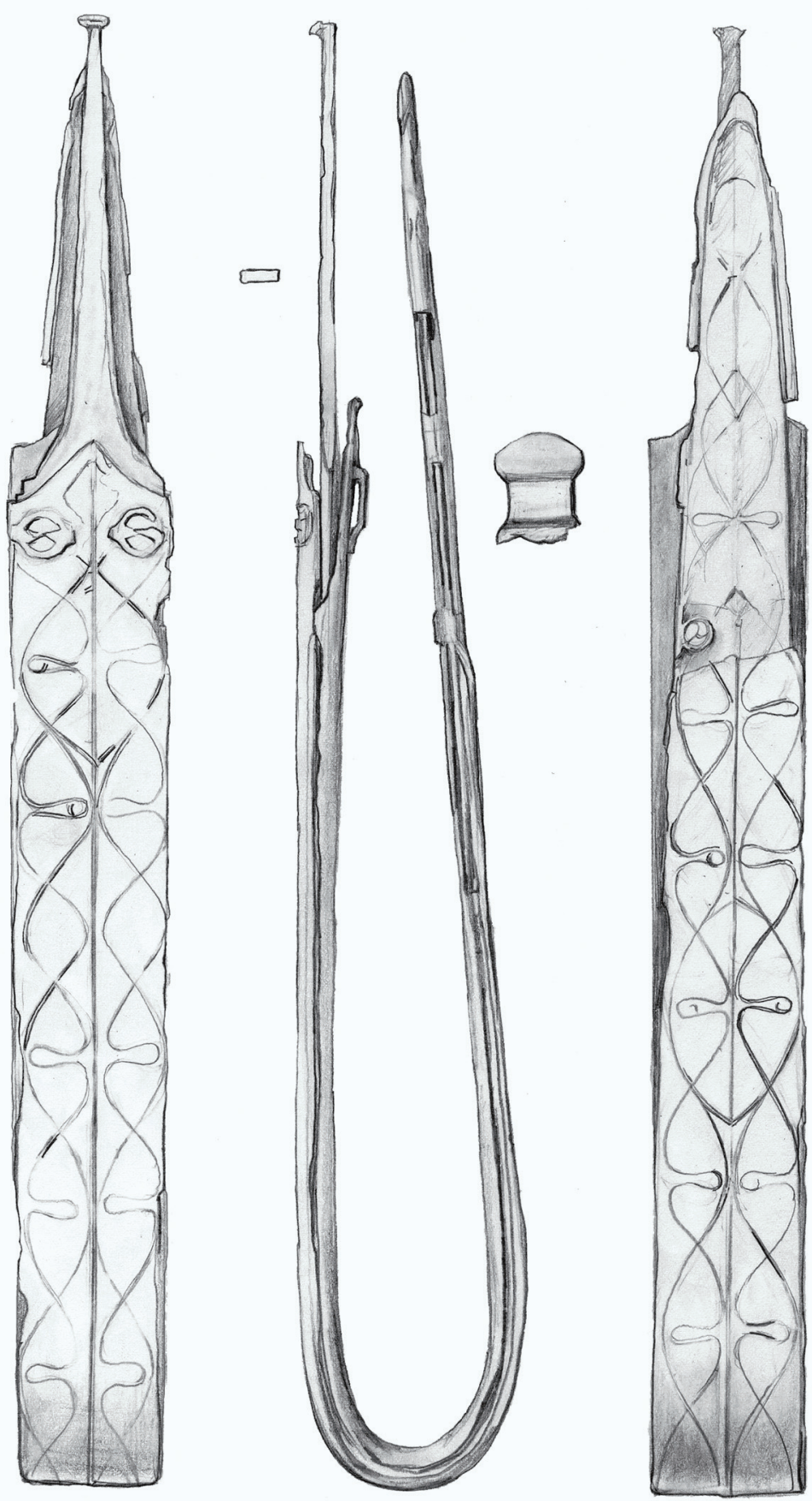

Fig. 8. Ludas: fourreau à décor gravé (sépulture 1056)

L'autre nécropole laténienne a été mise au jour sur le site de Sajópetri-Homoki-szőlőskertek entre 2004 et 2006. Ces fouilles avaient été précédées de l'exploration archéologique de l'habitat celtique de Sajópetri-Hosszúdülő, commencée en raison de la construction de la route M30 reliant l'autoroute A3 à Miskolc. Il s'agit donc d'une zone située dans le nord-est de la Hongrie, qui relie, par la vallée du Sajó, la Grande plaine aux monts Bükk. Avant la régularisation des cours d'eau, la carte hydrographique de la région était beaucoup plus complexe qu'aujourd'hui, ce qui expliquait la formation de terrasses naturelles et d'élévations de terrain propices à l'établissement de groupes 


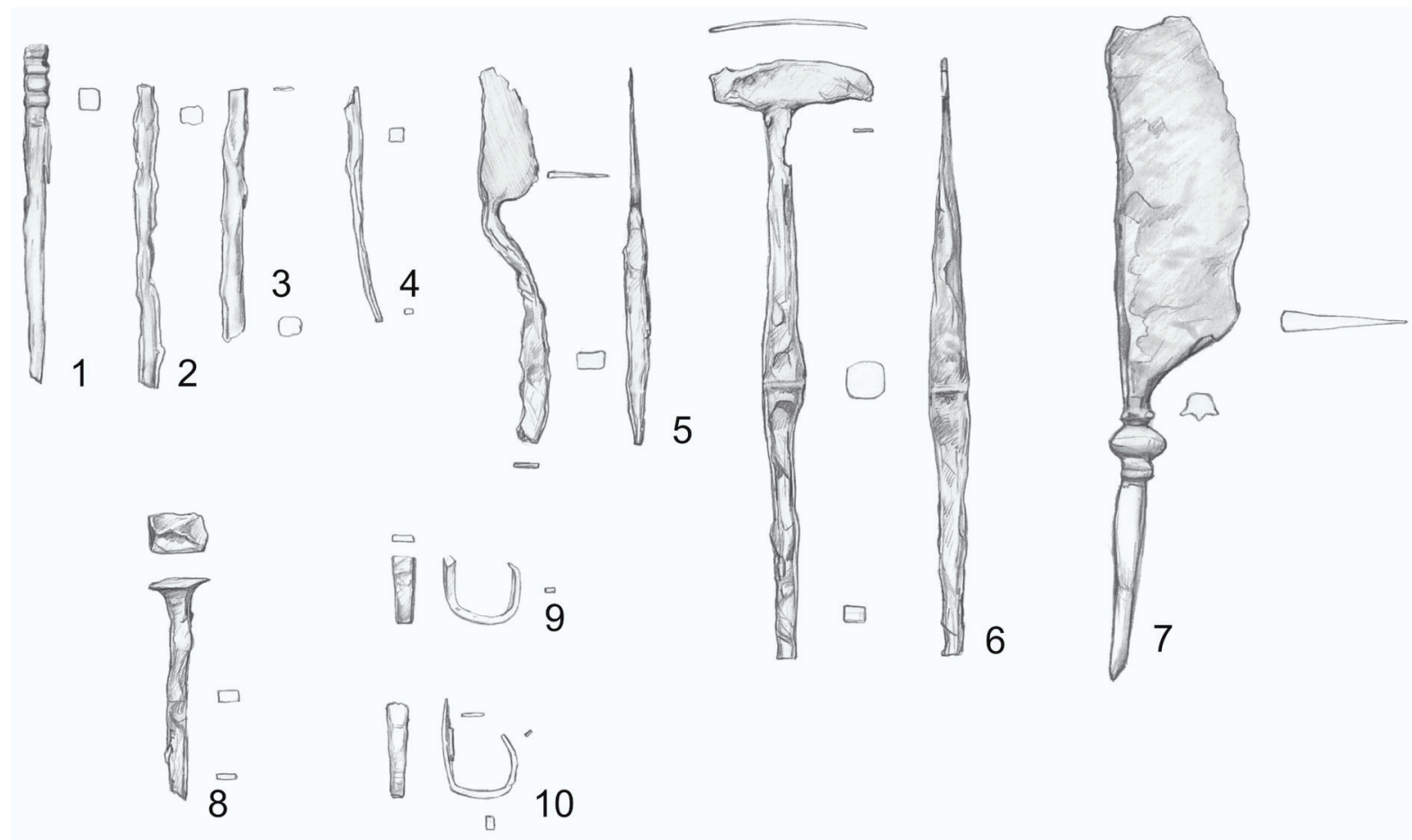

Fig. 9. Ludas: instruments de médecin (sépulture 904)

humains. Entre 1996 et 2003, indépendamment des fouilles de prévention nécessités par les travaux de l'autoroute, l'habitat laténien a été mis au jour puis il a été publié sous forme de monographie dans son intégralité. ${ }^{136}$ En parallèle, nous avons effectué, en 2002 et 2003, des explorations pédestres systématiques qui ont permis l'identification, à quelques centaines de mètres au sud de l'habitat, d'une nécropole située sur une butte de sable d'un diamètre d'environ cent mètres. Celle-ci a été mise au jour dans son intégralité entre 2004 et 2006 . Grâce aux 90 sépultures explorées par les archéologues, il s'agit d'une des nécropoles celtiques les plus importantes de Hongrie, datée de LT B2/C1. (Fig. 10) Nous avons retrouvé les traces de pillage de tombes à l'endroit le plus élevé du site, sans doute en rapport avec l'installation d'un poteau électrique en haut de la colline. Selon notre estimation, trois sépultures avaient été touchées par le pillage. ${ }^{137}$

La méthode appliquée lors de l'étude du cimetière de Ludas a aussi porté ses fruits dans le cas de l'analyse de la nécropole de Sajópetri. D'après l'analyse par sériation (fig. 11), les sépultures à incinération les plus anciennes (2/2 et 9/55) peuvent être datées de la limite ou plutôt du tournant des horizons 4 et 5 (LT B2a et LT B2b). D'un point de vue topographique, elles se situent légèrement au sud-ouest par rapport au centre géométrique du cimetière, et il semble justifié de les définir comme enclos funéraire A. (fig. 12) La sépulture 2 était une tombe à char (fig. 13), dont le mobilier comprenait un fourreau en fer de type Hatvan-Boldog, d'une importance particulière du point de vue de la datation. D'après le système de Gebhard, c'est un produit caractéristique de l'horizon 4, c'est-à-dire, de LT B2a, ${ }^{138}$ qu'on a cependant retrouvé à Ludas dans une tombe datée sans ambiguïté de l'horizon $5 .{ }^{139}$ L'épée de la sépulture 9 représente le type de Cernon-sur-Coole, rangé par Gebhard dans l'horizon 5, ${ }^{140}$ par contre, l'umbo bipartite du bouclier du défunt est davantage caractéristique de l'horizon $4 .{ }^{141}$ La fibule en fer du type de Duchcov semble

136 SZABÓ 2007.

${ }^{137}$ Pour les recherches voir pour le moment: GuILLAUMET - SzABÓ 2004 ; SzABó et alii 2005 ; SzABÓ 2005b ; SzABó et alii 2006; SZABÓ 2007, 322.

${ }^{138}$ GeBhard 1989, 86, fig. 27 /a1.
${ }^{139}$ Szabó - TANKó 2006, 332, fig. 5 /10 ; SzABó 2012, 143 , fig. $185 / 10$.

${ }^{140}$ Gebhard 1989, 86, fig. 27 /b11; à Ludas aussi: Szabó - TANKÓ 2006, 332, fig. 5 /11.

${ }^{141}$ GeBHARD 86, fig. 27/a2. 


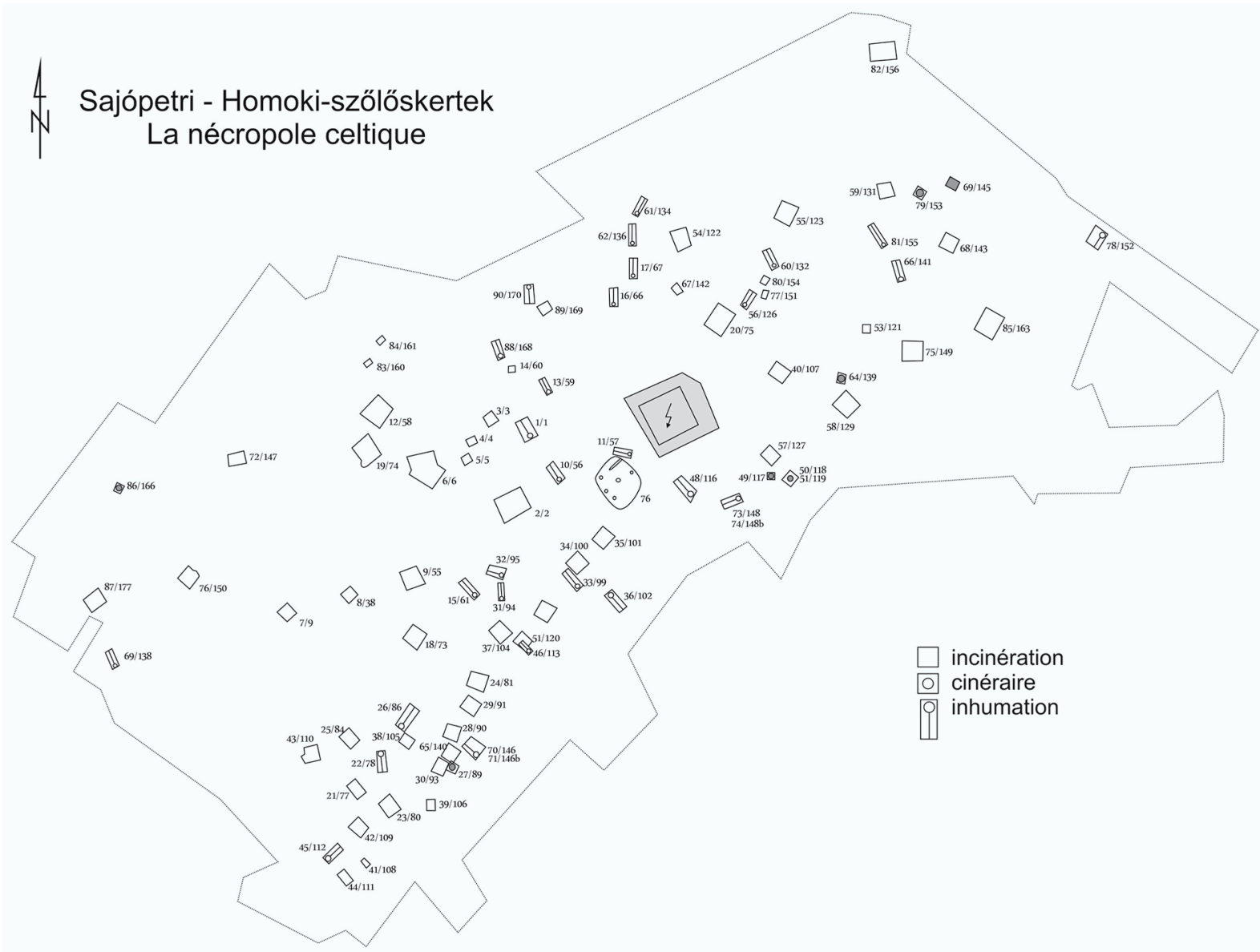

Fig. 10. Le plan de la nécropole de Sajópetri avec l'indication du rite funéraire

corroborer la datation plus ancienne, ${ }^{142}$ alors que l'autre (fibule à gros pied globulaire) appuie plutôt l'hypothèse d'une datation plus récente. ${ }^{143}$ Autrement dit, le mobilier des sépultures les plus anciennes mises au jour à Sajópetri recèlent encore des types caractéristiques de l'horizon 4 (LT B2a), mais les représentants de l'horizon 5 (LT B2b) y sont également présents, ce qui semble indiquer que certains types d'objets continuaient à être utilisés en Hongrie du Nord-Est durant la phase en question. Ajoutons à cela que les types d'armes et de bijoux déposés dans les tombes des personnes arrivées les premières à Sajópetri n'ont pas été retrouvés dans les sépultures plus récentes. La sépulture féminine $n^{\circ} 15 / 61$ à inhumation, mise au jour à la limite sud-est de l'enclos $\mathrm{A}$, semble appartenir à l'horizon 5 (LT B2b) d'après la fibule y découverte, ${ }^{144}$ malgré le fait que les anneaux de cheville permettraient même une datation de l'horizon $4 .{ }^{145}$

$\mathrm{Au}$ sud et au nord-ouest de l'enclos $\mathrm{A}$, les tombes d'hommes armés sont réparties en deux groupes. La particularité de l'enclos B, situé dans la proximité immédiate du précédent, est d'avoir abrité une tombe contenant des éléments de char. (fig. 12) En ce qui concerne la sépulture 72 à incinération, le sexe du défunt semblait être indiqué, en dehors des éléments de char, par un fragment de la gouttière d'un bouclier. La technologie de la plaquette rectangulaire se trouvant sur le dos de la fibule en fil de fer, ornée originellement d'incrustation, est étroitement liée à celle des ceintures de «type hongrois» datées de LT C1. ${ }^{146}$ D'un point de vue topographique, la sépulture 72 est située à la limite sud-ouest de l'enclos. Dans le centre de ce groupe, il y a la tombe 19 à incinération. : le guerrier y

${ }^{142}$ Cf. Kruta 1971, 24, pl. 32/5, n91 ; Bujna 2003, 62-4, fig. 31 et 33: groupes EF-HZ.

${ }^{143}$ Cf. SZABÓ - TANKó 2006, 332, fig. 5 /1.

\footnotetext{
${ }^{144}$ Cf. GebHard 107, fig. 40/6.

${ }^{145}$ Cf. SZABÓ - TANKÓ 2006. fig. $4 / 12$.

${ }^{146}$ HellebrandT 1999, 86-88, pl. XXVII.
}

Acta Archaeologica Academiae Scientiarum Hungaricae 65, 2014 

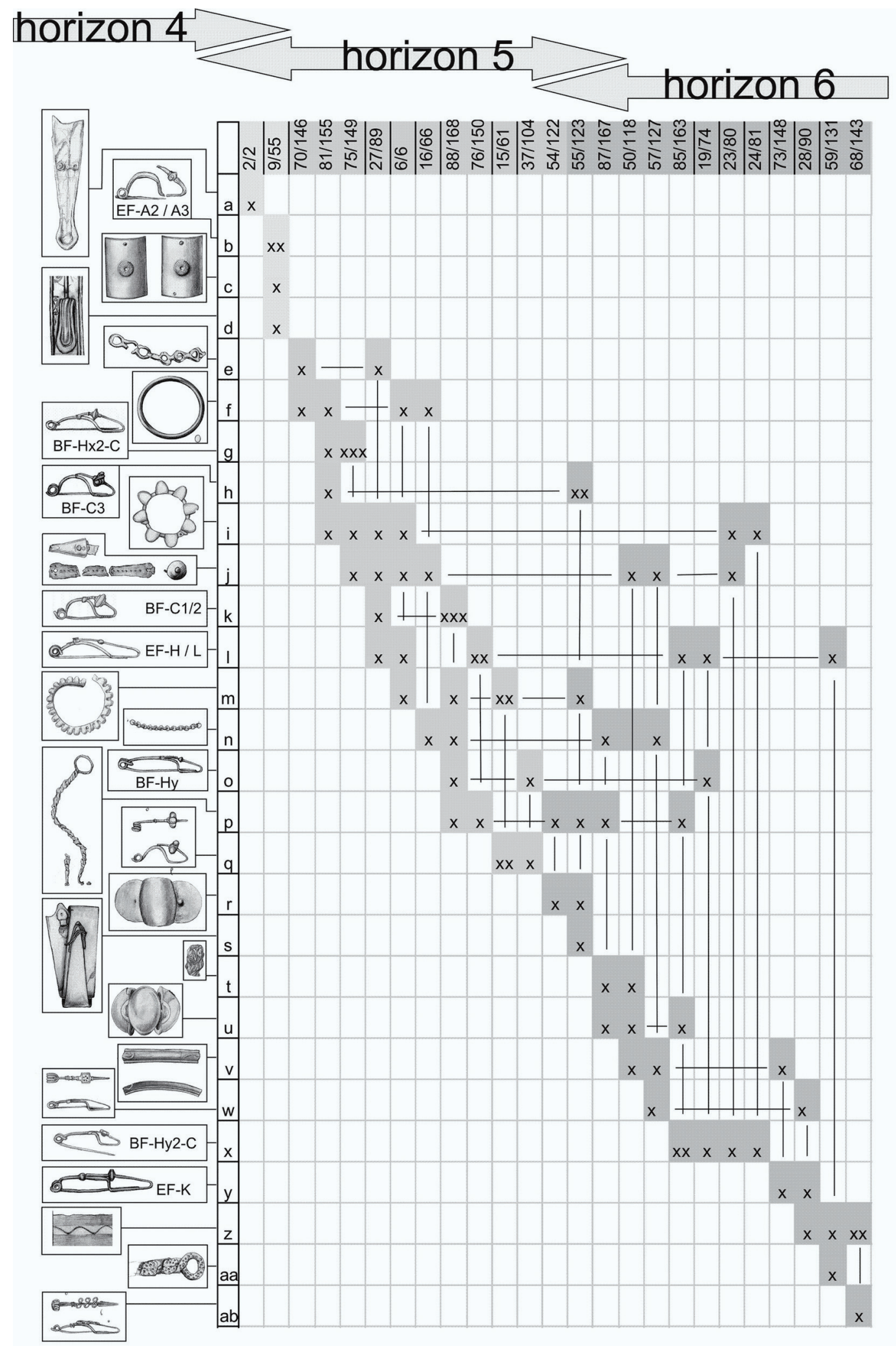

Fig. 11. Sajópetri: tableau de sériation des sépultures (K. Tankó et M. Szabó) 


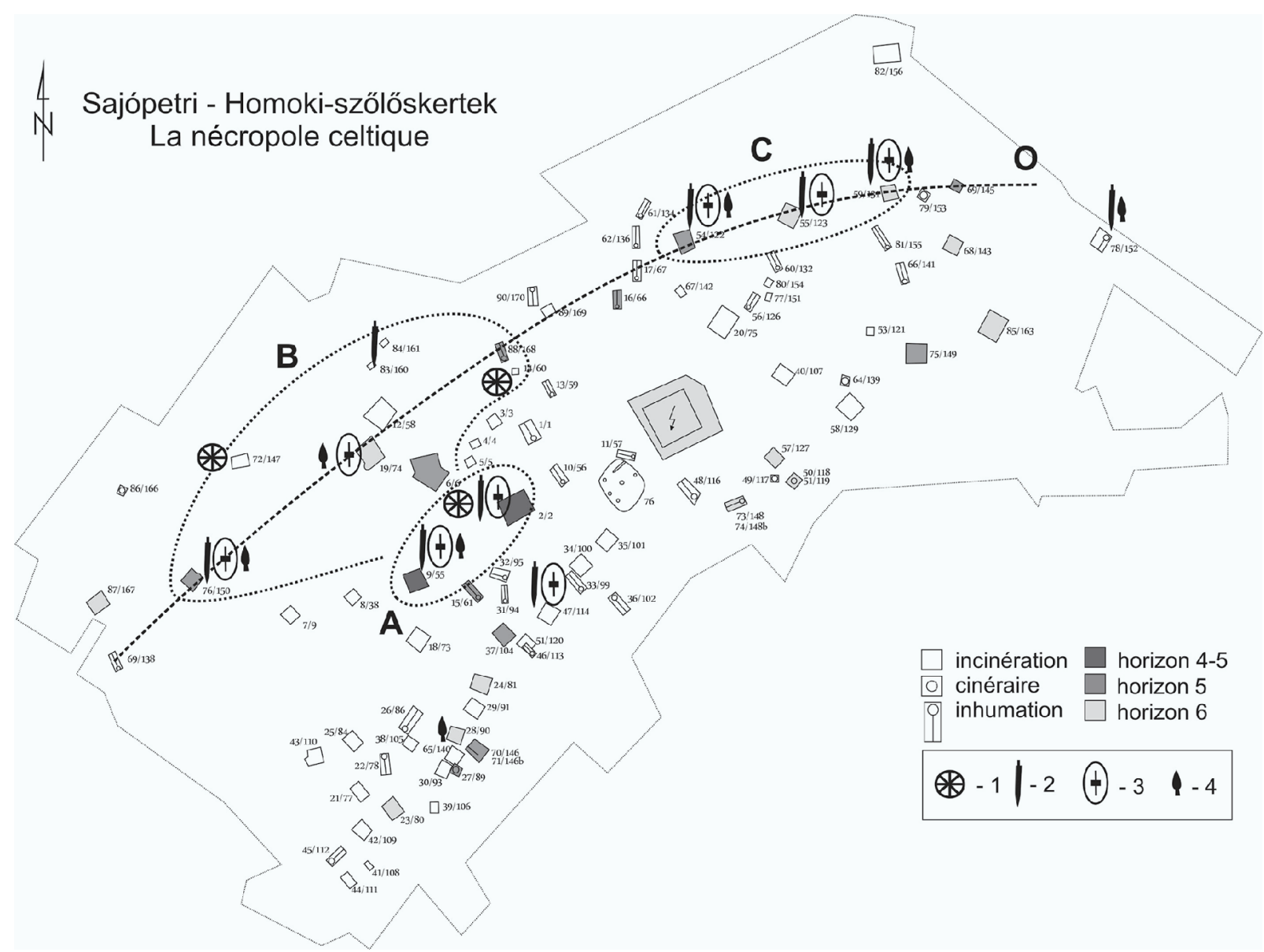

Fig. 12. Enclos funéraires (A-C) au cimetière de Sajópetri

enterré avait un bouclier, une lance et un coutelas. Compte tenu des fibules, cet ensemble peut être daté de l'horizon 6. La même remarque est valable pour la tombe 76, située à l'angle sud de l'enclos, où un armement presque complet (bouclier, épée avec son fourreau, bélière et lance) a été découvert. Une analogie évidente du fourreau de la sépulture 84 mis au jour à la périphérie nord-est est constituée par la pièce de la tombe 7 du cimetière LT B2/C1 d'Ipel'ské Predmostie. ${ }^{147}$

En ce qui concerne l'enclos $C$, les sépultures du centre ( $\mathrm{n}^{\circ} 55$ : épée dans son fourreau, bélière, bouclier, lance) et du côté sud ( ${ }^{\circ} 54$ : épée dans son fourreau, poignard, bouclier, lance, ciseaux) appartiennent à l'horizon 5 , tandis que celle du côté nord ( $n^{\circ} 59$ : épée dans son fourreau, bélière, bouclier) fait déjà partie de l'horizon 6 d'après la sériation. (Fig. 12)

Les trois autres tombes de guerrier de la nécropole se trouvent dans la zone est, plutôt loin les unes par rapport aux autres. La sépulture 78 (épée, bouclier, lance), qui se situe à la périphérie septentrionale, appartient à l'horizon 6 (LT C1a), tandis que dans la zone centrale, au sud-est de l'enclos A, la tombe 47 (épée dans son fourreau, bouclier) fait partie, à l'instar de la sépulture 54, de l'horizon 5 (LT B2b). Au contraire des autres, la sépulture 78 est à inhumation, ce qui pourrait expliquer son isolement au sein de la nécropole. Pour terminer, la tombe 28 , située le plus au sud, ne contenait qu'une seule lance.

Par rapport aux tombes de guerriers, les sépultures féminines, comme à Ludas, occupaient une position secondaire. La sépulture 15 à inhumation, qui se trouve à la périphérie sud-est de l'enclos A, a été datée de l'horizon 5 (B2b) d'après les fibules et la paire d'anneaux de cheville. Le mobilier des autres sépultures à inhumation (10, 31 ,

${ }^{147}$ FILIP 1956, pl. CII, 6 et 417. 
32) est plutôt pauvre : la 32 recelait deux vases de type scythe. Un peu plus au sud-ouest, la tombe 8 à incinération appartient, d'après sa fibule, à B2b. La sépulture 6 à incinération, située à l'ouest du groupe A, probablement au sein de l'enclos B, peut être caractérisée par les symptômes de la transition entre les horizons 5 et 6 . Au nord de la sépulture de guerrier centrale (19), on a découvert, dans la tombe 12, quatre vases et un bracelet en fil de fer. Finalement, la sépulture 88 à inhumation, qui se trouve à la périphérie nord-est, a été datée de la phase B2b.

La sépulture féminine la plus riche ( $\mathrm{n}^{\circ} 81$; fig. 14) est située à la limite nord-est de l'enclos funéraire C. D'après son mobilier, ${ }^{148}$ elle appartient à l'horizon 5 (LT B2b). Ce secteur est longé, vers le sud - sud-ouest, par d'autres tombes (sans doute féminines) à inhumation, mais ces dernières $(60,61,62)$ sont pauvres en mobilier. D'un point de vue chronologique, elles ont été classées dans LT C1a. Deux autres sépultures à inhumation $(56,66)$, mises au jour plus au sud - sud-est, se rangent dans l'horizon 5 (LT B2b). En ce qui concerne les autres sépultures, à incinération et pauvres en mobilier (voire sans mobilier) $(16,17,20,67,68,69,79,80)$, les 16 et 20 datent de B2b, la 68 de C1a. Ce groupe de sépultures en demi-cercle clôt la périphérie de l'enclos $\mathrm{C}$.

Dans les environs immédiats de la tombe de guerrier 47, on a découvert des inhumations pauvres en mobilier, ainsi que des incinérations contenant essentiellement des vases en terre cuite. Nous pouvons faire plus ou moins le même commentaire à propos de l'homme armé de lance $\mathrm{n}^{\circ} 28$. Parmi les sépultures à inhumation $(22,26,45)$, seule la $n^{\circ} 45$ dispose de trouvailles ayant une valeur chronologique; celles-ci appartiennent à l'horizon 6 (LT C1a). Les tombes à incinération $(38,65,70)$ se caractérisent avant tout par les céramiques y déposées. La sépulture de femme à incinération relativement riche, datée de LT B2b $\left(n^{\circ} 23\right)$, se trouve en dehors des environs immédiats du guerrier à lance.

Nous avons souligné plus haut l'isolement frappant du guerrier $n^{\circ} 78$; c'est ce qui caractérise aussi les deux tombes féminines situées un peu plus au sud-ouest. D'entre ces dernières, la 85 remonte à l'horizon 5, tandis que la 75 à l'horizon 6.

Les repères chronologiques que nous venons de passer en revue corroborent l'hypothèse de la division de la nécropole en enclos funéraires ou groupes de sépultures au sein desquels (à l'exception du groupe A) les premières tombes datent quasi simultanément de l'horizon 5, c'est-à-dire la phase LT B2b, puis l'utilisation continue pendant la phase LT C1a.

Du point de vue de la documentation archéologique des élites celtiques, la tombe à char $n^{\circ} 2$ (fig. 13) et les accessoires de char de la tombe $\mathrm{n}^{\circ} 72$ sont d'une importance primordiale. L'utilisation funéraire des chars par les Celtes remonte au VII e siècle av. J.-Chr., c'est-à-dire, au milieu «princier». Cependant, les véhicules à quatre roues ont été remplacés par les chars à deux roues, utilisables au combat mais aussi pour des courses, au deuxième quart du $\mathrm{V}^{\mathrm{e}}$ siècle av. J.-Chr., à l'époque de la formation de la culture laténienne. ${ }^{149}$ Les produits de l'art dit des situles, ainsi que les représentation ornant les monnaies celtiques et romaines, nous permettent d'avoir une bonne idée des différentes variantes du char celtique. ${ }^{150}$ Mais les textes des auteurs grecs et romains, ayant conservé les noms des chars de diverses fonctions (carrus/currus, carpentum, essedum, etc.) ainsi que de leurs éléments (rota, temo, iugum), constituent aussi une source d'informations particulièrement précieuse. ${ }^{151}$ Nous connaissons le rôle du char de combat au sein des armées celtiques surtout grâce à des descriptions de combats d'Italie (Polybe II, 28, 4 ; TiteLive X, 28, 8 , etc.) et des îles Britanniques (César BG 4, 33 ; Diodore V, 29, 1, etc.). ${ }^{152}$ L'évaluation de la situation réelle n'est cependant pas facilitée par le fait que dans certains cas, comme celui de l'invasion gauloise de 225 av. J.-Chr., laquelle se termine par le combat de Télamon, la source ancienne ne traite pas séparément les chiffres relatifs aux chars et à la cavalerie celtiques. (Polybe II, 23, 4.) En plus, compte tenu de la mention commune d'esseda et de carri à propos du combat de Sentinum (Tite-Live X, 28, 9), le transport des fantassins par des véhicules «lourds» (carri) ne peut pas être exclu. ${ }^{153}$ Selon une autre hypothèse, seul le chef aurait utilisé un char de combat, les autres membres du groupe ayant combattu à pied. Cela peut être illustré par le relief en terre cuite de Civitalba. ${ }^{154}$ Ce dernier mérite par ailleurs toute notre attention en ce qui concerne l'interprétation des tombes à char mises au jour dans les environs de Paris ou dans le bassin des Carpates. A propos de cette thématique, il est également intéressant de noter les pages y relatives de la littérature irlandaise ancienne. ${ }^{155}$ Certes, il serait difficile de douter de

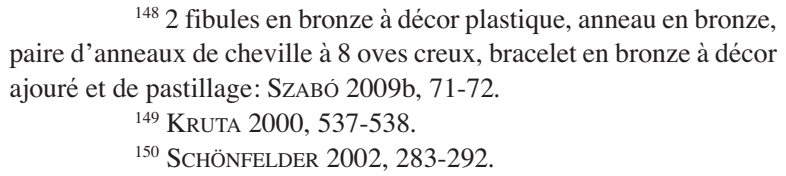

${ }^{148} 2$ fibules en bronze à décor plastique, anneau en bronze, paire d'anneaux de cheville à 8 oves creux, bracelet en bronze à décor ajouré et de pastillage: SZABÓ 2009b, 71-72.

149 KRUTA 2000, 537-538.

${ }^{150}$ SCHÖNFELDER 2002, 283-292.

${ }^{151}$ Ibid. 293.

152 SCHÖNFELDER 2002, 293-297.

${ }^{153}$ Peyre 1979, 88.

${ }^{154}$ Peyre 1979, 86, fig. 30.

${ }^{155}$ HARBISON 1969, 48-55. 


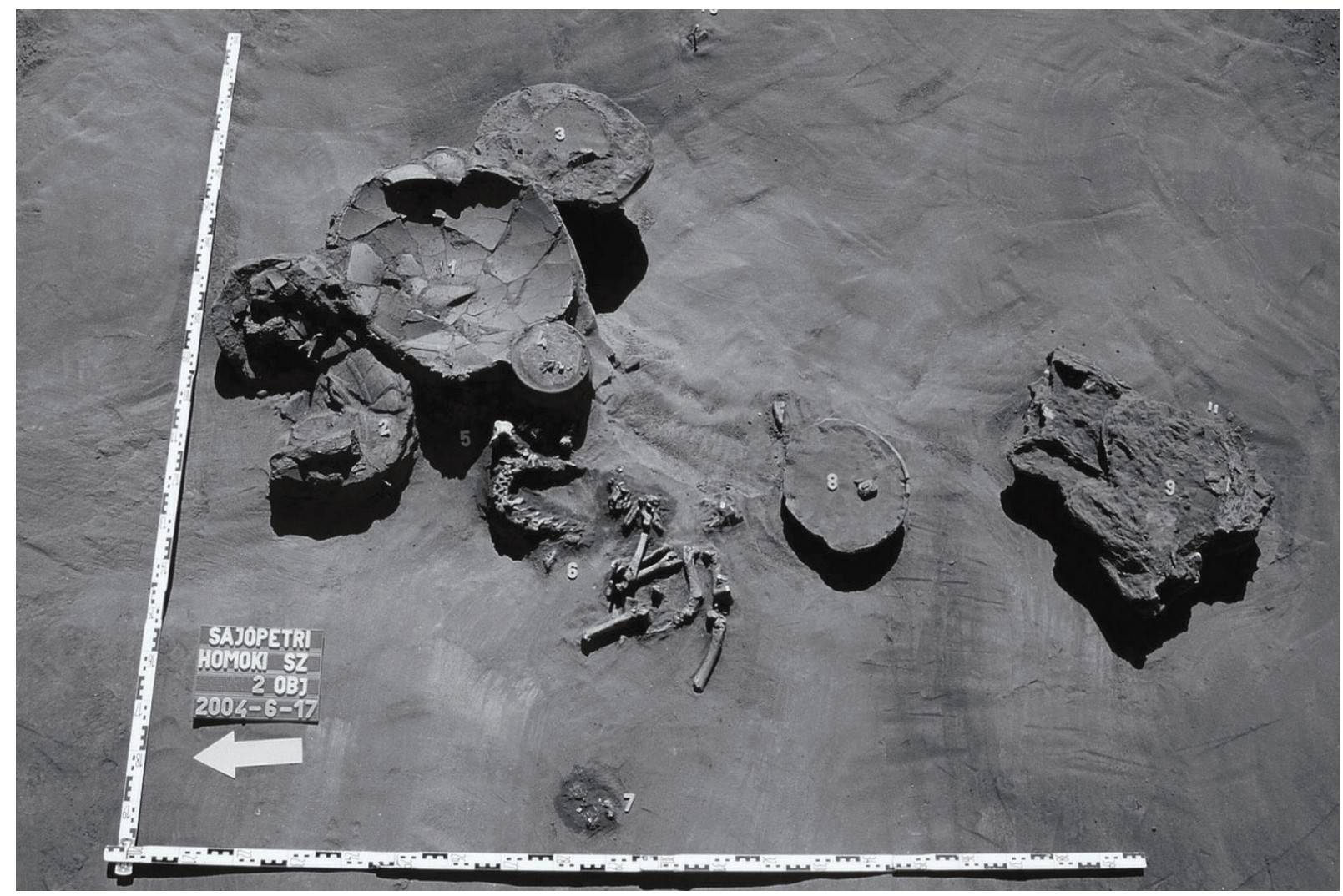

Fig. 13. Sajópetri: la tombe à char $\mathrm{n}^{\circ} 2$ (Photo prise pendant la fouille)

l'utilisation de chars de combat par les Celtes lors de leurs batailles italiques ou britanniques, mais il serait également difficile de ne pas mettre en cause la définition qui ne voit en ces véhicules à deux roues que des chars de combat. L'étude des cimetières semble appuyer l'hypothèse selon laquelle ils servaient avant tout à la représentation des élites. ${ }^{156}$ Nous ne pouvons ne pas penser à l'Arverne Luernios qui, en parcourant la campagne en char, jetait au peuple des monnaies en or et en argent. ${ }^{157}$ Cette interprétation est corroborée par la publication, au début des années 2000, de chars d'apparat de La Tène finale à quatre roues, ainsi que de mobiliers funéraires étonnamment riches, qui ne servaient certainement pas de buts militaires, mais la légitimation symbolique de l'élite. ${ }^{158}$.

Au III ${ }^{\mathrm{e}}$ siècle av. J.-Chr., à l'époque de l'expansion balkanique des Celtes, les tombes à char font leur apparition dans les nécropoles laténiennes des territoires nouvellement conquis. Le phénomène avait attiré l'attention de la recherche dès la fin des années 1960, ${ }^{159}$ alors que les découvertes et les publications des années voire des décennies suivantes ont fini par en modifier l'interprétation. ${ }^{160}$ Parallèlement à ce processus, comme nous l'avons déjà souligné dans l'introduction de ce travail, le contexte continental des tombes à char commençait aussi à se dessiner grâce aux cimetières d' «élite» du III ${ }^{\mathrm{e}}$ siècle av. J.-Chr. mis au jour en région parisienne, aux tombes à char découvertes au nord de la Seine, ${ }^{161}$ ainsi qu'aux sépultures à char de La Tène moyenne localisées en Rhénanie centrale. ${ }^{162}$ Ajoutons pour terminer que les tombes à char de la culture d'Arras de Yorkshire ${ }^{163}$ peuvent être considérées comme des conséquences «d'outre-mer» des migrations celtiques du III ${ }^{\mathrm{e}}$ siècle av. J.-Chr. $1988,44-50$

${ }^{156}$ Cf. SCHÖNFELDER 2002, 359-360; voir aussi CHYTRÁČEK

${ }^{157}$ Strabon, IV, 2, 3 ; cf. PeRrin - DeCourt 2002, 363, 98. FELDER 2003.

158 Boé: SCHÖNFELDER 2002; Verna: PERRIN - SCHÖN95, fig. 7.

${ }^{159}$ HARBISON 1969, 38-39, 42-45 ; cf. JOACHIM 1969, 92
160 Voir par ex., Arnót: VÉGH 1973;VÉGH 1984, 105-110; Brežice: GuŠTIN 1984, 114-120. Voir aussi SCHÖNFELDER 2002, 389-390.

${ }^{161}$ Ginoux 2009, 120-125.

162 HAFFNER - JOACHIM 1984, 77-81 et 84-86.

${ }^{163}$ Stead 1984 ; StEad 1991, 40-61. 

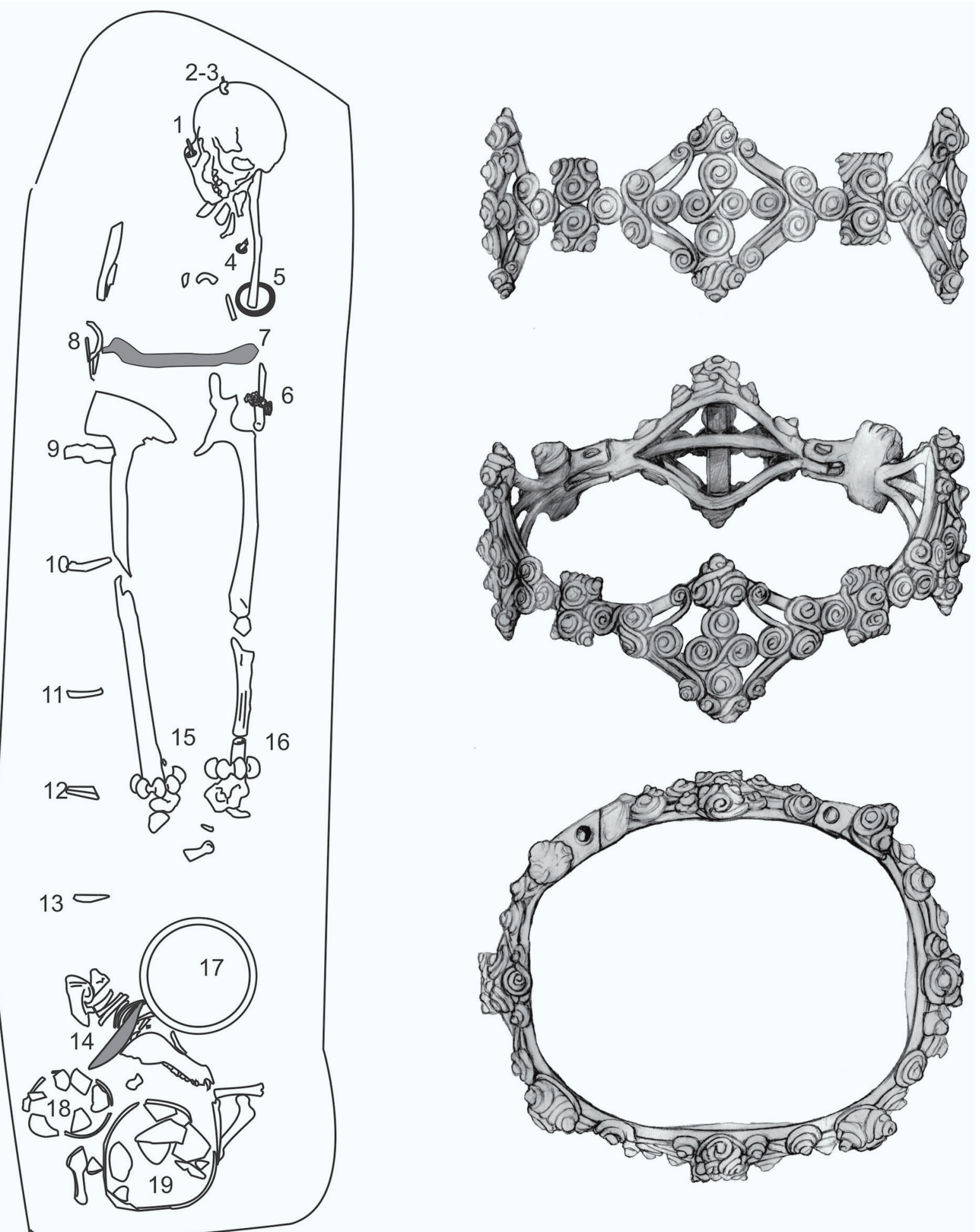

Fig. 14. Sajópetri: la sépulture féminine $n^{\circ} 81$ et le bracelet à décor en pastillage et en faux filigrane 
Certains des chars à deux roues déposés dans les sépultures du III' siècle étaient des chars d'apparat exceptionnels ornés de garnitures en bronze au décor de style plastique. Nous n'exagérons pas outre mesure en disant que ces derniers ont été découverts aux périphéries orientale et occidentale de la Celtique européenne, en Bulgarie et en région parisienne. Les trouvailles de char découvertes dans une des chambres funéraires latérales de la tombe à tholos de Mezek, et publiées en 1937 par B. Filov, ont attiré l'attention des recherches celtiques grâce à Jacobsthal ${ }^{164}$ et figurent depuis dans pratiquement toutes les synthèses consacrées à l'art celtique comme dans tous les travaux sur les découvertes laténiennes de Thrace. ${ }^{165}$ Leurs analogies les plus proches avaient été mises au jour en Île-deFrance ${ }^{166}$ et ce lien a été confirmé par les garnitures exceptionnelles en bronze de la tombe à char SP 1002 découverte sur le site de Roissy-La Fosse Cotheret dans la deuxième moitié des années 1990. ${ }^{167}$ Cette découverte a de nouveau attiré l'attention de la recherche sur le problème de la localisation des ateliers des garnitures de char de Mezek et d'Île-de-France, que V. Kruta, sur la base d'arguments essentiellement stylistiques, avait auparavant situés en Bohême ou en Moravie. ${ }^{168}$

Par rapport à ces chefs-d'œuvre exceptionnels, les chars découverts dans le bassin des Carpates ne permettent de conclure qu'à des véhicules beaucoup plus simples et purement fonctionnels, comme celui reconstitué et «mis en service» par A. Furger-Gunti. ${ }^{169}$ Mais avant d'aller plus loin, il serait utile de passer en revue l'état des trouvailles à notre disposition. Nous n'allons naturellement pas tenir compte des mobiliers funéraires appartenant à la catégorie de «pars pro toto». ${ }^{170}$

C'était K. K.Végh qui a remarqué qu'aucun des ensembles funéraires provenant du bassin des Carpates ne contenait tous les éléments du char. ${ }^{171}$ Cela pourrait s'expliquer en partie par les conditions des découvertes, c'està-dire que la grande majorité des tombes à char connues à l'état actuel de la recherche n'a pas été mise au jour par des fouilles conduites avec une précision scientifique. Cette constatation est valable pour les trouvailles d'Odžaci (Hódság) en Serbie, de Cristurul Secuiesc (Székelykeresztúr), Curtuişeni (Érkörtvélyes) et Toarcla (Prázsmár) en Roumanie, ainsi que pour celles d'Arnót, de Balsa et de Hatvan-Boldog en Hongrie. ${ }^{172}$ (Fig. 15) Cependant, le matériel issu de fouilles fiables n'est pas complet non plus, qu'il s'agisse des tombes à char de Sajópetri ou de Brežice. ${ }^{173}$ Le phénomène ne pourrait s'expliquer par le fait que nous avons affaire dans tous les cas cités à des sépultures à incinération. ${ }^{174} \mathrm{Et}$ nous devons une fois pour toutes rejeter l'hypothèse selon laquelle les éléments manquants auraient été en bois. ${ }^{175}$

C'était Joachim qui avait évoqué que les tombes à char contiendraient certains éléments choisis représentant tout le véhicule. ${ }^{176} \mathrm{~K}$. Végh est arrivée à une conclusion similaire. ${ }^{177}$ Malgré cette constatation, il est certain que dans tous les cas cités, il s'agit de chars à deux roues. ${ }^{178}$ Cela doit être souligné étant donné que dans le cas des mobiliers «pars pro toto» (phalère, esse, mors, etc.) le type de véhicule ne peut évidemment pas être défini. ${ }^{179}$ Par contre, les mobiliers des tombes à char actuellement connues dans le bassin des Carpates ne permettent pas de conclure à une sélection régulière et répétitive. Il est important d'évoquer ici la différence entre les sépultures 6 et 55 de Brežice citées ci-dessus.

Autrement dit, dans l'état actuel de la recherche, nous ne pouvons pas parler de rite spécifique aux Celtes orientaux en ce qui concerne le dépôt d'éléments de char dans la tombe.

Quant à la position chronologique de ces tombes, K. Végh semble avoir eu raison en les datant du tournant de LT B-C voire de LT C. ${ }^{180}$ Revu par l'approche chronologique actuelle, cela signifie LT B2 et C1. ${ }^{181}$ Végh, sans doute sous l'influence de Hunyady, fait dater la tombe à char de Balsa du tournant de LT C-D. ${ }^{182}$ Cependant, compte

164 JACOBSTHAL 1941.

165 AnASTASSOV 2012, 112-113.

${ }^{166}$ Ibid. 113-116.

${ }^{167}$ LEJARS 2005.

${ }^{168}$ Cf. récemment: KRUTA 2000, 730.

169 SCHÖNFELDER 2002, 278-282.

${ }^{170} \mathrm{Cf}$. SCHÖNFELDER 2002, 311-316.

${ }^{171}$ VÉGH 1973, 217 ; VÉGH 1984, 109-110.

${ }^{172}$ SCHÖNFELDER 2002, 387, $\mathrm{n}^{\circ} 68,389, \mathrm{n}^{\circ}$ s $74,76,77 ; 390$, $\mathrm{n}^{\text {os }} 80,81,82$.

173 Brežice, tombes 6 et 55: GUŠTIN 1984/a, 115-120; SCHÖNFELDER 2002, 390, 78 et 79 .
174 SCHÖNFELDER 2002, ibid.; cf. VÉGH 1973, 217 ; VÉGH 1984, 109.

175 Citation de l'hypothèse par VÉGH 1973, 217; VÉGH 1984, 109.

176 JOACHIM 1969, 97.

177 VÉGH 1973, 217 ; VÉGH 1984, 110.

178 SCHÖNFELDER 2002, 300, fig. 187.

${ }^{179}$ SCHÖNFELDER 2002, 312-313, tableau 52, fig. 190.

180 VÉGH 1973, 217; VÉGH 1984, 109.

${ }^{181}$ Cf. Gebhard 1989, 76-92; SzABó 2009a.

182 VÉGH 1973, loc. cit. 


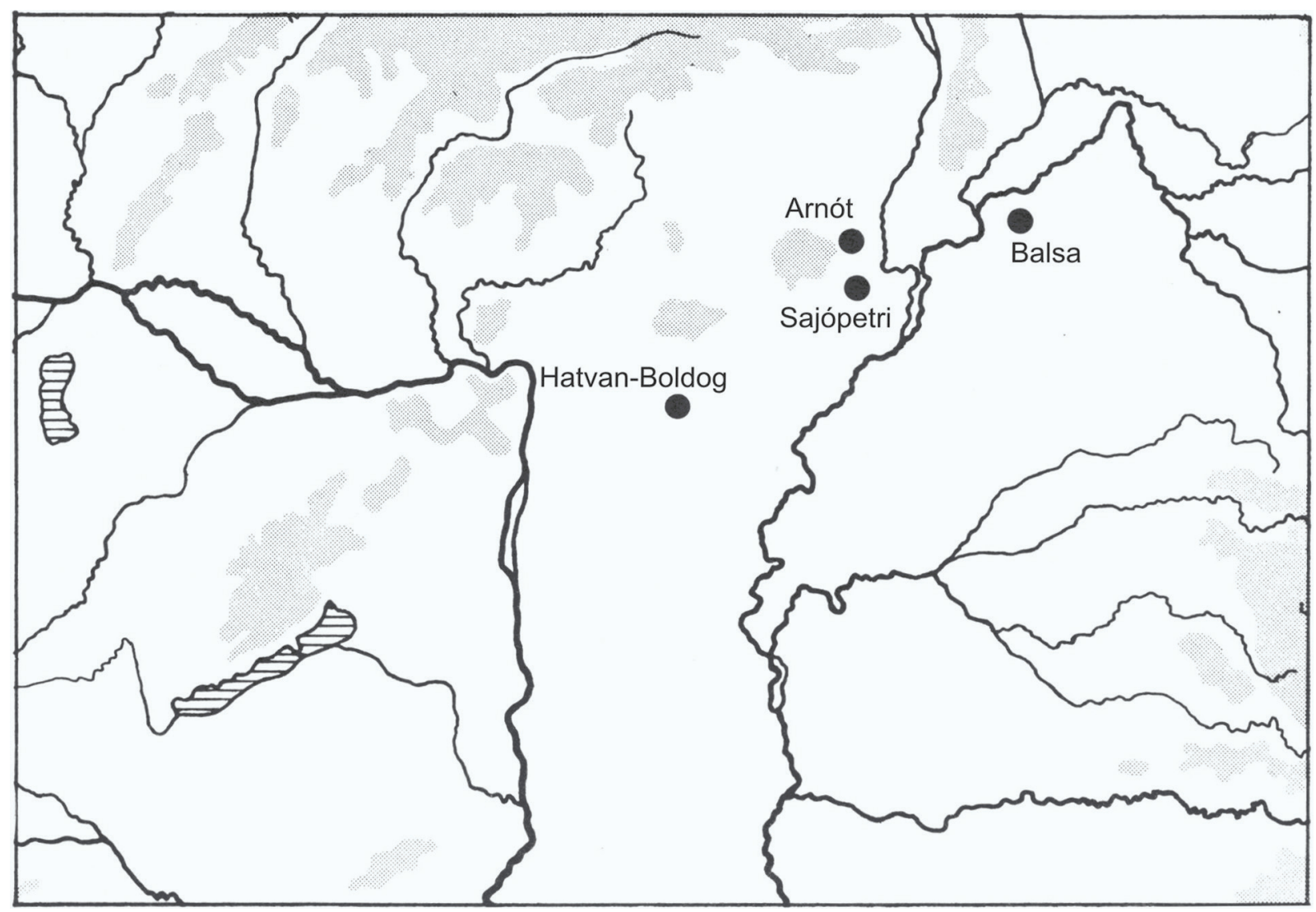

Fig. 15. Tombes à char dans le nord-est de la Hongrie (d'après VÉGH 1984, complété)

tenu des trouvailles métalliques de la sépulture II, ${ }^{183}$ cette datation est inacceptable; l'ensemble ne peut pas être postérieur à $\mathrm{C} 1 .^{184}$

Par contre, en ce qui concerne les découvertes de char de Hatvan-Boldog, une datation de LT B1 a été évoquée vu que le matériel provenant du site daterait exclusivement de la phase ancienne de LT B. ${ }^{185}$ En réalité, B. Posta a noté dès le début que les restes de char avaient été découverts en compagnie de fibules représentant la phase LT B «avancée ${ }^{186}$ Ce groupe comprend entre autres l'arme éponyme d'un type d'épée datant de LT B2. ${ }^{187}$ Nous pouvons en conclure hypothétiquement que la tombe date de LT B2.

La datation de LT C2 proposée par Guštin pour la sépulture d'Odžaci (Hódság) ${ }^{188}$ devrait également être revue et corrigée. Compte tenu des analogies (par ex., Ludas, tombe 904) plus récemment découvertes de l'épée décorée, cette dernière, à l'instar de la tombe 23 de Dobova, doit être datée de LT C1. ${ }^{189}$

La sépulture 72 de Sajópetri fait partie des tombes à mobilier «pars pro toto». On trouve des accessoires de chars dans des sépultures depuis l'époque de Hallstatt, et ils deviennent plus fréquents pendant les périodes de LT C-D dans la partie nord-ouest de la Celtique. ${ }^{190} \mathrm{Ce}$ rite est très rare sur les territoires des Celtes orientaux, jusqu'aux découvertes de Sajópetri, il n'était représenté ici que par deux clavettes provenant de la nécropole de Belgrade-Karaburma. ${ }^{191}$ L'interprétation des tombes à mobilier «pars pro toto» pour l'instant ne dépasse pas la spéculation: l'évocation du point de vue économique reste un lieu commun, tandis que l'hypothèse de la sépulture d'un aurige n'a aucun fondement réel. ${ }^{192}$

${ }^{183}$ RosKa 1915, 29-31, fig. 12-13; cf. GEBHARD 1989, 82, fig. 6 et 86 , fig. $27 / \mathrm{c}$.

\footnotetext{
${ }^{184}$ Cf. SCHÖNFELDER 2002, 390, nº 81.

${ }^{185}$ Par ex., SCHÖNFELDER 2002, 390, n82.

${ }^{186}$ MÁrTON 1933-34, 121, pl. LIII-LVI.

${ }^{187}$ SZABÓ - Petres 1992, 89, pl. 18.
}

${ }^{188}$ GUŠTiN 1984, 126-127.

$189 \mathrm{Ibid}$. 125, t. 7; SZABÓ 2009c, 238-243, fig. 3-7.

${ }^{190}$ SCHÖNFELDER 2002, 311-313, fig. 190.

191 GUŠTIN 1984, 127-128, fig. 5= SCHÖNFELDER 2002, $387, n^{\circ} 68$

${ }^{192}$ Cf. SCHÖNFELDER 2002, 314 
Pour conclure, les plus anciennes parmi les tombes à char actuellement connues dans le bassin des Carpates (Sajópetri, Hatvan-Boldog) datent selon toute probabilité de la phase LT B2b, tandis que la majorité remontent à la phase LT C1. D'un point de vue historique, cela correspond au retour des Celtes dans le bassin des Carpates qui succède l'expansion balkanique. Vu ce contexte, nous ne devons sans doute pas au hasard le fait que les tombes à char connues aient été découvertes à l'est du Danube (y compris la Transylvanie) ou au nord des Balkans (Slovénie, Serbie). ${ }^{193}$

En fin de compte, le temps des grandes migrations celtiques avait amené une situation contradictoire : les «tombes princières» des phases précédentes avaient disparu, mais la coutume de déposer le char dans la sépulture est restée. L'orientation ouest-est des migrations pourrait expliquer aussi la diffusion du rite dans le bassin des Carpates. La présence d'un char dans la sépulture suffit en elle-même pour indiquer le statut du défunt au sein de la communauté, et - abstraction faite des autres éléments du mobilier - elle reflète aussi la continuité de la structure sociale. Autrement dit, l'appartenance à l'élite n'était pas signalée, à cette époque-là, par la présence d'objets de luxe à côté du défunt. Du point de vue du problème de continuité, il n'est peut-être pas inintéressant de citer ici la situation dans le sud de l'Etrurie où, au VII ${ }^{\mathrm{e}}$ siècle av. J.-Chr., les tombes à char commençaient à se faire de plus en plus rares, étant donné que les nouvelles élites urbaines refusaient la réflexion de ce statut par l'ancien rite funéraire. ${ }^{194}$ Nous avons noté ci-dessus que selon les sources anciennes relatant l'expansion qui menaçait la Macédoine et la Grèce au III siècle av. J.-Chr., les armées celtiques étaient bien organisées et efficaces, et les auteurs anciens nous donnent aussi les noms de nombreuses tribus ayant participé aux opérations. ${ }^{195}$ Donc du point de vue de sa structure, la société devait être fort complexe et militarisée, comme en témoignent les analyses de cimetières présentées plus haut. Ajoutons que l'utilisation de la monnaie ainsi que le monnayage lui-même ${ }^{196}$ se répandent chez les Celtes en conséquence des grandes migrations. Tout cela semble contredire l'hypothèse supposant l'absence des élites ou l'existence d'une élite «égalitaire» dans les phases LT B2 et C1. ${ }^{197}$ La vraie question est de savoir comment se définissait l'élite guerrière. La tombe à char en était sans aucun doute une des manifestations, probablement le privilège du chef d'une communauté donnée.

Cependant, abstraction faite du char, il est pratiquement impossible, selon nos connaissances actuelles, de définir la position sociale du défunt en nous basant sur les armes déposées dans la tombe. Du moins, en ce qui concerne les tombes à char du bassin des Carpates que nous venons de passer en revue. La seule exception est constituée par la sépulture 55 de Brežice laquelle, selon la publication, ne contenait pas d'armes. ${ }^{198}$ Mais c'est loin d'être un cas unique dans le monde celtique : l'une des deux tombes à char de Roissy-La Fosse Cotheret était celle d'un guerrier (SP 5002), tandis que l'autre, une sépulture d'homme d'une richesse exceptionnelle (SP 1002), avait un mobilier composé, entre autres, d'un vase, d'un bracelet, d'une petite scie et d'un disque ajouré exceptionnel, orné d'animaux stylisés. ${ }^{199}$ Ainsi, dans la communauté en question, le privilège d'avoir un char revenait à deux personnes, l'une étant guerrier compte tenu des ses armes, tandis que l'autre, d'après la description de César (BG VI. 13-14), ne pouvait être que druide.

Mais la pratique archéologique semble réfuter cette hypothèse. Selon une interprétation répandue au sein de la profession, on considère comme «tombe de druide» des tombes de guerriers dont le mobilier comprend des outils relatifs à la médecine, au traitement de malades, ou des objets «inhabituels». Nous pouvons citer ici l' «hélice en os» de la sépulture 520 de la nécropole de Pottenbrunn. ${ }^{200}$

Cependant, l'identification de ce type n'est que spéculation, étant donné que l'affaire de la documentation archéologique des druides, comme nous l'avons noté ci-dessus, reste en suspens. ${ }^{201}$ Quant à la tombe 55 de Brežice, il faut attendre la fin de la restauration et la parution de la publication définitive. ${ }^{202}$

En fin de compte, l'analyse des mobiliers des tombes à char nous renvoie, dans l'essentiel, à la conclusion tirée plus haut, c'est-à-dire que les membres de l'élite de l'époque de l'expansion balkanique se définissaient avant tout comme guerriers. La question se pose ici de savoir selon quels critères nous pourrions distinguer les tombes riches de la moyenne parmi les sépultures d'hommes armés et quelles conclusions peuvent être tirées quant à la position sociale du défunt à partir du mobilier funéraire.

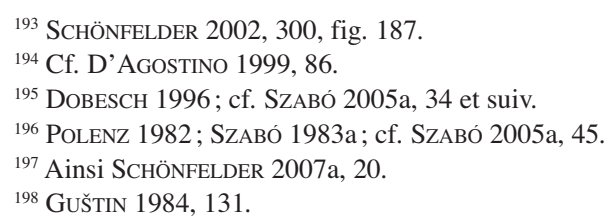

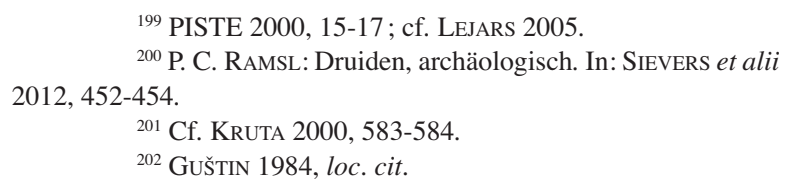


Nous avons évoqué plus haut la question des types d'armes considérés comme indicateurs de rang. Le problème, c'est que dans le bassin des Carpates, hormis quelques cas exceptionnels, la grande majorité des armes de ce type ont été des trouvailles isolées. Les casques sont relativement plus utiles de ce point de vue que la plupart des armes. L'ensemble mis au jour à Ciumeşti, le casque en fer orné d'oiseau (fig. 16.3), la cotte de mailles et la jambière grecque, n'a pas été rangé sans raison dans la catégorie de «tombe du chef ${ }^{203}$ Par contre, la sépulture 27.III.1900 d'Apahida ne doit l'appartenance à la même catégorie qu'aux restes de casque. ${ }^{204}$ (Fig. 16.4) Hormis le casque en fer, la sépulture 1656/35 de Mihovo (Slovénie) avait un mobilier encore plus humble que la précédente. ${ }^{205}$ Donc, dans ces deux cas, l'interprétation repose sur le casque en tant qu'indicateur de rang, ce qui pourrait être corroboré par la représentation d'un casque analogue, renforcé par une plaque triangulaire rivetée au-dessus du couvre-joues, sur la frise d'armes du sanctuaire d'Athéna de Pergame. ${ }^{206}$ Cette dernière appuie cependant la thèse de l'origine carpatique des casques en question et non pas le rang social de leur porteur. Dans le cas de deux autres casques ${ }^{207}$ les mobiliers leur appartenant se sont malheureusement mélangés à d'autres trouvailles découvertes sur le même site.

L'interprétation sociale de la sépulture 460 de Horný Jatov - Trnovec nad Váhom, en ce qui concerne les fragments de cotte de mailles, pose un problème analogue à celui des casques. ${ }^{208}$ Néanmoins, cet ensemble ne peut pas être comparé à celui de Ciumeşti quant à son importance. ${ }^{209}$

On a l'habitude de ranger parmi les indicateurs de rang les poignards et les épées à la poignée anthropomorphe ou pseudo-anthropomorphe. (Fig. 17) Selon une idée largement répandue, leurs porteurs occupaient une place de choix au sein de l'élite militaire. ${ }^{210} \mathrm{Il}$ s'agit cependant encore une fois d'une interprétation hypothétique qui devrait être appuyée de découvertes authentiques. Malheureusement, chacune des six pièces hongroises à avoir été publiées était une découverte isolée. ${ }^{211}$ Le seul appui de cette interprétation reste ainsi l'évaluation de la carte de répartition, ${ }^{212}$ mais cette méthode, en raison de problèmes méthodologiques, ne peut pas fournir de preuves décisives. ${ }^{213}$

Malgré les constatations négatives, nous pouvons tirer ici une conclusion importante : si nous comparons le matériel qui vient d'être présenté rapidement avec le mobilier des tombes à char du bassin des Carpates, nous ne trouvons aucune correspondance. Le chef de Ciumești ne possédait pas de char, les dirigeants enterrés avec leur char n'avaient pas de casques, ni de cottes de mailles, sans parler de jambière. Cela pourrait éventuellement s'expliquer par la donnée de Strabon (IV, 4, 3) selon laquelle les Gaulois élisaient chaque année un chef (hégémón), tandis qu'ils nommaient un chef militaire (stratégos) en cas de guerre. Si nous avons raison en pensant que le guerrier de Ciumeşti était revenu de Grèce avec ses hommes, nous n'avons peut-être pas tort non plus en le considérant comme un des chefs de militaires de l'offensive balkanique. ${ }^{214}$ Par contre, l'analyse des nécropoles de Ludas et de Sajópetri, malgré les différences observées, témoigne de la formation de la structure sociale «de paix » des Celtes établis dans le nord-est de la Hongrie.

La question se pose ici de savoir selon quels critères on peut parler de tombes riches au III' siècle av. J.Chr., à l'époque des grandes migrations où le rite funéraire ne reflète plus l'appartenance à l'élite. Pour illustrer la complexité de la situation, rappelons la constatation de P. Jud selon laquelle dans la nécropole de Münsingen-Rain, les hommes et femmes enterrés sans mobilier n'étaient pas forcément des pauvres. Le phénomène pourrait s'expliquer par le fait qu'à l'époque, il n'était pas nécessaire de «documenter» dans tous les cas la position sociale par le dépôt dans la tombe d'accessoires vestimentaires. ${ }^{215}$

En faisant abstraction, dans ce qui suit, de cette hypothèse (qui devrait être par ailleurs confirmée dans le cas d'autres nécropoles), ${ }^{216}$ retournons maintenant à notre point de départ. Lors de l'étude des céramiques funéraires de la nécropole laténienne de Dubnik (sud-ouest de la Slovaquie), J. Bujna distingue, dans le cas des tombes à inhumation, un «petit service» constitué de 3 vases et un «grand service» comprenant au moins 6 vases. Ce

\author{
${ }^{203}$ Rusu 1969, RustoIU 2006. \\ ${ }^{204}$ ZIRRA 1976, 142-144, fig. 11/1a. \\ ${ }^{205}$ SCHAAFF $1974,171, \mathrm{n}^{\circ} 1$. \\ ${ }^{206}$ SCHAAFF 1974,173 , pl. 86. \\ ${ }^{207}$ Batina: fig. 16.2 = SCHAAFF 1974, 171-172, fig. 23; cf. \\ KRUTA 2000, 455. - Silivaş: fig. 16.1 = MárTON 1933-34, 123-124, pl. \\ LVII, en bas à droite; cf. KRUTA 2000, 819. \\ ${ }^{208}$ Benadí 1957, 31-32, n ${ }^{\circ}$, pl. X/4.

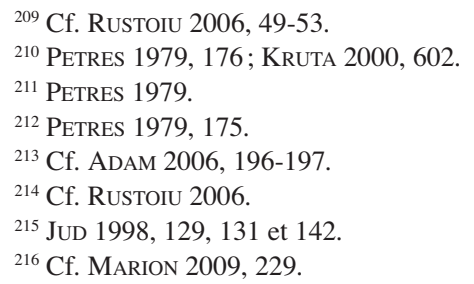

${ }^{209}$ Cf. Rustoiu 2006, 49-53.

PETRES 1979, 176; KRUTA 2000, 602

${ }^{212}$ Petres 1979, 175

${ }^{213}$ Cf. ADAm 2006, 196-197.

215 Jud 1998, 129, 131 et 142

${ }^{216}$ Cf. Marion 2009, 229. 


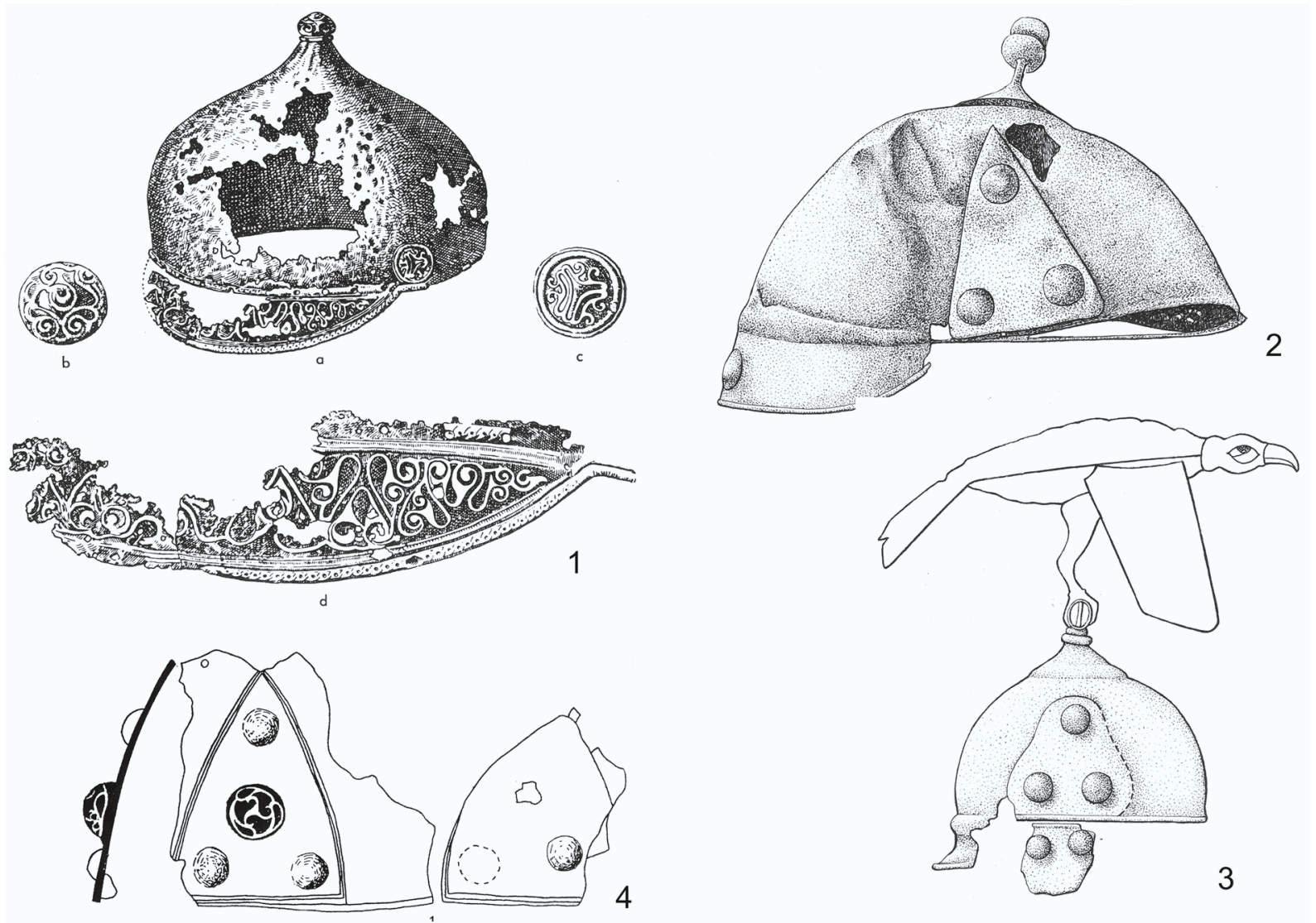

Fig. 16. Casques celtiques du bassin des Carpates. 1: Silivaş; 2: Batina; 3 : Ciumești ; 4: Apahida (1-3: d'après SCHAAFF 1974; 4: d'après ZIRRA 1976)

dernier a également été interprété comme un des critères d'une sépulture riche. ${ }^{217} \mathrm{~A}$ Ludas, où seulement 5 sépultures à inhumations ont été mises au jour, ${ }^{218} 1$ 'analyse de la répartition des céramiques peut se faire essentiellement d'après les tombes à incinération. Mais aucune régularité comparable ne semble se dessiner dans le cas de ces dernières. Des tombes qu'on peut considérer comme relativement riches d'après l'ensemble de leur mobilier (par ex., 879, 1003) ne recelaient que 2-3 vases, ce qui caractérise également les deux inhumations $(951,1274)$. Par contre, des sépultures considérées comme pauvres (par ex., 729, 1038, 1039, 1139) contenaient parfois 4-5 vases. Nous pouvons en conclure qu'au moins à Ludas, le nombre de céramiques enterrées avec le défunt ne constitue pas un critère de la détermination de la richesse. Néanmoins, certains types de vases semblent avoir un rapport avec le rite funèraire. ${ }^{219}$ Mais ce phénomène ne peut vraisemblablement pas servir à l'identification archéologique des élites. Pour terminer, il faut souligner que les résultats de l'étude des céramiques funéraires doivent être vérifiés dans un contexte régional plus large pour arriver à des conclusions valables en ce qui concerne le rite funéraire ou la position sociale du défunt. ${ }^{220}$

En examinant le problème des élites des périodes LT B et C, Schönfelder fait allusion aux vases d'importation en bronze, découverts dans les tombes, et précise qu'il s'agit de cas rares et isolés. ${ }^{221}$ L'identification d'objets d'importation correspond à la vision de Claude Rolley qui, plutôt que de relier les produits méditerranéens apparus dans le bassin des Carpates ou leurs «contemporains» découverts à l'Ouest - y compris la situle de la tombe princière de Waldalgesheim ! - à des faits historiques concrets, avait tendance à les mettre en rapport avec la «circulation

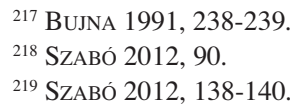

${ }^{217}$ Bujna 1991, 238-239.
${ }^{218}$ SZABÓ 2012, 90.

${ }^{219}$ SZABÓ 2012, 138-140.
${ }^{220}$ En ce qui concerne la Celtique occidentale, cf. BARAY 2003 ; MARION 2009.

${ }^{221}$ SCHÖNFELDER 2009, 68, note 60.

Acta Archaeologica Academiae Scientiarum Hungaricae 65, 2014 

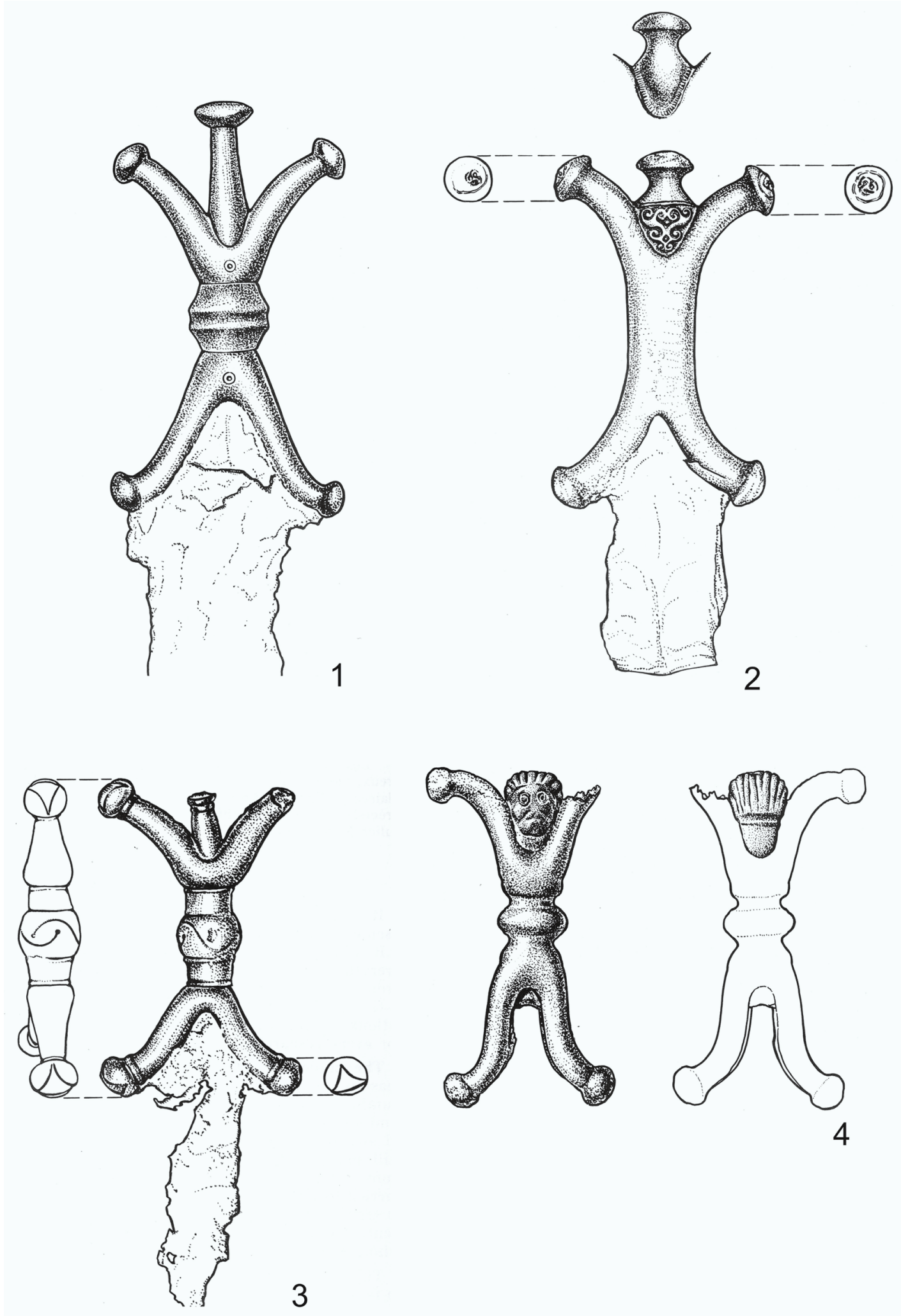

Fig. 17. Poignards à poignée anthropomorphe et pseudo-anthropomorphe découverts en Hongrie . 1: Kölesd-Lencsepuszta ; 2: Győrszemere; 3: Szendrő ; 4: Dinnyés. (d'après Petres 1979) 
d'œuvres d'art» entre le Sud et le Nord, l'Est et l'Ouest. ${ }^{222}$ Nous avons examiné cette hypothèse du point de vue des relations possibles entre les Celtes et la Macédoine. ${ }^{223}$ Selon cette interprétation, il n'est pas justifié de placer les vases grecs ou étrusco-italiques découverts dans des tombes celtiques danubiennes de la fin de LT ancienne ou du début de LT moyenne dans le contexte d'un seul événement historique, notamment l'offensive balkanique de 280/279 av. J.-Chr. ou l'attaque contre Delphes. Cette remarque concerne particulièrement le sceau étrusque en forme de calathos de la tombe 13 de Mannersdorf, ${ }^{224}$ lequel serait arrivé sur le site, selon l'hypothèse la plus probable, par la route de l'ambre au IV ${ }^{\text {e }}$ siècle av. J.-Chr., après l'occupation d'une partie du nord de l'Italie par les Celtes. ${ }^{225}$ L'histoire des autres pièces énumérées par Schönfelder (fig. 18) ${ }^{226}$ est différente : selon les dernières recherches, celles-ci pourraient être liées à la Macédoine. ${ }^{227}$ Une des clés de ce débat est la localisation de l'atelier de la situle de Waldalgesheim, que Claude Rolley, avec des arguments convaincants, attribue à la Macédoine. ${ }^{228}$ Le débat est, cependant, loin d'être clos, comme l'indique l'étude de Shefton ${ }^{229}$ dans laquelle l'auteur argumente en faveur de l'origine «égéenne» tout en s'opposant à la conception de Rolley. Il n'empêche pas que le matériel archéologique permet d'établir des liens antérieurs à 280-279 av. J.-Chr. entre la Macédoine et le monde celtique. La preuve la plus importante en est la circulation des monnaies d'or et d'argent de Philippe II au nord des Balkans et dans la vallée du Danube, ${ }^{230}$ ce qui est en soi-même un symptôme des relations constructives établies entre Celtes de l'Est et Macédoniens. C'est dans ce contexte qu'il faut interpréter l'ambassade celte envoyée chez Alexandre en 335 av. J.-Chr., suite à la campagne contre les Thraces et les Gètes. ${ }^{231}$

Un des documents archéologiques majeurs de ces relations est constitué par l'apparition au nord des Balkans (Pećine, tombe 316 = fig. 19.1) et dans le nord-est de la Hongrie (Ludas, tombe $1282=$ fig. 19/2) d'un type d' oinochoé répandu surtout dans l'ouest de la Macédoine, pendant la phase LT B2a, antérieure selon la conception chronologique contemporaine à l'offensive de 280/279 av. J.-Chr. Notons que la pièce découverte à Ludas est de fabrication locale, ${ }^{232}$ à l'instar des vases à boire celtiques du moyen Danube, à deux anses et pied profilé, inspirés par les canthares hellénistiques. ${ }^{233}$ (Fig. 20) La pièce de Chotin (fig. 20.1) provient d'une sépulture à mobilier riche, ${ }^{234}$ qu'on peut dater de LT B2a ou de la transition B2a-B2b. ${ }^{235}$ C'est-à-dire que le canthare de Chotin pourrait aussi dater d'avant la campagne des Balkans.

Nous voici de retour au problème des vases hellénistiques en bronze.

Les quatre vases en bronze, mis au jour dans des sépultures laténiennes de la région du moyen Danube, peuvent être datés grâce à des trouvailles grecques anciennes et récentes (par ex., Derveni, Vergina en Macédoine). ${ }^{236}$ Le vase de Szob, qu'on peut considérer selon des critères stylistiques comme un des prototypes des canthares celtiques en terre cuite (fig. 18.1), ${ }^{237}$ aurait été exécuté, d'après l'analyse de J. Gy. Szilágyi, au dernier quart du IV siècle av. J.-Chr. ou éventuellement au début du III ${ }^{\mathrm{e}}$ siècle. ${ }^{238}$ Le canthare en calice de Szabolcs (fig. 18.2) peut être considéré comme une réplique de l'objet du même type du trésor de Votonosi, et semble ainsi dater du $3^{\mathrm{e}}$ quart du IV siècle av. J.-Chr. ${ }^{239}$ Le lécythe aryballisque découvert au cimetière celtique de Hurbanovo ${ }^{240}$ présente de telles analogies avec un vase mis au jour à Derveni, que cela implique une datation du dernier tiers du $\mathrm{IV}^{\mathrm{e}}$ siècle av. J.-Chr. ${ }^{241}$ Finalement, la situle en bronze ornée d'une attache en forme de feuille de lierre, ${ }^{242}$ trouvée dans la tombe 22 de la nécropole de Belgrade-Karaburma (fig. 18.3), peut être datée du dernier tiers ou de la fin du $\mathrm{IV}^{\mathrm{e}}$ siècle av. J.-Chr. compte tenu de parallèles d'Elis et de Thrace. ${ }^{243}$

${ }^{222}$ Rolley 1987, 419.

${ }^{223}$ SZABÓ 2000.

${ }^{224}$ RAMSL 2011, 155, fig. 124/A.

${ }^{225}$ Cf. SZABÓ 1988, 393-394.

${ }^{226}$ Le lécythe aryballisque de HuRBanovo, la situle et la phialé de Karaburma, le canthare en calice de Szabolcs et le canthare de Szob: SCHÖNFELDER 2009, 68, note 60. ; cf. SZABÓ 2000, 288-289, fig. 1-4.

${ }^{227}$ Rolley 1987, 419.

${ }^{228}$ Rolley 1987, 416-419; cf. SZABó 2000, 288.

${ }^{229}$ SHEFTON 1994

${ }^{230}$ LE RIDER 1977, 255-319.

${ }^{231}$ Cf. NACHTERGael 1977, 7-9.

${ }^{232}$ SZABÓ 2012, 135, voir pl. L.11.

${ }^{233}$ KRUTA - SZABÓ 1982.
${ }^{234}$ Sépulture 21: RATIMORSKÁ 1975, 87, 94, pl. IV.

${ }^{235}$ Cf. Busna 2003, 94, fig. 62 /E; 96, fig. 64 /C3-4; Busna

2006, 214 et 219: premier quart du III ${ }^{\mathrm{e}}$ siècle av. J.-Chr.

${ }^{236}$ Cf. Rolley 1987; SZABó 2000, 288-289.

${ }^{237}$ Horváth 1945, 60 et suiv., fig. 1; SZABÓ, 2000, 289,

fig. 3 .

${ }^{238}$ Art antique $1976,13-15, \mathrm{n}^{\circ} 4$

${ }^{239}$ SZABÓ 2000, 288, fig. 2.

${ }^{240}$ Bujna 2006, Hurbanovo-Konkol' sépulture 18/64:

204, fig. $2 ; 235$, pl. 2 = Fig. 18.4 .

${ }^{241}$ SZABÓ 1983b, 14-17, fig. 15. et 17

${ }^{242}$ Le dessin corrigé de l'ensemble funéraire: BožIĆ 1981 , pl. 11, 2 ; cf. SZABÓ 2000 , 288, fig. 2.

${ }^{243}$ Rolley 1987, 419; VeNEDIKov 1977, 87-88, fig. 46. 

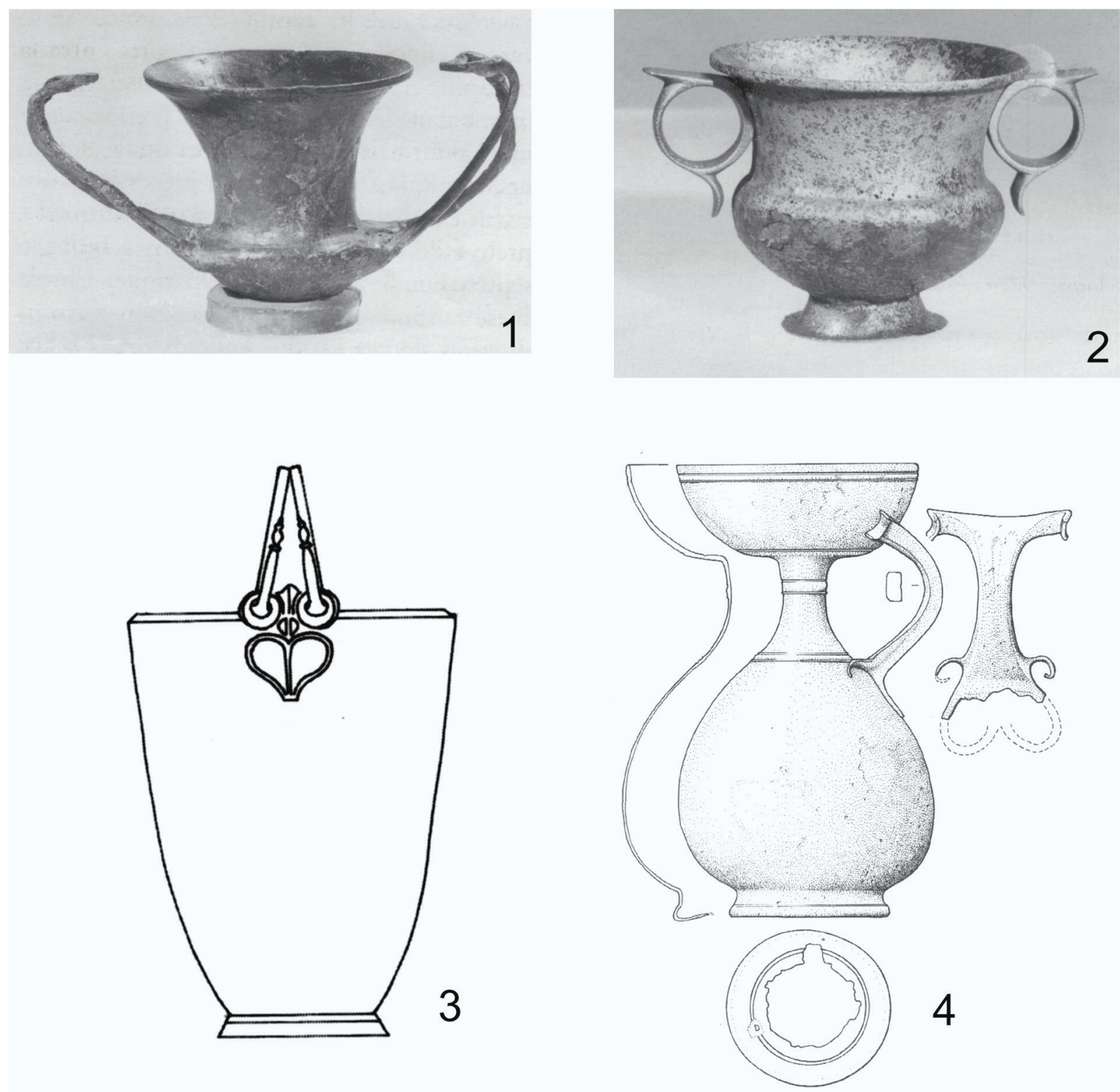

Fig. 18. Vases hellénistiques en bronze en provenance de tombes celtiques de la région du moyen Danube.

1: Szob ; 2: Szabolcs ; 3: Karaburma, sépulture 22; 4: HuRBANovo-Konkol' (1-3: d'après SZABÓ 2000 ; 4: d'après BuJNA 2006)

Pour résumer ce qui vient d'être présenté, les quatre vases en bronze sont les produits de la toreutique hellénistique ancienne qui atteint son apogée dans les dernières décennies du IV siècle av. J.-Chr. Vu que cette période n'est pas loin de l'offensive celtique de 280/279 av. J.-Chr., il pouvait sembler naturel de penser que ces vases étaient arrivés dans le bassin des Carpates après l'échec de l'opération, comme butin. ${ }^{24}$ Néanmoins, la réévaluation des relations entre le monde celtique et la Macédoine nous doit inciter à une certaine prudence quand il s'agit de relier à un seul événement historique l'arrivée de vases en bronze de Grèce dans le «Barbaricum». ${ }^{245}$ C'est-à-dire que l'analyse des conditions de la découverte de ces vases d'importation ne peut pas être évitée. 

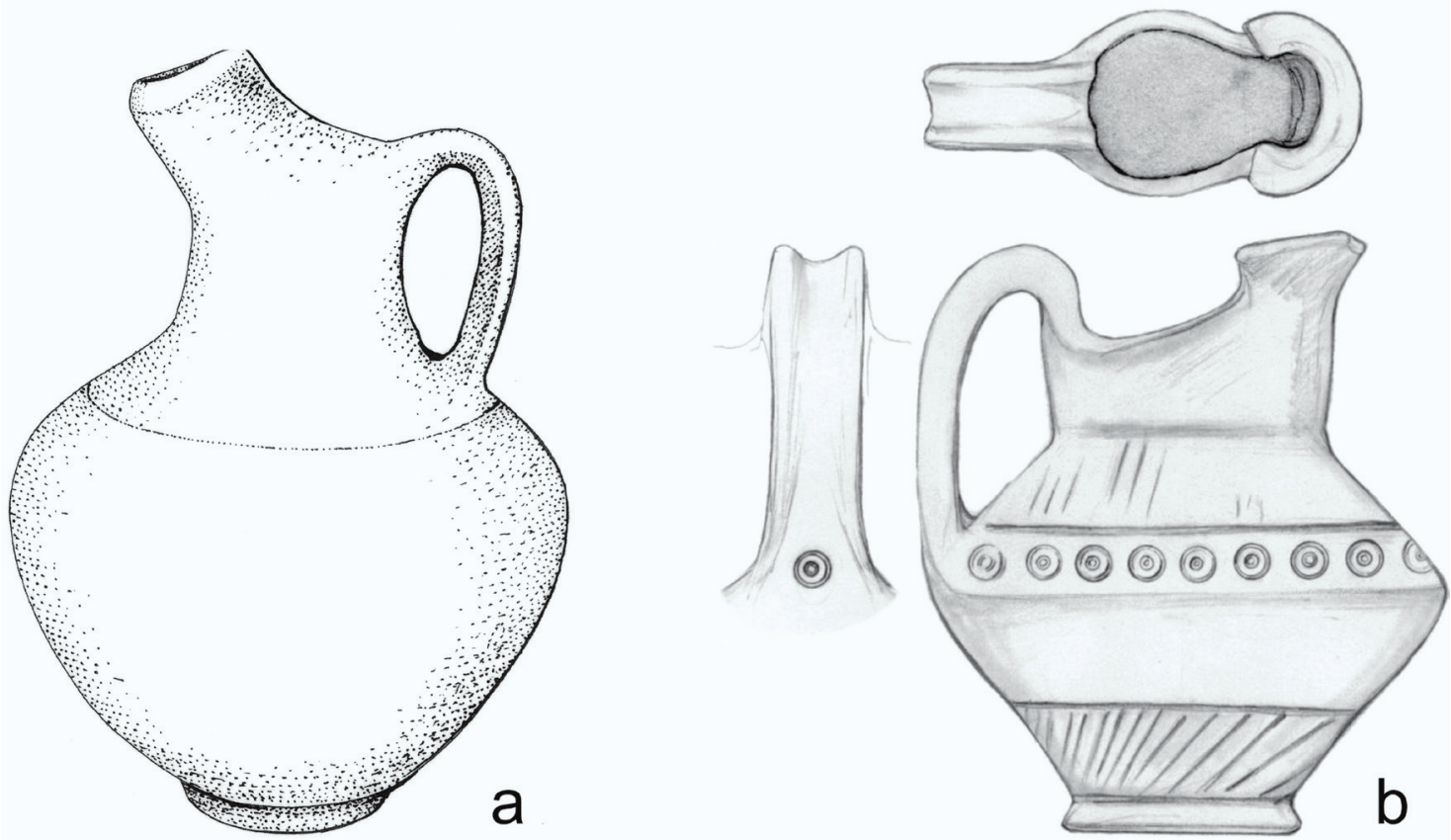

Fig. 19. Oinochoés en terre cuite. 1: Pećine, sépulture 316 (d'après SzaBó 2000); 2: Ludas, sépulture 1282

La sépulture 1 de Szob avait été perturbée. ${ }^{246}$ Les données relatives aux céramiques funéraires fournies par Hunyady ${ }^{247}$ ne sont pas suffisantes pour déterminer si le canthare a été enseveli avant ou après 280 av. J.-Chr. Les circonstances de la mise au jour du vase de Szabolcs restent, du moins pour le moment, inconnues.

Par contre, les armes ${ }^{248}$ déposées dans la tombe 22 de Karaburma reflètent le mélange d'éléments de LT $\mathrm{B} 2 \mathrm{a}^{249}$ et LT B2 $\mathrm{b}^{250}$. La fibule $\mathrm{n}^{\circ} 6$ fait cependant basculer la datation en faveur de la phase de LT B2b. ${ }^{251}$

Compte tenu des éléments sauvegardés du mobilier de la tombe 18/64 de Hurbanovo-Konkol', cette dernière ne peut pas être antérieure à la phase LT B2b. Cela n'empêche pas que la «réalité» de la phase de transition B2/C1 suggérée par Bujna reste, à notre avis, en suspens à défaut de nouveaux arguments. ${ }^{252}$ En tout cas, Bujna considère le fait que l'enterrement était postérieur à $280 \mathrm{av}$. J.-Chr. comme la preuve qui l'autorise à lier le lécythe aryballisque à des Celtes revenant de Grèce. ${ }^{253}$ Cependant, à ce point, l'interprétation suppose l'existence de données biographiques dont malheureusement nous ne disposons pas. Cela n'exclut naturellement pas la possibilité d'un butin, mais rien ne prouve la participation du guerrier de Hurbanovo à l'offensive grecque. Cette seconde hypothèse, ainsi que la position sociale éminente du guerrier, devrait être prouvée par un type de vase grec pouvant être considéré comme une curiosité, ${ }^{254}$ lequel en tant qu'huilier a essentiellement joué, en Méditerranée, un rôle dans le culte funéraire. ${ }^{255}$ L'analyse fonctionnelle des trois autres vases en bronze promet cependant des résultats autrement prometteurs.

Les vases de Szob et de Szabolcs (fig. 18.1-2) étaient, quant à leur fonction, des vases à boire. La forme de vase en elle-même, comme nous l'avons signalé plus haut, pouvait servir de prototype aux canthares celtiques en terre cuite du moyen Danube du III ${ }^{\mathrm{e}}$ siècle av. J.-Chr. comme la pièce de Chotin, citée ci-dessus, ou celle de la sépulture 3 de Kosd (fig. 20). ${ }^{256}$ Différents des précédents, les vases dits pseudo-canthares remontent, selon la conception traditionnelle, à la composante «illyro-pannonnienne» de la céramique celte orientale. ${ }^{257}$

\footnotetext{
${ }^{246}$ HORVÁTH 1945, ibid.

${ }^{247}$ HunYADY 1957, 156, sépulture X.

${ }^{248}$ BožIĆ 1981 ; SZABÓ 2000, loc. cit.

${ }^{249}$ Epée: GebHard 1989, 86, fig. 27/a1.

${ }^{250}$ Bélière: GEBHARD 1989, 86, fig. 27 /b8.

${ }^{251}$ Bujna 2003, 94, fig. 62 /C3-B.

252 Bujna 2006, 207-217; cf. SZABó 2012, 93.

${ }^{253}$ Bujna 2006, 218-219.
}

${ }^{254}$ Bujna 2006, 219.

${ }^{255}$ Cf. Bujna 2006, 216.

${ }^{256}$ KRUTA - SZABÓ 1982, 55, fig. 2; 66-67, pl. II-III ; carte de répartition: 62 , fig. 8 .

${ }^{257}$ HunYADY 1942-44, 33-39; SzABó 2005a, 149-150; 161-165 ; cf. Bujna 2006, 211-215. Carte de répartition: HelleBRANDT 1989, 454, fig. 16 . 

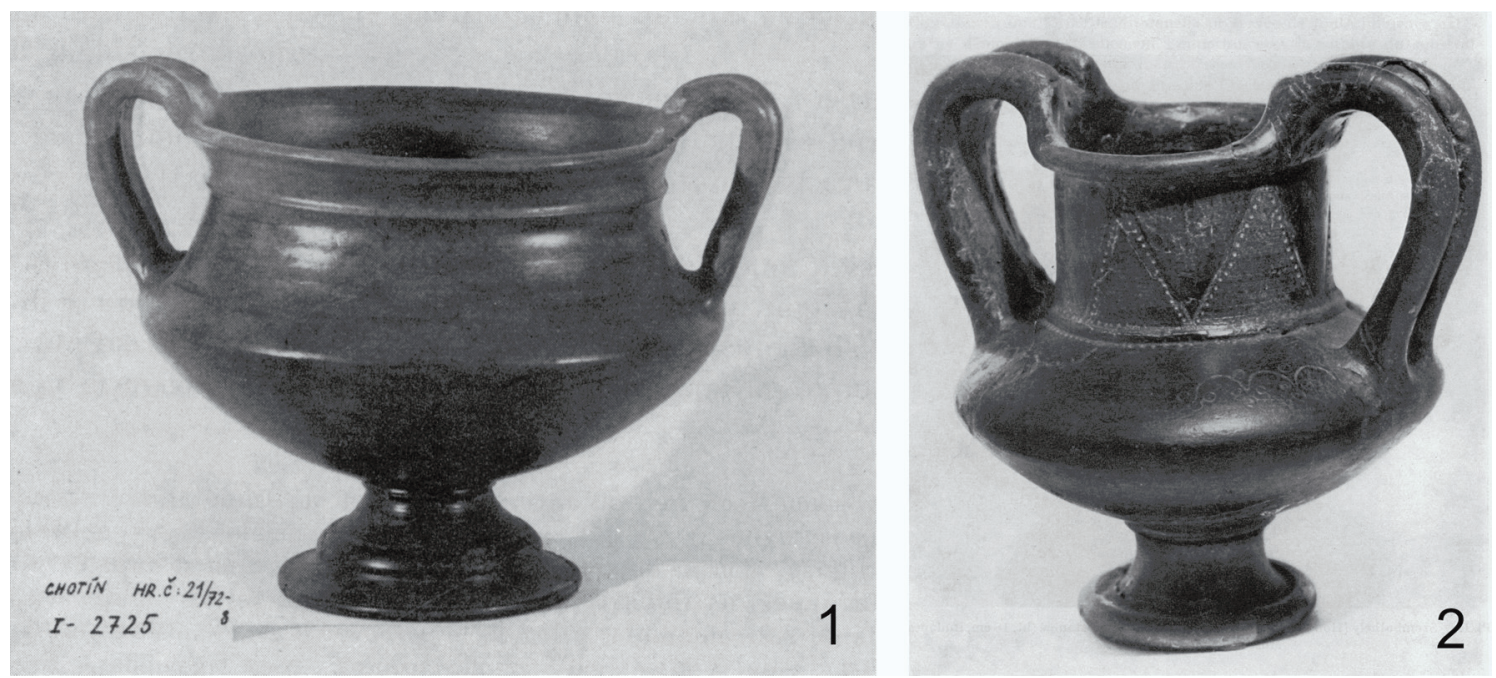

Fig. 20. Canthares celtiques en terre cuite d'inspiration hellénistique.

1: Chotin, sépulture 21; 2: Kosd, sépulture 3 (d'après KrUTA - SzABÓ 1982)

Les canthares et les pseudo-canthares ont certainement joué un rôle important dans le rite funéraire laténien au bassin des Carpates, cette constatation étant corroborée par la carte de distribution citée ci-dessus. Leur apparition et la longévité de la mode sont sans doute en relation avec les substrats hallstattiens non celtiques de la région: «illyro-pannonien» à l'ouest du Danube et «thraco-scythe» sur la Grande plaine hongroise. ${ }^{258}$ Pourtant, ces racines n'expliquent pas de manière satisfaisante les nouveautés qui font leur apparition sur les céramiques laténiennes. ${ }^{259}$ En ce qui concerne cependant le rôle du canthare dans le rite funéraire, Hunyady avait sans doute raison en ramenant la coutume celtique à des origines illyriennes. Sur la représentation du coffre funéraire 2 de Ribić, on tend un canthare au défunt représenté en héros sur un trône. Le cercueil en pierre est orné de l'autre côté d'un sanglier. Cela pourrait témoigner du mélange d'idées religieuses illyriennes et celtiques. ${ }^{260}$

La sépulture 5 de Balatonfőkajár constitue une preuve majeure à l'appui de la fonction particulière du canthare dans le rite funèbre des Celtes orientaux : dans la tombe féminine à «squelette», ce vase à deux anses était situé sur un banc au-dessus du niveau de l'inhumation. ${ }^{261}$ (Ici : fig. 21)

C'est un fait connu que des canthares faisaient partie du mobilier de tombes de guerriers celtes. ${ }^{262}$ Cependant, à l'instar de la défunte de la sépulture de Balatonfőkajár, des femmes avaient été enterrées dans les tombes 21 de Chotin, ${ }^{263} 40$ de Kosd, ${ }^{264} 34$ de Karaburma ${ }^{265}$ ainsi que dans celle de Csobaj. ${ }^{266}$ En terminant ce tour d'horizon, nous voudrions attirer l'attention sur le fait que contrairement au pseudo-canthare exceptionnel de Csobaj, aux anses ornées de tête de bélier (fig. 22.1), qui faisait partie du mobilier d'une sépulture féminine très riche, ${ }^{267}$ un des chefs-d'œuvre de l'art celtique oriental, un vase avec deux anses en forme de sanglier ${ }^{268}$ (ici : fig. 22.2), a été découvert au sein d'un mobilier humble, constitué de deux récipients en terre cuite et un bracelet en bronze, dans la tombe 726 de Ludas.

Nous sommes ainsi de nouveau confronté au dilemme de l'époque de l'expansion celtique : les mobiliers funéraires ne nous renseignent pas dans tous les cas sur la position ou rang dans la société ou la fonction profane ou religieuse du défunt. En ce qui concerne le problème des canthares, leur rôle dans le rite funéraire celtique, attesté dans le cas des sépultures des deux sexes, nous rend sceptique quant à la valeur d'indicateur de rang des «origi$214-215$, t. 9

${ }^{258}$ Kruta - Szabó 1982, 51, notes 1-2; cf. Bujna 2006,

${ }^{259}$ Cf. Hunyady 1942-44, 33-39: en ce qui concerne les relations illyriennes; KRUTA - SzABÓ 1982: quant à l'influence hellénistique.

\footnotetext{
${ }^{260}$ HunYADY 1942-44, 38, pl. LXVI/12.

${ }^{261}$ HORVÁth 1972, fig. 97, fig. 9.

${ }^{262}$ Szob : HorVÁth 1945, ibid.; Kosd, sépulture 3: KRUTA
} - Szabó 1982, 66-67, pl. II-III ; Szabó 1995, 53, fig. 8; Hurbanovo Konkol': Bujna 2006, 205, nº 8, 236, pl. 3.

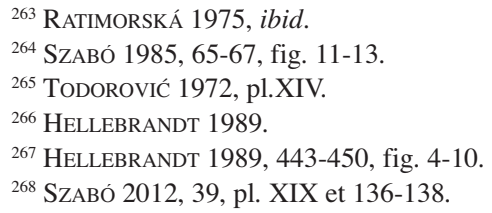




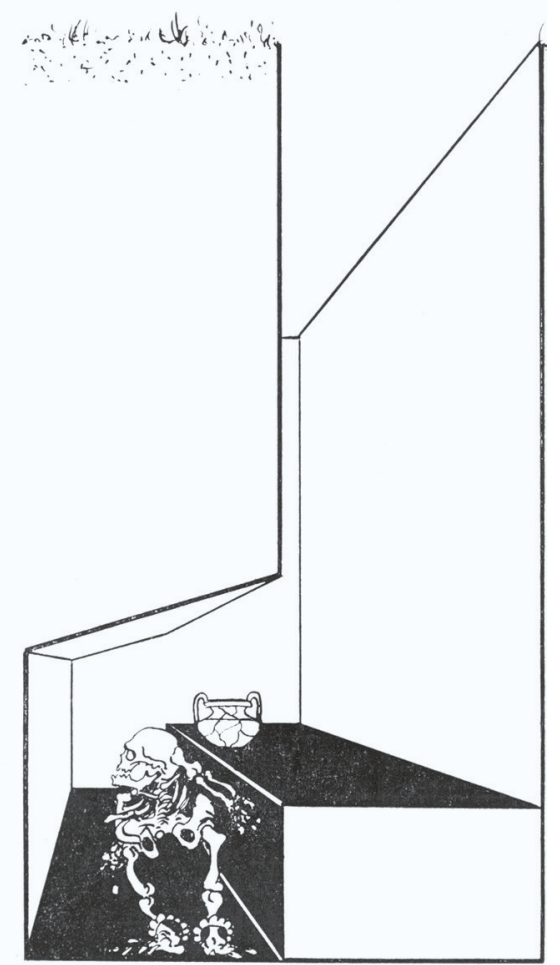

Fig. 21. Balatonfökajár, sépulture 5 (d'après HoRvÁtH 1972)

naux» hellénistiques ou de leurs copies locales. Sinon, à l'instar des guerriers porteurs de casques en Italie, ${ }^{269}$ il faudrait supposer l'existence parallèle d'une douzaine de chefs en Transdanubie et dans le nord-est de la Hongrie, ce qui, vu les dimensions du territoire ou le nombre des tribus celtiques connues grâces aux sources anciennes, ${ }^{270}$ est une absurdité.

A notre avis, c'est la sépulture 22 de Karaburma où les importations grecques semblent avoir une fonction d'indicateur de rang. Notamment, la coexistence d'une situle et d'une phialé dans le mobilier funéraire d'un guerrier, ${ }^{271}$ en tant que rite pars pro toto, ${ }^{272}$ pourrait témoigner de la fonction d' «hôte», d'organisateur de cérémonies du défunt. ${ }^{273}$ Les fouilles de Corent ont fourni la documentation archéologique des festins aux aspects religieux des tribus celtiques, connus grâce aux sources anciennes (Posidonios, Pline l'Ancien, etc.). ${ }^{274}$

Pour mettre fin à l'analyse des vases «d'importation» en bronze, il faut souligner que vu le contexte de l'époque, les relations entre les Celtes et la Macédoine puis leur offensive contre la Macédoine et la Grèce, ainsi que leur rôle de mercenaires dans la Méditerranée, ${ }^{275}$ l'apparition de produits grecs n'a rien de surprenant. Ce qui peut surprendre davantage, c'est plutôt la rareté des trouvailles de ce type. Mais l'interprétation des vases faisant partie du mobilier funéraire est loin d'être une tâche facile. Il est fort probable qu'ils sont arrivés en tant qu'objets personnels dans la région du moyen Danube. Il est cependant impossible de prouver que le vase grec et le Celte enterré dans la tombe avaient effectivement fait ensemble le voyage du Sud vers le Nord. En principe, ces objets «exotiques» pourraient témoigner de l'appartenance à l'élite, pourvu que les relations extérieures aient été contrôlées par la couche dirigeante. Mais quatre ou cinq vases en bronze ne suffisent pas pour appuyer une telle hypothèse. ${ }^{276} \mathrm{Il}$ reste donc, en ce qui concerne les trouvailles citées, la possibilité d'une interprétation cas par cas, ou, quant aux canthares, la probabilité de leur intégration aux idées religieuses des Celtes danubiens.

${ }^{269}$ LEJARS 2006, loc.cit.

${ }^{270}$ Cf. SzABó 2005a, 36-40, 46-54.

${ }^{271}$ BoŽIĆ 1981, loc.cit.; TODOROVIĆ 1972, 17, pl. VIII.

${ }^{272}$ Pour les services à boire des tombes princières LT A

${ }^{273}$ Cf. SCHÖNFELDER 2009, 68

${ }^{274}$ Poux 2011, 141-163.

${ }^{275}$ Cf. SZabó 2000; SZABó 2005a, 29-46; SChÖNFELder 2007b. voir Kimmig 1988, 258-265.

${ }^{276}$ Cf. Marion 2009, 235. 

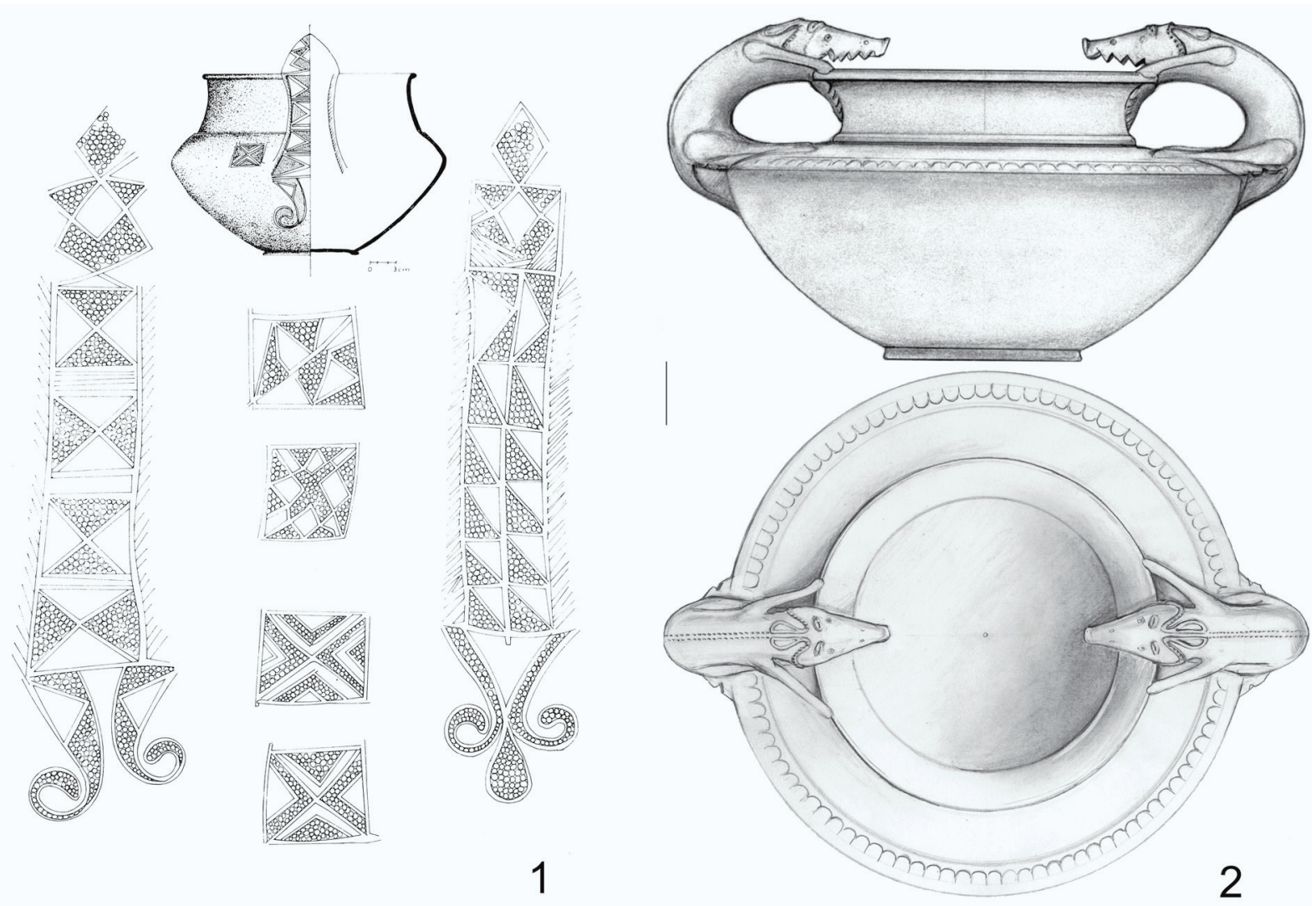

Fig. 22. Pseudo-canthares aux anses zoomorphes. 1: Csobaj (d’après SzABÓ 1992); 2: Ludas, sépulture 726

Au niveau de l'armement, c'est dans le cas des talons de lance que l'influence grecque a été attestée au bassin des Carpates. Hunyady les appelle talons à douille ${ }^{277}$ : elles étaient coniques et creuses, et fixées à l'extrémité du manche, pouvaient servir à planter l'arme dans le sol. Outre ce type élémentaire, il existe aussi, parmi les trouvailles laténiennes, des talons de lance ressemblant au sauroter grec. C'était selon toute probabilité la publication de Baitinger sur Olympie qui a attiré l'attention de la recherche sur cette correspondance, ${ }^{278}$ et c'était M. Schönfelder qui a fait de ce problème jusqu'alors ignoré un sujet d'étude. ${ }^{279}$ Le talon de lance hoplitique devait dépasser 20 $\mathrm{cm}$, occasionnellement $40 \mathrm{~cm}$, ce qui était avantageux du point de vue de la répartition du poids de l'arme. Sa pointe, généralement à quatre tranchants, était fixée à la douille par une «bosse», souvent un anneau profilé en bronze. Du point de vue de leur structure, les variantes laténiennes sont fidèles aux prototypes, mais elles sont beaucoup plus petites. Il est ainsi difficile d'imaginer que les Celtes avaient adopté le mode de combat caractéristique des fantassins méditerranéens. ${ }^{280}$

Pour revenir à notre région, A. Rapin était le premier à constater la présence dans le bassin des Carpates du type identifié par Schönfelder. Mais Rapin s'est servi essentiellement des analogies champenoises du V $\mathrm{V}^{\mathrm{e}}$ siècle av. J.-Chr. (cf. fig. 23) du talon de lance de la tombe 2 du cimetière de Kosd (fig. 23.b) pour modifier la datation de LT B2 de la sépulture hongroise. ${ }^{281}$ Schönfelder a le mérite d'avoir identifié les origines grecques de ce type de talon, ainsi que d'avoir prouvé l'utilisation des dérivés laténiens au III' siècle av. J.-Chr., c'est-à-dire à l'âge d'or de l'expansion et des mercenaires celtiques. ${ }^{282}$ Cette constatation a été confirmée par la description de la tombe à canthare de Szob : «auprès des ossements, il y avait un manche de lance en fer (sa forme : son pied commence par une extrémité pointue, elle continue par un octaèdre, puis une pyramide quadrangulaire, et se termine en une sphère. $)^{283}$

\footnotetext{
${ }^{277}$ HUNYADY 1942-44, 120, pl. LIII 12-13.

${ }^{278}$ BAITINGER 2001, 54 et suiv.

${ }^{279}$ SCHÖNFELDER 2007b, 311 et suiv.
}

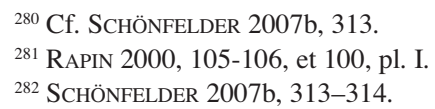




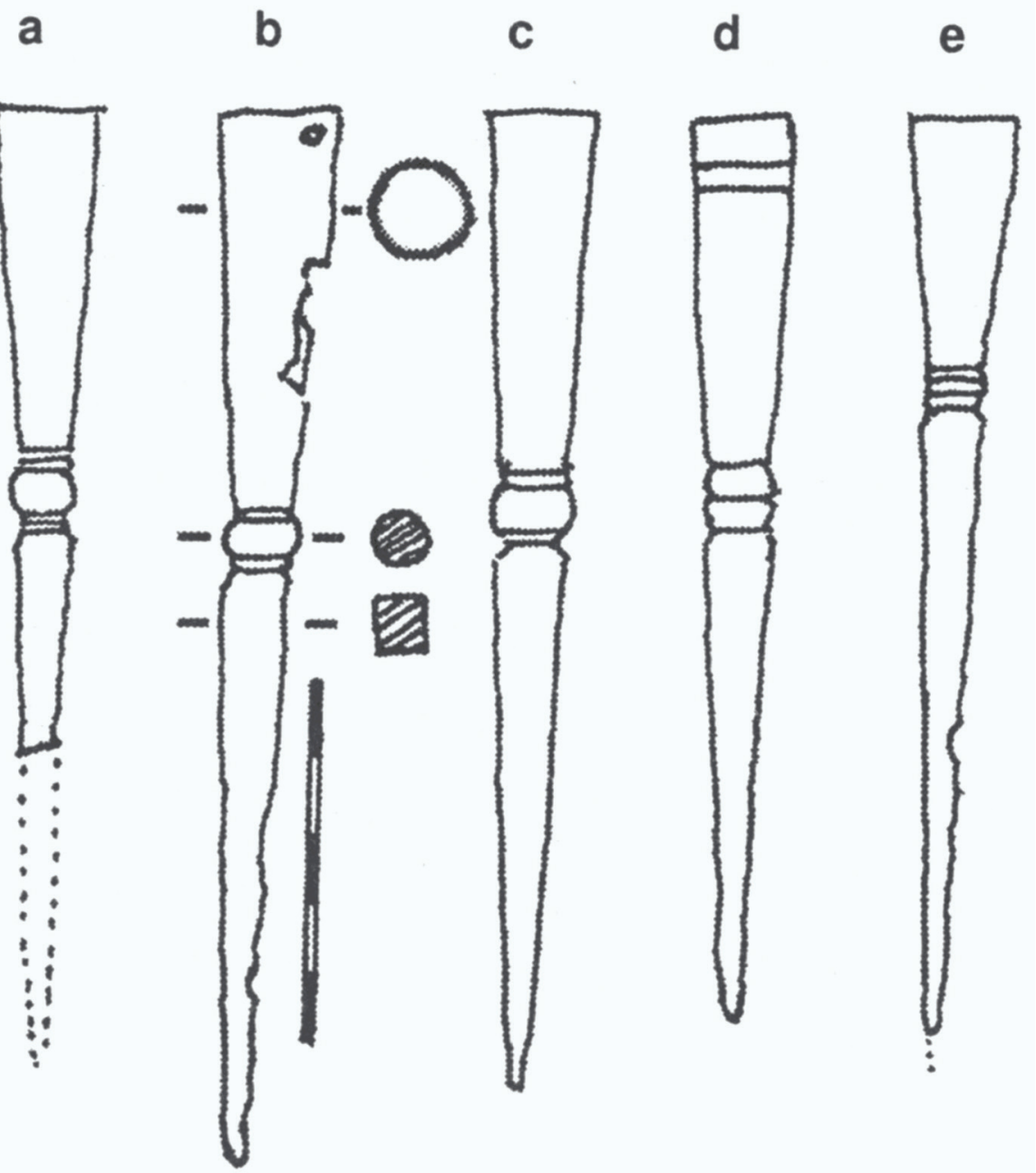

Fig. 23. Talons de lance d'inspiration grecque. a: Inzersdorf, sépulture 277; b: Kosd, sépulture 2; c: Suippe (Marne); d: Mairy (Marne); e: Bussy-le-Long (Aisne), sépulture 75 (d'après RAPIN 2000)

Nous n'avons sans doute pas tort en pensant qu'il s'agit d'un talon de lance de type sauroter grec que l'archéologue n'a pas reconnu. Compte tenu du canthare en bronze de type hellénistique ancien, il pourrait sembler justifié de définir maintenant le guerrier enterré dans la tombe - malheureusement - perturbée de Szob comme un des protagonistes de l'offensive contre la Macédoine et la Grèce. En principe, cela ne peut pas être exclu ; mais c'est justement le talon de lance de type sauroter, ne correspondant pas d'un point de vue fonctionnel au prototype, qui attire notre attention sur le fait que cet ensemble (ou plus exactement ce qui en reste) s'intègre au contexte plus large du mercenariat celtique. ${ }^{284}$ Cependant, le retour des mercenaires ayant terminé leur service au pays, ne peut pas être daté à nos connaissances actuelles.

Pour résumer les résultats de cette analyse, il faut souligner que le matériel archéologique, y compris les trouvailles liées aux nécropoles, ne fournit que des repères d'une validité limitée quant aux critères de l'appartenance aux élites. Cette remarque est particulièrement valable pour l'époque de l'expansion celtique aux IV-III ${ }^{\mathrm{e}}$ siècles av. J.-Chr., lorsque, contrairement au V $\mathrm{V}^{\mathrm{e}}$ siècle av. J.-Chr., le temps des «princes », ou au I ${ }^{\text {er }}$ siècle av. J.-Chr., c'est-à-dire la civilisation des oppida, le rite funéraire ne permet pas directement de définir l'appartenance à la couche dirigeante. La disparition des objets de prestige du mobilier rend, de toute façon, impossible d'évaluer la 
situation matérielle du défunt. Alors que selon les sources anciennes, il s'agit d'un des critères de l'appartenance à l'élite. Nous rencontrons la même difficulté quant aux origines du défunt. Dans l'état actuel des analyses interdisciplinaires, nous ne pouvons qu'espérer que l'archéologie disposera d'ici peu de repères biologiques quant aux origines (autochtone, étranger), ou à la parenté. ${ }^{285}$

Il nous reste donc l'examen de la structure des cimetières et l'analyse du statut social du défunt à partir de ce dernier. De ce point de vue, l'importance des nécropoles de Ludas et de Sajópetri est due au fait que, dans la mesure du possible, elles ont été fouillées dans leur intégralité.

La conclusion majeure tirée de l'étude de la nécropole de Ludas est le fait qu'elle a évolué à partir de plusieurs enclos funéraires grâce à l'utilisation quasi parallèle de ces derniers. Mais ce phénomène en lui-même ne reflète pas la division de la société; il fait néanmoins poser la question de savoir si tous les défunts faisaient partie de la même communauté. L'éventualité de l'utilisation du cimetière par plusieurs communautés pourrait être corroborée par la découverte de plusieurs habitats sur les terrasses longeant le ruisseau Bene ${ }^{286}$ sans que cela puisse être considéré comme une preuve irréfutable. Cependant, l'observation selon laquelle l'organisation du cimetière était déterminée par la position des tombes d'hommes armés, reflète selon toute probabilité le caractère militaire de l'élite, noté également par les sources écrites de l'Antiquité. Cela est particulièrement frappant dans le cas de l'enclos C où les sépultures des hommes armés, entrecoupées de tombes de femmes et d'enfants, forment un demi-cercle autour de la sépulture du guerrier considéré comme le plus important au vu de son anneau en or et son bracelet d'une beauté exceptionnelle (686). Les fourreaux de trois hommes armés d'épées sur six sont ornés de motifs gravés du Style des épées hongroises. Cela peut témoigner de la disparition de l'hétérogénéité originelle des migrants au sein de la nouvelle communauté. D'autre part, il n'est peut-être pas injustifié de supposer que le port d'une épée signalait l'appartenance à l'élite. ${ }^{287}$ Une donnée fournie par César (B.G. VI, 18, 3) renvoie à la signification symbolique, quasi magique du port d'une arme, ce qui déterminait en même temps la place de ceux qui en avaient le droit dans la hiérarchie sociale. ${ }^{288}$ Cette hypothèse peut être corroborée à Ludas par la comparaison des enclos $\mathrm{C}$ et $\mathrm{D}$ : dans ce dernier reposaient uniquement des hommes équipés d'une ou deux lances. Le fait de les enterrer à part devait indiquer que ce groupe de guerriers ne faisait pas partie de l'élite. A l'origine, ces derniers devaient être des gaesati, des guerriers qui luttaient avec un gaesum, c'est-àdire un javelot. L'appel à l'aide des gaisatai contre les Romains par les Celtes du nord de l'Italie doit être à l'origine du nouveau sens du mot : «mercenaire gaulois». ${ }^{289}$ Dans tous les cas, cette hypothèse n'est pas en contradiction avec les conclusions de l'étude de la nécropole de Sajópetri où la tombe masculine 28 à lance se trouve loin des enclos funéraires, dans le secteur sud, entourée de sépultures à inhumation et à incinération à mobilier pauvre. Quant à la structure de la nécropole de Sajópetri, elle ressemble aussi à celle de Ludas dans la mesure où la sépulture à char $n^{\circ} 2$ considérée comme la plus prestigieuse se situe non loin du centre géométrique de la nécropole, dans le groupe A. La majorité des tombes de guerriers armés d'épées sont positionnées de façon quasi linéaire un peu plus au nord et nord-ouest, dans les enclos B et C. (L'intrus est la sépulture 19 dont le mobilier comprenait un bouclier, une lance et un coutelas.) En ce qui concerne les deux autres tombes à épée, la 47 est située immédiatement au sud-est de l'enclos funéraire A. Finalement, la sépulture 78, unique par son rite à inhumation, était isolée au secteur nord-est de la nécropole.

L'analyse du plan du cimetière permet ainsi d'identifier trois enclos funéraires d' «élite». La délimitation de ces derniers n'est pas facilitée par la mise au jour, au nord-est et au sud-est, de nombreuses tombes sans caractère, les zones nord-est et sud-est de la nécropole étant occupées par les sépultures du «bas peuple». Il y a quelques sépultures féminines à la périphérie des enclos d'élite (groupe A: sépulture 15; groupe B : sépulture 6; groupe C : sépulture 81), par contre, les tombes voisines sont très pauvres.

Etant donné que l'habitat mis au jour sur le site de Sajópetri-Hosszú-dülő était très vaste, ${ }^{290}$ nous n'avons aucune raison de supposer que la nécropole fouillée à Homoki- Szőlőskertek ait été utilisée par d'autres communautés aussi. Ce qui, par contre, semble probablement plus vraisemblable, c'est l'appartenance du cimetière celtique de Kistokaj-Kültelkek ${ }^{291}$ à l'habitat de Sajópetri. ${ }^{292}$ Mais pour résoudre ce problème, nous aurions besoin d'effectuer de nouvelles recherches microrégionales.

${ }^{285}$ Pour les analyses des isotopes du strontium en cours cf. HAUSCHILD 2010, 171 et suiv.

${ }^{286}$ Cf. SZABÓ 2012, 176-180: les explorations de Z. Czajlik et K. TANKÓ.

${ }^{287}$ Cf. par ex., SCHÖNFELDER 2009, 73-74.

${ }^{288}$ Pour l'interprétation: BrunauX 2004, 86-87.

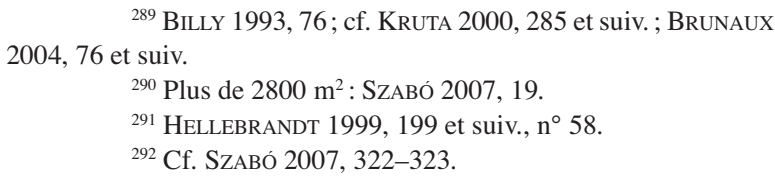


En fin de compte, l'étude de la nécropole de Sajópetri corrobore l'hypothèse selon laquelle à l'époque de l'expansion balkanique, les membres de l'élite se définissaient avant tout comme guerriers.

Compte tenu de ces analyses, il semble justifié de constater que dans le cas de nécropoles mises au jour dans leur intégralité comme celles de Ludas et de Sajópetri, la hiérarchie sociale peut se dessiner grâce à la structure du cimetière et aux mobiliers funéraires. Cependant, l'identification du membre le plus éminent de la communauté ne s'est pas faite selon les mêmes critères dans les deux cas : à Ludas, c'était les parures exceptionnelles, à Sajópetri, le char enterré avec le défunt qui ont fourni l'argument décisif. Le fait que des différences tellement marquantes aient été observées dans le cas de sites se trouvant à 60-70 km l'un de l'autre, semble appuyer la thèse selon laquelle l'élite laténienne ne peut pas être considérée comme homogène et ne peut être décrite selon aucun modèle évolutif général : elle était hétérogène, elle différait selon les endroits et les époques. Autrement dit, les spécificités d'une région ne peuvent pas servir de modèle pour la reconstitution de la hiérarchie sociale d'une autre. ${ }^{293}$

C'est-à-dire qu'à défaut de sources historiques, les recherches consacrées aux élites, fondées uniquement sur des méthodes archéologiques, ne peuvent produire que des données isolées, mais ces dernières pourront servir, plus tard, d'éléments pour une future synthèse. Une autre question à résoudre, liée déjà à la problématique des oppida de la région du moyen Danube, est celle de savoir quel rôle l'élite militariste du temps de l'expansion allait jouer dans l'éclosion de l'urbanisation celtique. ${ }^{294}$

Cette étude a bénéficié du soutien du programme OTKA (Fonds national pour la recherche scientifique) $\left(\mathrm{N}^{\circ} 78303\right)$

\section{BIBLIOGRAPHIE}

ADAM 2006

ANASTASSOV 2012

ARCELIN - RAPIN 2002

Art antique 1976

BAITINGER 2001

BARAY 2003

BENADÍK 1957

BILLY 1993

BoŽIĆ 1981

BRUNAUX 2004

BUCHSENSCHUTZ - RALSTON 2012

BUJNA 1982

BUJNA 1991

BUJNA 2003

BUJNA 2005

BUJNA 2006

CHARPY - RAPIN 2001
= A.-M. ADAM: L'Europe tempérée dans ses contacts avec le monde méditerranéen ( $\mathrm{V}^{\mathrm{e}}-\mathrm{II}^{\mathrm{e}} \mathrm{s}$. av. J.-C.) In: M. SzABó (éd.): Les Civilisés et les Barbares du Ve au II ${ }^{\mathrm{e}}$ siècle avant J.-C. Collection Bibracte 12/3. Glux-en-Glenne 2006, 193-203.

= I. AnAstassov: Vestiges laténiens de Bulgarie (IV e $-\mathrm{I}^{\mathrm{er}} \mathrm{s}$. av. J.-C.). De l'archéologie à l'histoire de la migration des Celtes en Thrace. Vols 2. [Thèse de doctorat.] Université de Genève 2012.

= P. ARCELIN - A. RAPIN: Images de l'aristocratie du second âge du Fer en Gaule méditerranéenne. À propos de la statuaire d'Entremont. In: GuICHARD - PERrin 2002, 29-66.

= Art antique au Musée Déri Debrecen et dans d'autres collections hongroises. BMHB 46-47 (1976) $3-85$.

= H. BAITINGER: Die Angriffwaffen aus Olympia. OlForsch 29. Berlin-New York 2001.

$=$ L. BARAY: Pratiques funéraires et sociétés de l'âge du fer dans le bassin parisien (fin du VII ${ }^{\mathrm{e}}-$ troi- $^{-}$ sième quart du $\mathrm{II}^{\mathrm{e}}$ s. avant J.-C.) 56 ${ }^{\mathrm{e}}$ suppl. à Gallia. Paris 2003.

= B. BENADíK et alii: Keltské pohrebiská na juhozápadnom Slovensku - Keltische Gräberfelder der Südwestslowakei. Bratislava 1957.

= P.-H. Billy: Thesaurus Linguae Gallicae. Hildesheim - Zürich - New York 1993.

= D. Božıć: Relativna hronologija mlajše železne dobe v jugoslavenskem Podunavlju. AV 32 (1981) 315-336.

$=$ J.-L. BRunauX: Guerre et religion en Gaule. Paris 2004.

$=$ O. BuchsENSCHUTZ - I. RALSTON: Urbanisation et aristocratie celtiques. In: S. Sievers - M. Schönfelder (éds.): Die Frage der Protourbanisation in der Eisenzeit. Bonn 2012, 347-364.

= J. BuJNA: Spiegelung der Sozialstruktur auf latènezeitlichen Gräberfeldern im Karpatenbecken. PA 73 (1982) 312-431

= J. BujNA: Das latènezeitliche Gräberfeld bei Dubnik. II: Analyse und Auswertung. S1A 39 (1991) 221-255.

= J. BujnA: (Rés.) Fibeln aus keltischen waffenlosen Gräbern aus dem Gebiet der Slowakei. (Typochronologische Gliederung der LTB- und C1- Fibeln). SlA 51 (2003) 39-108.

= J. BuJnA: Kruhový šperk z laténskych ženských hrobov na Slovensku (Ringschmuck aus latènezeitlichen Frauengräben in der Slowakei). Nitra 2005.

= J. BuJnA: Das reich ausgestattete Kriegergrab aus dem keltischen Gräberfeld in Hurbanovo-Konkol' (Bez. Komárno), Südwestliche Slowakei. Pravĕk NŘ 16 (2006) 201-242.

= J.-J. CHARPY - A. RAPIN: L'armement celtique de la fin du premier âge du Fer. In: Splendeurs celtes: armes et bijoux. Treignes 2001, 12-23.
${ }^{293}$ Cf. SCHÖNFELDER 2009, 73.
${ }^{294}$ Voir BUCHSENSCHUTZ - RALSTON 2012.

Acta Archaeologica Academiae Scientiarum Hungaricae 65, 2014 
CHYTRÁČEK 1988

Colbert De Beaulieu - Fischer 1998

CRUMmy 2002

D’Agostino 1999

DelamarRe 2001

DOBESCH 1983

DOBESCH 1996

EGG - QUAST 2009

FERNOUX - STEIN 2007

FILIP 1956

FISCHER 1981

FREY 1969

GEBHARD 1989

GINOUX 2003

GINOUX 2009

GUICHARD - PERRIN 2002

GuillaumET - SZABÓ 2004

GUŠTIN 1984

GUŠTIN 1984/a

GuŠTiN - PAULI 1984

HAFFNER - JOACHIM 1984

HARBISON 1969

HAUSCHILD 2010

HELLEBRANDT 1989

HELlEBRANDT 1999

Historia 2006

Hodson 1968

HoRVÁtH 1945

HoRVÁTH 1972

HuNYADY 1942-44

HunYADY 1957
= M. CHYTRÁČEK: Le char laténien à deux roues en Bohême. EC 25 (1988) 15-58.

= J.-B. Colbert De Beaulieu - B. Fischer: Recueil des Inscriptions Gauloises (R.I.G.). vol. IV: Les légendes monétaires. Suppl. à Gallia 45. Paris 1998.

= Ph. CRummy: Des tombes aristocratiques à Stanway. In: Guichard - Perrin 2002, 145-152.

= B. D'Agostino: I principi dell'Italia centro-tirrenica in epoca orientallizzante. In: P. Ruby (éd.): Les princes de la protohistoire et l'émergence de l'état. Coll. du Centre Jean Bérard, 17. Naples - Rome 1999, 81-88.

$=$ X. Delamarre: Dictionnaire de la langue gauloise. Paris 2001.

= G. DobEsch: Aus der Geschichte der Kelten in Österreich. Österreich in Geschichte und Literatur 27 (1983) 1-24.

= G. Dobesch: Überlegungen zum Heerwesen und zur Sozialkultur der Kelten. In: Die Kelten in den Alpen und an der Donau. Akten des Internationalen Symposions St.Pölten 1992. Archaeolingua 1. Budapest - Vienne 1996, 13-71.

$=$ M. EGG - D. QuAsT (éds.): Aufstieg und Untergang. Zwischenbilanz des Forschungsschwerpunktes «Studien zu Genese und Struktur von Eliten in Vor- und Frühgeschichtlichen Gesellschaften». Monographien des Römisch-Germanischen Zentralmuseums 82. Mainz 2009.

$=$ H.-L. FERnOUX - C. STEIN (éds.): Aristocratie antique. Modèles et exemplarité sociale. Éditions Universitaires de Dijon, Collection Sociétés. Dijon 2007.

= J. FILIP: Keltové ve středni Evropě. Monumenta Archaeologica V. Praha 1956.

= FISCHER, F.: Die Kelten und ihre Geschichte. In: K. Bittel - W. Kimmig - S. Schiek: Die Kelten in Baden-Württemberg. Stuttgart 1981, 45-76.

= O.-H. FreY (éd.): Marburger Beiträge zur Archäologie der Kelten. Festschrift für Wolfgang Dehn zum 60. Geburtstag am 6. Juli 1969. Fundeberichte aus Hessen 1. 1969.

= R. GeBhARD: Der Glasschmuck aus dem Oppidum von Manching. Die Ausgrabungen in Manching 11. Wiesbaden - Stuttgart 1989.

$=$ N. GINOUX: L'excellence guerrière et l'ornementation des armes aux IV et III $^{\mathrm{e}} \mathrm{s}$. av. J.-C. Découvertes récentes. EC 35 (2003) 33-67.

= N. GinOuX: Élites guerrières au Nord de la Seine au début du III ${ }^{\mathrm{e}}$ siècle av. J.-C. La nécropole celtique du Plessis-Gassot (Val- d'Oise). Revue du Nord, hors série. Lille 2009.

= V. GUICHARD - F. PERrin (éds.): L'aristocratie celte à la fin de l'âge du Fer (du II ${ }^{\mathrm{e}}$ siècle avant J.-C. au ${ }^{\text {er }}$ siècle après J.-C.). Actes de la table ronde organisée par le Centre archéologique européen du Mont Beuvray, l'UMR 5594 du CNRS université de Bourgogne, Glux-en-Glenne 10, 11 juin 1999. Collection Bibracte 5. Glux-en-Glenne 2002.

= J.-P. Guillaumet - M. Szabó: Recherches archéologiques franco-hongroises en Hongrie. In: Rapport annuel d'activité scientifique 2004 de Bibracte, Centre archéologique européen du Mont Beuvray. Glux-en-Glenne 2004, 61-66.

= M. Guštin: Die Kelten in Jugoslawien. Übersicht über das archäologische Fundgut. JRGZM 31 (1984) 305-363.

= M. GUŠTIN: Prazgodovinski grobovi z vozovi na ozemlju Jugoslavije. In: GuŠTIN - PAULI 1984, 11-132.

= M. Guštin - L. PAUli: Keltski vož (Keltische Wagengräber). Brežice 1984.

= A. HAFFNER - H.-E. JOACHIM: Die keltischen Wagengräber der Mittelrheingruppe. In: GuŠTIN PAUli 1984, 71-87.

= P. HARBison: The chariot of Celtic funerary tradition. In: Frey 1969, 34-58.

= M. HAusCHILD: «Celticised» or «assimilated»? In search of foreign and indigenous people at the time of Celtic migrations. In: S. Berecki (éd.): Iron Age Communities in the Carpathian Basin. ClujNapoca 2010, 171-180.

= M. Hellebrandt: A csobaji kelta sír és régészeti kapcsolatai (La tombe celtique de Csobaj et ses relations archéologiques). HOMÉ 27 (1989) 439-461.

= M. HellebrandT: Celtic Finds from Northern Hungary. Corpus of Celtic Finds in Hungary 3. Budapest 1999.

= Focusing on Iron Age Elites. Historia (Studia Universitatis «Babeş-Bolyai».) 51. Cluj-Napoca 2006, $\mathrm{n}^{\circ} 1$.

= F. R. Hodson: The La Tène Cemetery at Münsingen-Rain. Catalogue and relative chronology. (Acta Bernensia 5. Bern 1968

= J. HoRVÁtH: A szobi kelta temető (La nécropole celtique de Szob). FolArch 5 (1945) 60-65.

= L. HoRvÁTH: A balatonfőkajári kelta temető leletmentése (Les fouilles de prévention de la nécropole celtique de Balatonfökajár). VMMK 11 (1972) 93-107.

= I. HunYADY: Kelták a Kárpátmedencében - Die Kelten im Karpatenbecken. DissPann II.18. Budapest 1942-1944.

= I. HunYADY: Kelták a Kárpátmedencében. Leletanyag (Des Celtes dans le bassin des Carpates. Trouvailles). RégFüz I/2. Budapest 1957. 
JACOBSTHAL 1941

JOACHIM 1969

JUD 1998

KAENEL 1990

KIMMIG 1988

KRUTA 1971

KRUTA 1975

KRUTA 2000

KRUTA 2001

KRUTA POPPI 1984

KRUTA - SZABÓ 1982

LAMBERT 1994

LAMBRECHTS 1954

LEJARS 1994

LEJARS 2003

LEJARS 2005

LEJARS 2006

LE RIDER 1977

MALITZ 1983

MARÁZ 2008

MARION 2007

MARION 2009

MÁRTON 1933-34

MenNESsieR-Jouannet et alii 2007

Moscati et al. 1991

Mócsy 1974

NACHTERGAEL 1977

PerRin - DeCOURT 2002

PERRIN - SCHÖNFELDER 2003

Petres 1979
= P. JACOBSTHAL: Kelten in Thrakien. Epitymbion Christou Tsounta. Athen 1941, 391-400.

= H.-E. JOACHIM: Unbekannte Wagengräber der Mittel- bis Spätlatènezeit aus dem Rheinland. In: FREY 1969, 84-111.

= P. JuD: Untersuchungen zur Struktur des Gräberfeldes von Münsingen-Rain. In: F. Müller (éd.): Münsingen-Rain, ein Markstein der keltischen Archäologie. Bern 1998. 123-144.

= G. KAENEL: Recherches sur la période de La Téne en Suisse occidentale. Analyse des sépultures. Cahiers d'Archéologie Romande 50. Lausanne 1990.

= W. KIMMIG: Das Kleinaspergle. Studien zu einem Fürstengrabhügel der frühen Latènezeit bei Stuttgart. Forschungen und Berichte zur Vor- und Frühgeschichte in Baden-Württemberg 30. Stuttgart 1988.

= V. KRUTA: Le trésor de Duchcov dans les collections tchécoslovaques. Ústi nad Labem 1971.

$=$ V. KRUTA: L'art celtique en Bohême. Les parures métalliques du $\mathrm{V}^{\mathrm{e}}$ au II ${ }^{\mathrm{e}}$ siècle avant notre ère. Bibl. E.P.H.É. IV ${ }^{\mathrm{e}}$ Section 324. Paris 1975.

= V. KRUTA: Les Celtes, histoire et dictionnaire: des origines à la christianisation. Coll. Bouquins. Paris 2000.

= V. KrutA: Aux racines de l'Europe. Le monde des Celtes. Paris 2001.

$=$ L. KRUTA Poppr: Contacts transalpin au III ${ }^{\mathrm{e}}$ siècle avant J.-C.: Le fourreau de Saliceta San Giuliano (Prov. de Modène). EC 21 (1984) 51-61.

$=$ V. KRUTA - M. SzABó: Canthares danubiens du III ${ }^{\mathrm{e}}$ siècle avant notre ère: un exemple d'influence hellénistique sur les Celtes orientaux. EC 19 (1982) 51-67.

= P.-Y. LAMBERT: La langue gauloise. Paris 1994.

= P. LAMBRECHTS: L'exaltation de la tête dans la pensée et dans l'art des Celtes. Dissertationes archaeologicae Gandenses 2. Brugge 1954.

$=$ T. LEJARS: Gournay III: Les fourreaux d'épée. Paris 1994.

$=$ T. LEJARs: Les fourreaux d'épée laténiens. Supports et ornamentations. In: D. Vitali (éd.): L'immagine tra mondo celtico e mondo etrusco-italico: aspetti della cultura figurativa nell'antichità. Bologna 2003. 9-70.

$=\mathrm{T}$. LEJARS: Le cimetière celtique de la Fosse Cotheret, à Roissy et les usages funéraires aristocratiques dans le nord du Bassin parisien à l'aube du III' siècle avant J.-C. In: O. Buchsenschutz (éd.) L'âge du fer en Île-de-France. XXVI colloque de l'association française pour l'étude de l'âge du fer, Paris et Saint-Denis, 9-12 mai 2002. RACF Supplément 26. Vichy 2005, 73-83.

$=$ T. Lejars: Les Celtes d'Italie. In: M. Szabó (éd.): Les Civilisés et les Barbares du Ve au II ${ }^{\mathrm{e}}$ siècle avant J.-C. Collection Bibracte 12/3. Glux-en-Glenne 2006, 77-96.

= G. Le RIDER: Le monnayage d'argent et d'or de Philippe II frappé en Macédoine de 359 à 294. Paris 1977.

= I. MaLITZ: Die Historien des Poseidonios. Zetemata 79. München 1983.

= B. MARÁZ: Archäologische Angaben zur mittleren und späten La Tène-Zeit in Südosttransdanubien. CommArchHung 2008, 65-93.

= S. MARION: Les IV et III ${ }^{\mathrm{e}}$ siècles avant notre ère en Île-de-France. In: MENNESSIER - JOUANNET et alii 2007, 91-115.

= S. MARION: Des objets dans les tombes: éléments d'interprétation des assemblages funéraires du III ${ }^{e}$ siècle avant J.-C. dans les sépultures des environs de Paris. Revue Archéologique de Picardie 2009, 225-236.

= L. MÁRTon: A korai La Tène sírok leletanyaga - Das Fundinventar der Frühlatènegräber. Dolgozatok (Szeged) 9-10 (1933-34) 93-165.

= C. Mennessier-Jouannet - A.-M. Adam - P.-Y. Milcent: La Gaule dans son contexte européen aux IV e et III e siècles avant notre ère. Actes du XXVII ${ }^{e}$ colloque int. de l'AFEAF. Clermont-Ferrand, 29 mai $-1^{\text {er }}$ juin 2003. Lattes 2007.

= Moscati et alii: Les Celtes (Palazzo Grassi). Milano 1991.

= A. Mócsy: Pannonia and Upper Moesia. A history of the Middle Danube. Provinces of the Roman Empire. London - Boston 1974.

= G. NAChtergael: Les Galates en Grèce et les Sôtéria de Delphes. Académie Royale de Belgique. Mémoires de la Classe des Lettres 63. Bruxelles 1997.

= F. PERRIN - J.-C. DECOURT: L'aristocratie celte dans les sources littéraires. Recueil de textes commentés. In: GuichaRD - PERRIN 2002, 337-412.

= F. PERRIN - M. SCHÖNFELDER (éd.): La tombe à char de Verna (Isère): témoignage de l'aristocratie celtique en territoire allobroge. Documents d'Archéologie en Rhône-Alpes et en Auvergne 24. Lyon 2003.

= É. F. PETRES: Some remarks on anthropoid and pseudoanthropoid hilted daggers in Hungary. In: P.-M. Duval - V. Kruta (éds.): Les mouvements celtiques du V $\mathrm{V}^{\mathrm{e}}$ au I ${ }^{\text {er }}$ siècle avant notre ère. Actes du XXVIII colloque de l'U.I.S.P.P. de Nice 1976. Paris 1979, 171-176. 
PeYre 1979

Piggott 1974

PINK 1974

Piste 2000

Polenz 1982

Poux 2011

RAMSL 2011

RAPIN et al. 1992

RAPIN 1999

RAPIN 2000

RATIMORSKÁ 1975

RoLLEy 1987

RosKA 1915

Rusu 1969

Rustoiu 2006

SANKOT 2002

SCHAAFF 1974

SCHÖNFELDER 2002

SCHÖNFELDER 2007a

SCHÖNFELDER $2007 \mathrm{~b}$

SCHÖNFELDER 2009

SHeFton 1994

SIEVERS et alii

STEAD 1983

STEAD 1984

STEAD 1991

STOJIĆ 2003

SzABÓ 1983a

SZABÓ 1983b

SZABÓ 1985

SzABó 1988

SzABÓ 1989a

SzABÓ 1989b

SZABÓ 1993

SZABÓ 1995

SZABÓ 1996

SZABÓ 2000
= Chr. PeYre: La Cisalpine gauloise du III ${ }^{\mathrm{e}}$ au I ${ }^{\mathrm{er}}$ siècle avant J.-C. ÉNS - Études d'Histoire et Archéologie 1. Paris 1979.

= S. PIgGotT: The Druids. Penguin books. Harmondswort 1974

= K. PINK: Einführung in die keltische Münzkunde mit besonderer Berücksichtigung des österreichischen Raumes. 3. durchges. u. erw. Auflage bearbeitet von R. Göbl. Wien 1974.

= Sur la piste des Gaulois. Exposition Aéroport Roissy-Charles-de Gaule 2000. Paris 2000.

$=$ H. Polenz: Münzen in latènezetitlichen Gräbern Mitteleuropas aus der Zeit zwischen 300 und 50 v. Chr. Geburt. BVbl 47 (1982) 27-222.

$=$ M. Poux (dir.): Corent. Voyage au coeur d'une ville gauloise. Paris 2011.

= P.C. RAMSL: Das latènezeitliche Gräberfeld von Mannersdorf am Leithagebirge, Flur Reinthal Süd, Niederösterreich. Wien 2011.

= A. Rapin - M. Szabó - D. Vitali: Monte Bibele, Litér, Rezi, Pişcolt. CommArchHung 1992, 23-54.

= A. RAPIN: L'armement celtique en Europe: chronologie de son évolution technologique du $\mathrm{V}^{\mathrm{e}}$ au $\mathrm{I}^{\mathrm{er}}$ siècle av. J.-C. Gladius 19 (1999) 33-67.

= A. RAPIN: L'armement laténien en Hongrie. In: J.-P. Guillaumet (éd.): Dix ans de coopération francohongroise en archéologie 1988-1998. Budapest 2000, 97-134.

= P. RATIMORSKÁ: Das keltische Gräberfeld von Chotin (Südwestslowakei). Alba Regia 14 (1975) 85-95.

= Cl. Rolley: Deux notes de chronologie celtique. RAE 38 (1987) 415-419.

= M. RoskA: Kelta sírok és egyéb emlékek Balsáról (Tombes celtiques et autres trouvailles de Balsa). Dolgozatok (Kolozsvár) 1915, 18-46.

= M. Rusu: Das keltische Fürstengrab von Ciumeşti in Rumänien. BRGK 50 (1969) 267-300.

= A. Rustolu: Peregrinations of a Celtic Warrior from Transylvania. In: Historia 2006, 42-85.

= P. SANкот: Zur Problematik des Kunsthandwerkes und der Werkstattbeziehungen in Böhmen während der Früh- und Mittellatènezeit. In: C. DoBiat et al. (éd.): Dürrnberg und Manching. Wirtschaftsarchäologie im ostkeltische Raum. Bonn 2002. 331-348.

= U. SCHAAFF: Keltische Eisenhelme aus vorrömischer Zeit. JRGZM 21 (1974) 149-204.

= M. SCHÖNFELDER: Das spätkeltische Wagengrab von Boé. Studien zu Wagen und Wagengräbern der jüngeren Latènezeit. RGZM Monographien 54. Mainz 2002.

= M. SCHÖNFELDER: Élite ou aristocrates? Les Celtes vus par les sources archéologiques. In: FERNOUX - STEIN 2007, 11-23.

= M. SCHÖNFELDER: Zurück aus Griechenland - Spuren keltischer Söldner in Mittelauropa. Germania 85 (2007) 307-328.

= M. ScHÖNFELDER: Archäologische Untersuchungen zur Elite in der keltischen Gesellschaft - eine Zwischenbilanz. In: EGG - QUAST 2009, 59-78.

= B. B. ShEFTON: The Waldalgesheim Situla: Where was it made? In: Festschrift Otto-Hermann Frey zum 65. Geburtstag. Hitzeroth 1994, 583-593.

= S. SIEVERS - O. H. URBAN - P. C. RAMSL: Lexikon zur keltischen Archäologie. Vienne 2012.

= J. STEAD: La Tène Swords and Scabbards in Champagne. Germania 61 (1983) 488-510.

= J. STEAD: Cart-burials in Britain. In: GuŠTin - PAUli 1984, 31-41.

= J. STEAD: Iron Age cemeteries in East Yorkshire. English Heritage, Archaeological report 22. London 1991.

= M. StojIĆ: Veliki Vetren. Archaeological Institut, Special editions 38. Beograd 2003.

= M. SzABó: Audoleon und die Anfänge der ostkeltischen Münzprägung. Alba Regia 20 (1983) 43-56.

= M. SzABÓ: Une cruche de bronze grecque. BMHB 60-61 (1983) 9-19.

= M. Szabó: Nouvelles vues sur 1'art des Celtes orientaux. EC 22 (1985) 53-72.

= M. SzABó: La vaiselle métallique dans la cuvette des Karpates à l'époque des princes celtes. In: Les princes celtes et la Méditerranée. Rencontres de l'Écoles du Louvre. Paris 1988, 384-396.

= M. SzABó: Beiträge zur Geschichte des keltischen Drachenpaarmotivs. CommArchHung 1989, 119-128.

= M. SZAвÓ: Élements anthropomorphes dans le décor des fourreaux danubiens. In: Les représentations humaines du néolithique à l'âge du fer. $115^{\mathrm{e}}$ Congrès Nat. Soc. Sav. Avignon 1990. Paris 1993. 271-286.

= M. SzABÓ: Éléments anthropomorphes dans le décor des fourreaux danubiens. In: Les représenta-

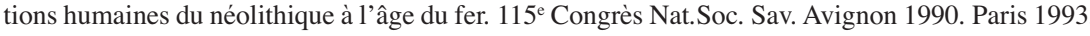
271-286.

= M. SzABó: Guerriers celtiques avant et après Delphes. Contribution à une période critique du monde celtique. In: J.-J. ChARPY (éd.): L'Europe celtique du Ve au III ${ }^{\mathrm{e}}$ siècle av. J.-C. Actes du deuxième symposium international d'Hautvillers 8-10 octobre 1992. Sceaux 1995. 49-67.

= M. SzABÓ: L'expansion celte et l'armement décoré. MEFR 108 (1996) 523-553.

= M. Szabó: La Macédoine hellénistique et le monde celtique. Ocnus 8 (2000) 287-295. 
SzABÓ 2001

SzABÓ 2005a

SzABÓ 2005b

SzABÓ 2007

SZABÓ 2009a

SzABÓ 2009b

SzABÓ 2009c

SZABÓ 2012

SZABÓ - PETRES 1992

SzABÓ et alii 2005

SzABÓ et alii 2006

SZABÓ - TANKÓ 2006

SZILÁGYI 1965

THOLLARD 2006

TODOROVIĆ 1972

TOMASCHITZ 2002

VENEDIKOV 1977

VÉGH 1973

VÉGH 1984

WALDHAUSER 1998

WERNER 1984

ZIRRA 1976
= M. SzABÓ: L'or des Celtes. In: Trésors préhistoriques de Hongrie. Collection du musée national de Hongrie. Paris 2001. 103-116.

= M. SzABÓ: A keleti kelták. A késő vaskor a Kárpát-medencében (Les Celtes de l'Est. Le second âge du Fer dans le bassin des Carpates). Bibliotheca archaeologica. Budapest 2005.

= M. SzABó: La Tène-kori temető Sajópetri határában. (A 2005. évi feltárás) - La Tène period cemetery at Sajópetri (Excavation in 2005). Régészeti kutatások Magyarországon - Archaeological Investigations in Hungary. Budapest 2005, 61-71.

= M. SzABó (éd.): L’habitat de l'époque de La Tène à Sajópetri Hosszú-dülő. Budapest 2007.

= M. SzABó: Megjegyzések a Délkelet-Dunántúl késő vaskorához (Remarques sur le second âge du Fer du sud-est de la Transdanubie hongroise). CommArchHung 2009, 85-100.

= M. SzABó: L'art du pseudo-filigrane. Une technique des peuples celtiques d'Europe centrale. In: Artisans et savoir-faire des Gaulois. Dossiers d'Archéologie 335 (2009) 68-73.

= M. Szabó: Réflexions sur les styles des épées. In: M. Honegger et alii (éds.): Le site de La Tène: bilan des connaissances - état de la question. Archéologie neuchâteloise 43. Hauterive 2009. 235-249.

= M. SzABó (dir.): La nécropole celtique à Ludas-Varjú-dűlő. Budapest 2012.

= M. Szabó - É. Petres: Decorated Weapons of the La Tène Iron Age in the Carpathian Basin. Inventaria praehistorica Hungariae 5. Budapest 1992.

= M. Szabó - J.-P. Guillaumet - D. Vitali: Recherche archéologique franco-italo-hongroise en Hongrie. In: Rapport annuel d'activité scientifique 2005 de Bibracte, Centre archéologique européen du Mont Beuvray. Glux-en-Glenne 2005, 61-68.

= M. Szabó - J.-P. Guillaumet - P. MÉniel - D. Vitali: L'occupation celtique de la Grande plaine hongroise. In: Rapport annuel d'activité scientifique 2006, Centre archéologique européen du Mont Beuvray. Glux-en-Glenne 2006, 221-225.

= M. SZABÓ - K. TANKÓ: Nécropole laténienne à Ludas-Varjú-dűlő. ActaArchHung 57 (2006) 325-343.

= J. Gy. SzILÁGYI: Trouvailles grecques sur le territoire de la Hongrie. In: Le rayonnement des civilisations grecque et romaine sur les cultures périphériques. Paris 1965. 386-390.

= P. Thollard: Le regard des «civilisés». In: M. Szabó (éd.): Les Civilisés et les Barbares du V $\mathrm{V}^{\mathrm{e}}$ au $\mathrm{II}^{\mathrm{e}}$ siècle avant J.-C. Celtes et Gaulois. L'Archéologie face à l'Histoire. Actes de la table ronde de Budapest, 17-18 juin 2005. Collection BIBRACTE 12/3. Glux-en-Glenne 2006, 15-27.

= J. Todorović: Praistorijska Karaburma. I: Nekropola mlađeg gvozdenog doba. Monografije 3. Beograd 1972

= K. TomaschiTZ: Die Wanderungen der Kelten in der antiken literarischen Überlieferung. MPK 47. Wien 2002.

= J. VeNEDIKOV: Les situles de bronze en Thrace. Thracia 4 (1977) 61-103.

= K. K. VÉGH: Adatok a kelta kocsitemetkezések kérdéséhez (Données relatives à la question des tombes à char celtiques). ArchÉrt 100 (1973) 208-218.

= K. K. VÉGH: Keltische Wagengräber in Ungarn. In: GUŠTIN - PAULI 1984, 105-110.

= J. Waldhauser: Die Goldfingerringe von Münsingen-Rain. In: F. Müller (éd.): Münsingen-Rain, ein Markstein der keltischen Archäologie. Bern 1998. 85-122.

= W. M. Werner: Latènezeitliche Trensen in Jugoslavien. In: GušTIN - PAULI 1984, 141-151.

= V. ZIRRA: La nécropole La Tène d'Apahida. Nouvelles considérations. Dacia 20 (1976) 129-165. 